NBER WORKING PAPER SERIES

\title{
WOULD PEOPLE BEHAVE DIFFERENTLY IF THEY BETTER UNDERSTOOD SOCIAL SECURITY? EVIDENCE FROM A FIELD EXPERIMENT
}

\author{
Jeffrey B. Liebman \\ Erzo F.P. Luttmer \\ Working Paper 17287 \\ http://www.nber.org/papers/w17287
NATIONAL BUREAU OF ECONOMIC RESEARCH
1050 Massachusetts Avenue
Cambridge, MA 02138

August 2011

We thank Michael Anderson, Dan Benjamin, John Geanakoplos, Jeffrey Kling, David Laibson, Annamaria Lusardi, Brigitte Madrian, Susann Rohwedder, Mark Shepard, Stephen Zeldes, and seminar participants at Collegio Carlo Alberto, Harvard University, the NBER Summer Institute, and Stanford University for helpful comments. We thank Kate Mikels, Abdul Tariq, and Victoria Levin for superb research assistance. We thank Michael Anderson for sharing Stata code on familywise error rates. This research was supported by the U.S. Social Security Administration through grant \#10-M- 98363-1-01 to the National Bureau of Economic Research as part of the SSA Retirement Research Consortium. The findings and conclusions expressed are solely those of the author(s) and do not represent the views of SSA, any agency of the Federal Government, or the NBER. All errors are our own.

NBER working papers are circulated for discussion and comment purposes. They have not been peerreviewed or been subject to the review by the NBER Board of Directors that accompanies official NBER publications.

(C) 2011 by Jeffrey B. Liebman and Erzo F.P. Luttmer. All rights reserved. Short sections of text, not to exceed two paragraphs, may be quoted without explicit permission provided that full credit, including (C) notice, is given to the source. 
Would People Behave Differently If They Better Understood Social Security? Evidence From

a Field Experiment

Jeffrey B. Liebman and Erzo F.P. Luttmer

NBER Working Paper No. 17287

August 2011, Revised December 2011

JEL No. C93,D83,H55,J26

\begin{abstract}
$\underline{\text { ABSTRACT }}$
This paper presents the results of a field experiment in which a sample of older workers was randomized between a treatment group that was given information about key Social Security provisions and a control group that was not. The experiment was designed to examine whether it is possible to affect individual behavior using a relatively inexpensive informational intervention about the provisions of a public program and to explore the mechanisms underlying the behavior change. We find that our relatively mild intervention (sending an informational brochure and an invitation to a web-tutorial) increased labor force participation one year later by 4 percentage points relative to the control group mean of 74 percent and that this effect is driven by a 7.2 percentage point increase among female subjects. In addition to affecting actual labor supply behavior, the information intervention increased survey measures of the perceived returns to working longer, especially among female respondents.
\end{abstract}

Jeffrey B. Liebman

John F. Kennedy School of Government

Harvard University

79 JFK Street

Cambridge, MA 02138

and NBER

jeffrey_liebman@harvard.edu

Erzo F.P. Luttmer

6106 Rockefeller Center, Room 305

Department of Economics

Dartmouth College

Hanover, NH 03755

and NBER

Erzo.FP.Luttmer@Dartmouth.Edu 


\section{Introduction}

The provisions of government tax, social insurance, and means-tested transfer programs create complex sets of incentives for individuals making labor supply, retirement, and savings decisions. If individuals do not understand or do not otherwise come to correctly perceive the incentives, they may make economic decisions that are privately suboptimal and may also fail to participate effectively as political actors. ${ }^{1}$

An important policy question is whether there exist relatively inexpensive approaches to providing information that improve decision making and ultimately increase individual wellbeing. For example, to what extent could a simple brochure mailed by the Social Security Administration correct the widespread misperceptions about the Social Security earnings test? The answer to this question will depend in part on why incentives are currently misperceived. In some cases, the necessary information may be straightforward to understand, but expensive (in either monetary or psychic terms) to acquire. In other cases, the information about program rules may be readily available, but the calculation necessary to determine an individual's own incentives may be very complicated. In still other cases, cognitive biases may cause people to misperceive even relatively simple incentive schedules. Finally, powerful social cues may point people toward a suboptimal decision, even when the correct information is also readily available. While factors such as these that can produce poor decision making are well documented, there is little evidence on how easy they are to overcome.

This paper presents the results of a field experiment in which a sample of older workers was randomized between a treatment group that was given information about key Social Security provisions, and a control group that was not given the information. One year after the information was provided, we administered a follow-up survey and measured the impact of the information provision on labor supply and Social Security benefit claiming behavior. We find that our relatively mild intervention (a mailed brochure combined with an invitation to participate in a 15-minute online tutorial) raised the fraction of the sample remaining in the labor force by 4 percentage points. This impact, while statistically significant for the entire sample, is driven by female sample members. We do not find statistically significant effects of the treatment on the probability that respondents have started claiming Social Security benefits. To explore the mechanism by which the intervention affected behavior, we ask respondents a series

\footnotetext{
${ }^{1}$ In some cases these privately suboptimal decisions can be socially optimal. See Liebman and Zeckhauser (2008).
} 
of questions about their understanding of the incentives that the Social Security program provides for labor supply and benefit claiming. We find that the information intervention increased the perceived return to working longer, especially among women, which is consistent with a pathway in which the intervention affected behavior by changing knowledge of incentives. We cannot, however, rule out the possibility that the gestalt of our message was responsible either in part or in full for the change in behavior.

\section{Background}

It is becoming increasingly clear that responses of economic actors to the incentives created by government tax- and spending programs are affected not only by the size of the incentives, but also by contextual factors that affect how the incentives are perceived. ${ }^{2}$ Duflo et al. (2006) show that customers of a tax preparation firm who were offered a match of contributions to retirement savings accounts were much more responsive to the simple and transparent match offer than are U.S. taxpayers who face a similar match via a provision in the U.S. tax code. Chetty, Looney, and Kroft (2009) find that changes in excise taxes yield larger behavioral responses than economically equivalent changes in sales taxes, most likely because the sales taxes are added at the tax register and are therefore less salient. Kling et al. (2011) posit that many Medicare beneficiaries are poorly informed about the prices offered by different prescription drug plans and show that providing information can cause beneficiaries to switch to lower-priced plans. Chetty and Saez (2009) demonstrate that EITC recipients alter their labor supply when the incentives provided by the program are explained by a tax preparer. Mastrobuoni (2010) shows that the mailing of Social Security statements by the SSA increases knowledge about benefit levels. While Mastrobuoni estimates small and statistically insignificant impacts on retirement behavior, the 95-percent confidence interval around these estimates is wide and ranges from a 108 percent increase in the impact of Social Security incentives on retirement to a 66 percent decrease. The context-specific nature of behavioral responses to incentives increases the dimensionality of the challenge for researchers seeking to reach a consensus about the magnitude of behavioral responses to policy provisions because there will not be a single parameter that can be averaged across multiple studies if the studies measure behavior in disparate contexts. However, the sensitivity of behavioral responses to how

\footnotetext{
${ }^{2}$ Bernheim and Rangel (2009) refer to these contextual factors as ancillary conditions.
} 
incentives are perceived by individual decision makers also provides policy makers with an additional instrument; relatively inexpensive interventions that provide information or alter the framing of decisions have the potential to significantly improve economic well-being.

Social Security policy is likely to be a particularly fruitful area in which to apply these insights. Decisions about when to retire and when to claim benefits can have large implications for well-being over many subsequent years. Such decisions also have elements of irreversibility that make it hard to undo poor decisions. And retirement-related decisions are very challenging to get right. ${ }^{3}$ The Social Security tax- and benefit schedules themselves involve several features that make it hard to perceive incentives correctly - complex nonlinearities and interactions with other sources of retirement income that make calculations difficult, a remote connection between choices and payoffs because benefits are often not received for many years after the point at which labor supply decisions are made, and a dependence of one's own incentives on individualspecific factors such as martial history and life expectancy that make it hard to learn one's own incentives from that of a peer. In addition to schedule complexity, these choices involve uncertainty and tradeoffs over time - the two contexts in which difficulty in decision making have been the most widely documented. ${ }^{4}$ Simulations by Benítez-Silva et al. (2009) using a dynamic life-cycle model suggest the potential for large welfare gains from improving people's understanding of Social Security. Moreover, experiments have shown effects of how information about Social Security is presented on hypothetical or intended behavior - raising the possibility that interventions could also alter actual behavior. ${ }^{5}$

How people perceive the incentives of Social Security factors critically in several policy debates. For example, there is no consensus on the extent to which people perceive the marginal

\footnotetext{
${ }^{3}$ There is a large literature on the accuracy of people's perceptions about future levels of Social Security and pension benefits and the implications of lack of knowledge on retirement and saving behavior. See Bernheim (1988), Mitchell (1988), Gustman and Steinmeier (2005), Rohwedder and Kleinjans (2006), Dominitz, Hung, and van Soest (2007), and Chan and Huff Stevens (2008). See also Lusardi and Mitchell (2009) for an analysis of the link between financial literacy and retirement planning.

${ }^{4}$ See Liebman and Zeckhauser (2004) for a discussion of decision making under complex schedules. See Beshears et al. (2008) and Liebman and Zeckhauser (2008) for a review of the literature on contexts in which individuals have difficulties making wise decisions.

${ }^{5}$ Hastings and Tejeda-Ashton (2008) show in the context of the privatized Mexican social security system that financially illiterate workers are more price sensitive in their hypothetical choice of retirement fund when fees are expressed in pesos rather than in terms of annual percentage rates. Brown, Kapteyn, and Mitchell (2011) and Luttmer and Liebman (2011) find that the intended age of claiming Social Security benefits depends on how the early versus late claiming decision is framed.
} 
future Social Security benefits they receive when they work an additional hour. ${ }^{6}$ Knowing the answer to this question is important for understanding the amount of deadweight loss caused by the OASDI payroll tax and also for assessing the potential welfare gains from switching to a system - either based on notional defined contribution accounts or funded personal retirement accounts - with more transparent linkage between initial collections and later benefits. Similarly, there remains no consensus about why so many people retire and claim benefits at age 62. Knowing the answer to this question is important for understanding the welfare implications for adjusting the earliest eligibility age and the full-benefit age.

In an earlier paper (Liebman and Luttmer, 2011), we administered a survey about Social Security benefit rules to a representative sample of Americans aged 50-70. We found that the majority of respondents believe that their Social Security benefits increase with labor supply, i.e., that the Social Security benefit rules provide a positive work incentive. The magnitude of this perceived incentive varies across respondents, but people generally cite an incentive that is somewhat greater than the actual figure. We also surveyed people about their understanding of various provisions in the Social Security benefit rules, and found that some of these provisions (e.g., effects of delayed benefit claiming and rules on widow benefits) are relatively well understood while others (rules on spousal benefits and provisions on which years of earnings are taken into account) are less well understood.

In order to achieve the potential welfare gains from improving people's understanding of the tradeoffs they face, researchers need to make progress in two areas. The first is in understanding the reasons for current misperceptions. The second is in testing interventions to discover which approaches are most effective in correcting misperceptions. Our current study makes three contributions in these areas. First, it provides further confirmation that interventions affecting people's perceptions of incentives can affect individual behavior in important policy contexts. Second, by measuring both the change in behavior and the change in people's perceptions it helps show how the intervention worked to change behavior. In some of the studies cited above, it is unclear whether behavioral changes were obtained because people better understood their choices or because they simply accepted advice of a trusted intermediary to "save more" or "work more." As we discuss later in the paper, the normative and policy implications of these sorts of interventions hinge critically on the mechanisms through which

\footnotetext{
${ }^{6}$ See Liebman, Luttmer, and Seif (2009) for evidence on this subject.
} 
they have their impacts. Third, the study demonstrates an approach to altering perceived incentives - a combination of a mailing and an online tutorial - that is both relatively inexpensive and which allows full researcher control over the information that is provided. In particular, it does not rely on a caseworker-style approach in which one-on-one counseling is used to influence people. For many applications, the approach we demonstrate is likely to be scalable to the population level once an effective intervention is identified. Our approach also removes the ambiguity over what information or message was provided to the sample member. This ambiguity, along with cost, is a drawback of the caseworker approach.

\section{Survey Design and Experimental Manipulations}

\subsection{Population for the Information Intervention}

We contracted with Knowledge Networks to administer our experimental intervention and a follow-up survey to a sample drawn from of its panel of respondents. These panelists, originally recruited through random-digit dialing, agree to take a 15-20 minute survey once a week via the Internet using a PC or WebTV in exchange for free Internet or WebTV access. ${ }^{7}$ The panelists receive incentive payments and rewards through a loyalty program. Knowledge Networks collects basic demographic characteristics for all its panelists, and its panelists are roughly representative of the adult U.S. population according to these characteristics.

In 2008, we fielded a baseline survey of knowledge about Social Security using the Knowledge Network panel (for details see Liebman and Luttmer, 2011). The sample for that survey spanned the ages of 30 to 70, with an oversample of individuals who were ages 60 to 65 . For the current study, we started with the 3611 individuals who were invited to participate in our 2008 survey. We dropped 668 individuals who were younger than 55 years old, 419 individuals who were not working (based on the employment status variable that is part of the Knowledge Networks standard demographic profile variables), and 41 individuals who told us in the 2008 survey that they were not covered by Social Security. This procedure resulted in an experimental sample of 2483 working individuals who were randomized between the treatment group and the control group. Most of our sample members (90 percent) were between the ages of 60 and 65 in November 2008. We focus on working individuals near the retirement age because that is the

\footnotetext{
${ }^{7}$ The WebTV option means that individuals did not need to be computer users to be recruited into the panel.
} 
population most likely to display behavioral effects of the information intervention within the time frame of our experiment.

\subsection{Information Intervention}

The members of the treatment group received an informational intervention that consisted of two parts. In February of 2009, Knowledge Networks sent them by regular mail an informational brochure that we had created for this purpose. In March of 2009, members of the treatment group were invited to participate in a web-tutorial about Social Security. The completion rate of the web-tutorial was 76.8 percent for the treatment group as a whole and 91.6 percent for treatment group members who also took part in the follow-up survey. ${ }^{8}$ Members of the control group did not receive any materials from us (either in the mail or online).

In both the brochure and the web-tutorial, we provided information on three topics. First, we provided information about longevity to emphasize the need for an adequate planning horizon for retirement finances. For example, the brochure mentions "For the average 65-yearold couple living in America today, there is a 47\% chance that at least one spouse will live to age 90." Second, we explained the relationship between retirement age and the standard of living during retirement. In particular, we explain how Social Security benefits rise with the age at which benefits are claimed and how Social Security benefits depend on a person's work history. For example, the web-tutorial introduces a hypothetical worker and shows what happens to this person's Social Security benefits if the person works more years. Third, we provide information about the Social Security earnings test and explain that cuts in current benefits due to the earnings test are offset by higher benefits in the future. In designing the information intervention, we took into account that many respondents may have trouble remembering benefit formulae and information presented with figures and statistics. We therefore complemented such information with vignettes about actual retirees whom we had interviewed and from whom we had received permission to incorporate their information in our materials. These vignettes helped to underline the broader message of the intervention and contribute to the "gestalt" of the message.

Before giving information about Social Security in the brochure, we explained that the

\footnotetext{
${ }^{8}$ As we explain below, some sample members were no longer active with Knowledge Networks at the time the invitations to participate in the web-tutorial were sent out.
} 
brochure was sent to them by Knowledge Networks on behalf of us ("researchers at Harvard University") as a follow-up to a recent survey that the individual had been invited to take (our 2008 baseline survey). Moreover, we emphasized that the brochure was not a comprehensive source of Social Security facts, and we provided phone numbers and links to additional sources of information about Social Security. We printed the brochure on glossy paper, used a relatively large font, and provided it with a professional layout in color in order to entice respondents to read it. The complete brochure is included in Appendix A.

The web-tutorial covered the same three basic topics as the brochure, but was tailored to each respondent's situation - something we were able to do because it was administered online. For example, we gave information about the typical longevity of people of the same sex as the respondent; the characters in examples had the same sex as the respondent, and returns to delaying claiming were calculated exactly based on the respondent's birth cohort. The webtutorial also contained a number of questions about the information we presented in order to induce the respondents to pay attention to the information. In the web-tutorial, as in the mailed brochure, we emphasized the gestalt of the information intervention by including vignettes of actual retirees. For example, the tutorial contained the following vignette:

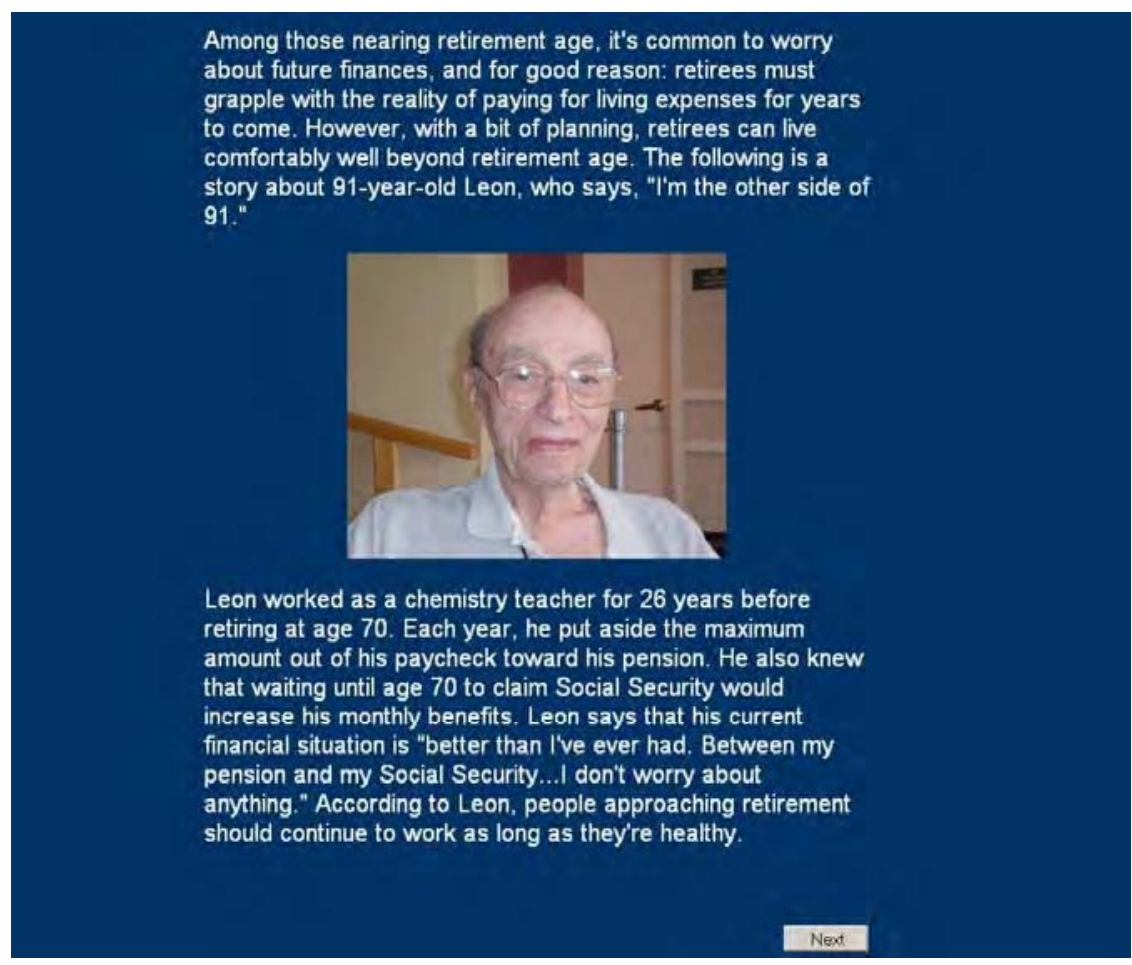

At the end of the web-tutorial, we provided phone numbers and Internet links to further resources for information about Social Security. The complete web-tutorial is included in 
Appendix B.

\subsection{Follow-up Survey}

In April 2010, thirteen months after the information intervention, members from both the treatment group and the control group were invited to participate in our follow-up survey. The follow-up survey was designed to measure the effects of the information intervention on labor supply and Social Security benefit claiming behavior. In order to explore what mechanisms underlie the behavior change, it also included questions intended to measure understanding of the incentives that the Social Security program provides for labor supply and benefit claiming. In addition, because one year is a relatively short period in which to observe changes in retirement behavior, the survey also contained questions about planned future behavior. The follow-up survey contained 67 questions and the median time to complete it was 18 minutes. We paid respondents a $\$ 5$ incentive for completing the survey. Inactive panelists were offered an additional $\$ 5$ to return to the panel to take the survey. The follow-up survey was fielded between April 8 and June 9 of 2010. While the vast majority (90\%) of respondents completed the survey in April, we kept the survey open until June to maximize the response rate. The full survey instrument is provided in Appendix C.

Of the 2483 members of the experimental sample, 1596 completed the follow-up survey for an overall response rate of 64.3 percent. Appendix Figure A1 contains a flow chart describing the evolution of our analysis sample. It shows that attrition from the experimental sample occurred in three steps and that most of it appears to have been for reasons unrelated to the intervention.

First, only 89 percent of experimental sample members were invited to take the follow-up survey because 11.4 percent of the sample had permanently left the Knowledge Networks panel or had informed Knowledge Networks that they were temporarily unavailable for surveys. The attrition rate at this first step was similar between the treatment group (11.0 percent) and control group (11.7 percent).

Second, not all sample members who were invited to take the survey clicked on the link to learn the topic of the survey. In particular, 78.3 percent of invited treatment group members and 74.2 percent of invited control group members clicked on the link. The particular way in which invitations to take the follow-up survey were extended minimized the opportunity for 
treatment-induced differential non-response between the treatment and control groups. As is typical of Knowledge Network survey invitations, the invitation simply invited sample members to take a survey - without specifying the subject of the survey - and provided a link to click on if the sample member wanted to participate. Moreover, the overwhelming majority (86 percent) of invited sample members who failed to click on the link had been identified by Knowledge Networks as inactive panelists prior to the date of our survey invitation - based on failing to participate in surveys for an extended period of time. Thus over 90 percent of the combined attrition that occurred in these first and second steps occurred because of respondents who were not longer actively participating in Knowledge Networks surveys, rather than from a decision to skip our particular survey.

Third, conditional on clicking on the link and thereby learning the topic of the survey, 3.8 percent of treatment group members and 4.0 percent of control group members failed to complete the survey. ${ }^{9}$ Conditional on completing the survey, the item-response rates were very high, generally well above $95 \%$.

In forming our analysis sample, we drop one observation of a sample member for which the age according the Knowledge Network profile variable increased by three years between November 2008 and April 2010, which is logically impossible. This yields a final sample of 1595 observations for our main analyses.

\subsection{Analysis of Attrition Patterns}

Despite the blinded nature of the survey invitation, the overall response rate to the follow-up survey was 4.4 percentage points higher in the treatment group than the control group, and this difference is significant at the 5-percent level. As described above, this difference can be explained by the fact that members of the treatment group were more likely to still be active Knowledge Networks panelists at the April $1^{\text {st }}$ date of the survey invitation. Among panelists active as of the invitation date, the response rates for the treatment group and for the control group were not significantly different from each other. And nearly all of the differential attrition occurred before sample members were aware of the survey topic. Thus, the differential response rate is unrelated to the topic or content of the follow-up survey.

\footnotetext{
${ }^{9}$ An additional 1 percent of respondents in each group was skipped out of the survey early in administration once screening questions revealed that they were not eligible for Social Security.
} 
The concern, of course, is that the attrition process may not be random and may result in treatment and control populations that would no longer have the same expected outcomes if they received the same treatment. To explore this issue, we examined whether the demographic characteristics of the treatment and control groups differ among takers of the follow-up survey. These results are presented in Appendix Table 2. Panel A tests whether these demographic characteristics are jointly statistically different between the two groups by regressing treatment status on the full set of demographics listed in Panel B. Consistent with successful random assignment and no differential attribution by demographics, the full set of demographics is jointly insignificant (p-value 0.759). Panel B shows that the samples are well balanced on the individual demographic variables as well. Only 1 of 35 pairwise comparisons has a p-value below 0.05. We, nevertheless, control for baseline demographics in our regressions in order to increase the statistical precision of treatment effect estimates and to adjust for any random differences between the treatment and control groups in observable characteristics.

Even though the treatment and control groups are balanced on observable demographics, it is possible that they differ on some unobserved characteristics. This would be particularly worrisome if something about the treatment caused treatment groups members to be more willing to take the survey in a way that directly affected the mean of the outcome variable. For example, if treatment group members who were working were more inclined to answer the survey because they were proud to exhibit behavior that was consistent with the general message of the intervention, then our results could be biased toward finding a positive impact of the intervention on labor supply. However, as we noted above, the differential attrition occurred before respondents were aware of the survey topic, so we can rule out this sort of mechanism. ${ }^{10}$

With direct channels between survey participation and treatment group/outcome status ruled out, it is very unlikely that a 4 percent difference in response rates could bias the results in a meaningful way. Indeed, we can bound the potential bias. Under the extreme assumption that all of the extra response in the treatment group was made up of people who were employed, this differential response would account for less than half of the estimated overall employment

\footnotetext{
${ }^{10}$ In theory, the information intervention could have affected panelist decisions about whether to remain active with Knowledge Networks. Given that panelists take weekly surveys, it is highly unlikely that our survey (out of the fifty or so that a typical panelist would have taken during a year) would have had a quantitatively significant impact on the decision to remain active.
} 
impact and less than one-quarter of the impact among women. ${ }^{11}$

In summary, while we cannot completely rule out bias due to the differential attrition, there is no evidence in the data to suggest lack of balance between the treatment and control groups, the blinded nature of the survey invitation rules out some of the most troublesome types of attrition bias, and the magnitude of the differential attrition is small enough that it would take a very extreme attrition process to significantly alter the findings of this paper. ${ }^{12}$

\section{Results}

\subsection{Sample Characteristics}

Table 1 shows the demographic composition of the sample that completed the follow-up survey. We split the table by the gender of the respondent because labor market responses often differ by gender. About three quarters of the sample performed paid work in the calendar month previous to the follow-up survey, and this fraction is only slightly lower for women. The labor force participation rate may seem high for this age group, but recall that only individuals who were working in 2008 were eligible to participate in the experiment. About forty percent of sample members are receiving Social Security benefits in 2010, which implies that a nonnegligible fraction is combining work and benefit receipt. The fraction receiving benefits in 2010 is slightly higher for women than for men.

We present the demographic characteristics of sample members at the time of the baseline survey (2008) because the regressions control for demographics as measured in 2008. We include the 2008 controls rather than the 2010 controls in the regressions because the treatment could conceivably affect some of the control variables in 2010. The specific controls that we present and use in regressions are maintained by Knowledge Networks and are therefore available for all sample members, even those who did not participate in the 2008 survey.

\footnotetext{
${ }^{11}$ These calculations are performed as follows. The control group mean employment rate was 74.4\% (Table 4). The control group response rate was $62.0 \%$ and the treatment group response rate was $66.4 \%$ (the differential response was 4.4 percentage points). If there were no true treatment effect but all the extra response in the treatment group consisted of working individuals, then the treatment group mean employment rate would have been $(0.620 \times$ $0.744+.044 \times 1.00) / 0.664=.761$ or an impact of $1.7 \%$ relative to $74.4 \%$. The upper bound of $1.7 \%$ is well below half of the $4.2 \%$ overall employment estimate.

12 The differential attrition rates were similar among males (4 percent) and females ( 5 percent). If differential attrition were responsible for a significant portion of the estimated impact of the intervention, we would expect to see employment rate effects for both males and females. Instead, the employment effects are concentrated among females.
} 
Knowledge Networks recruits its panelists (e.g., using random digit dialing) such that the demographic characteristics of its panelists are broadly representative of those in the U.S. adult population. However, because we conditioned our sample on the respondent being in a narrow age range (90\% of our panel is between 60 and 65 in November 2008) and on the respondent working in 2008, the demographic characteristics of our sample are not representative of the general population but instead is broadly representative of working individuals approaching the age at which most people are making retirement decisions. ${ }^{13}$

The mean age in our sample in 2010 is 63 . About 89 percent of the sample is white, and about 85 percent has at least some college or more. These percentages would be high for the general population in our age group, but recall that our sample is limited to working individuals. About 55 percent of the female respondents are married as are about 78 percent of the men. This difference is mostly accounted for by the fact that working women in this age range are much more likely to be divorced than are working men. The sample is geographically dispersed, with all regions of the country well represented. About 80 percent of respondents live in one- or twoperson households. Finally, respondents come from households from throughout the income distribution, though higher-income households are disproportionately represented because of the higher-than-average labor market participation in our sample.

\subsection{Manipulation Checks}

To verify that our experimental manipulation was effective and was implemented correctly, we asked two questions about the information intervention to all respondents at the end of the follow-up survey. We first asked them whether they recalled receiving "about a year ago ... the following informational brochure" about Social Security rules, showing them a picture of

\footnotetext{
${ }^{13}$ Appendix Table A examines the representativeness of the experimental sample by comparing its demographic characteristics to those of observations in the Current Population Survey (CPS) that match our sample selection criteria of working and being between the ages of 60 and 65. Relative to the CPS, our experimental sample has somewhat more whites ( $85 \%$ vs. $81 \%$ ), is more educated ( $47 \%$ with a Bachelor's vs. $37 \%)$, is slightly less likely to be married (64\% vs. $70 \%$ ), and has somewhat lower incomes ( $46 \%$ with incomes exceeding $75 \mathrm{k}$ vs. $51 \%$ ). While many of the demographic characteristics are statistically significantly different between the CPS sample and the experimental sample, the economic magnitude of these differences is moderate in size. We therefore think of the sample as broadly representative of the U.S. population of working individuals between the ages of 60 and 65 . In terms of demographic characteristics, the 1595 respondents to the follow-up survey look very similar to the 2483 individuals of the experimental sample, with the exception that respondents to the follow-up survey are 3.8 percentage points more likely to be white and 4.5 percentage points more likely to have a Bachelors degree. Overall, our survey sample is quite similar to our full experimental sample and, as we discussed earlier, there are no statistically significant demographic differences between the treatment group and the control group in the survey sample.
} 
the front page of our informational brochure on the screen. We then asked them whether they recalled participating "about a year ago ... in an online module that provided additional information about Social Security rules, and which was tailored to each person's individual information." We further told the respondents "To help you remember this survey from the many other surveys you have taken, the online module contained stories about the experiences of two retirees, 91-year-old Leon and 66-year-old Elena," and showed them the same pictures of these two retirees as they had seen in the online module.

The first row of Table 2 presents the results for the recall rate of the brochure. The first column shows that 4.8 percent of sample members in the control group report receiving the brochure, even though they should not have received, and to the best of our knowledge did not receive, the brochure. We believe this 4.8 percent may have confused our brochure with other mailings they have received about Social Security. The second column shows that the recall rate is 28.6 percentage points higher for respondents in the treatment group than for those in the control group, and that this effect is highly significant. ${ }^{14}$ For consistency with the other regressions in the paper, the treatment effect is estimated in an OLS regression of the outcome variable (recall of the brochure) on an indicator of belonging to the treatment group and a set of demographic controls, including a quadratic in age. The estimate is extremely similar if the demographic controls are omitted. The significant treatment effect on the brochure recall rate is reassuring in that it shows that our treatment had an impact on the respondents and appears to have been implemented correctly. Yet, even in the treatment group, the recall rate is only $33.4 \%$. In other words, a majority of respondents in the treatment group do not recall receiving the brochure, even though they should all have received it. Because it is possible to be influenced by information without recalling where or when one received the information, we do not believe the treatment effects on other outcome variables should be scaled up by the reciprocal of the treatment effect on recall. We therefore do not treat the recall rate as a first-stage regression for estimating a treatment-on-the-treated effect.

Columns 3 and 4 show the control group recall rate and the treatment effect for female respondents while columns 5 and 6 show these estimates for male respondents. Although the treatment effect is slightly larger for female respondents than for male respondents, this

\footnotetext{
${ }^{14}$ Our finding that a significant fraction of sample members recall a mailing about Social Security is consistent with the Mastrobuoni (2010) finding that the annual mailing of Social Security benefit statements affects expectations of future benefit levels.
} 
difference is not statistically significant, as column 7 indicates.

The second row of Table 2 shows the results for the recall rate of participating in the web-tutorial on Social Security. While only 1.0 percent incorrectly recalls taking part in this tutorial, the treatment effect is only 8.4 percentage points. Though this estimate is highly statistically significant, it implies that merely 9.4 percent of respondents in the treatment group recall participating in the web-tutorial. We know that 76 percent of individuals in the treatment group in fact participated in the web-tutorial, and even among the participants the recall rate is only 10.2 percent. We surmise that the low treatment effect on recall of the web-tutorial is related to the fact that the respondents take online surveys from Knowledge Networks quite frequently (typically a couple per month), and it is hard for them to recall with confidence based on the relatively limited information we provided them whether they took our specific webtutorial. It is also possible that because this question was asked at the end of the survey, respondents may have feared follow-up questions if they answered "yes." The remaining columns of row 2 show that the treatment effect on recall of the web-tutorial is very similar for women and men.

\subsection{Impacts of the Intervention on Labor Supply and Benefit Claiming Behavior}

The experiment was designed to investigate the effect of better knowledge about the Social Security benefit rules on (i) labor supply and (ii) Social Security claiming behavior. The first three rows of Panel A of Table 3 present the effects on labor supply; the final row of Panel A contains the results for claiming behavior.

Our simplest measure of labor supply is the answer to the question whether the respondent performed any paid work in the previous calendar month (generally March 2010). In the control group, 74.4 percent of respondents worked in the previous month. This percentage may seem surprisingly high at first, but recall again that only individuals who were working in 2008 were included in the experiment. The information intervention increased this percentage by 4.2 percentage points, and this effect is (just) significant at the 5-percent level. The treatment effect is due almost entirely to the female subsample. Female respondents are 7.2 percentage points more likely to work if they received the information intervention, while male respondents in the treatment group are a statistically insignificant 0.3 percentage points more likely to work.

We also measured labor supply by hours worked in the previous calendar month and own 
earnings in the previous calendar month. Consistent with our finding that labor force participation increased, we find positive point estimates for the effect of the information intervention on hours worked and earnings, but only the estimate on earnings for female respondents is significant at the 5-percent level. The dispersion across respondents in hours worked and earnings is relatively high, which increases standard errors relative to the mean value of the variable, and which makes it more difficult to detect a statistically significant effect. For example, the treatment effect for the participation variable needs to exceed only $5.6 \%$ of the control group mean in order for it to be statistically significant. For the hours and earnings variables, however, it needs to reach at least $7.7 \%$ and $15.8 \%$ of the control group mean, respectively, to attain statistical significance.

It is not the case that the information intervention primarily induced labor force participation at only very minimal hours or earnings. If we redefine labor force participation to include just individuals who work at least 20 hours per month, we continue to find significant effects of the information treatment on labor force participation in the entire sample and in the subsample of female respondents. If we redefine labor force participation to only include individuals with at least $\$ 500$ in monthly earnings, we continue to find significant effects of the information treatment on female labor force participation, though the effect for the entire sample falls just short of marginal significance (p-value 0.110). Overall, the first three rows of Table 3 provide clear evidence that the information treatment increased labor supply among female respondents.

The final row of Panel A of Table 3 shows results regarding the claiming of Social Security benefits. The sample is smaller than that for the labor supply results because we measured benefit claiming only among those who were 60 and older but not claiming benefits at the time of our baseline survey (November 2008). The table shows that just over 70 percent of those who were 60 or older but not claiming benefits at the time of our baseline survey have not started yet claiming Social Security benefits by the time of the follow-up survey (April/May 2010). The information treatment did not have a significant effect on this percentage.

The presence of multiple outcome measures increases the risk that some of them are statistically significant by chance even if in truth there is no treatment effect. We address this multiple inference problem in two ways. First, we reduce the number of outcome variables by creating summary indices, an approach that originated in biostatistics (O’Brien, 1984). Second, 
we calculate p-values that are adjusted for the multiple inference problem using the Westfall and Young (1993) free stepdown resampling algorithm. Both approaches are increasingly used in economics (e.g., Kling et al. 2007, Acemoglu and Finkelstein 2008, Anderson 2008, and Heckman et al. 2010).

In panel B of Table 3, we present indices of the primary outcome measures. Because claiming behavior is conceptually different from labor supply, we created two indices: one of the three labor supply measures, and one that combines the labor supply measures with claiming behavior. We construct the indices by first standardizing each of the primary outcome variables by the control group mean and variance, then taking a simple average of the non-missing values of the standardized variables, and finally standardizing the average by the control group mean and variance. Thus, the index measures effect sizes in terms of standard deviations of the control group.

Row 5 presents the index of labor supply outcomes, and shows that the information treatment increased labor supply in the entire sample by $8.2 \%$ of a control-group standard deviation, but that this effect is only marginally statistically significant. As before, the labor supply effect is driven by the female subsample, where the effect is larger in magnitude (15.4\% of a control-group standard deviation) and statistically significant. Thus, when we eliminate the multiple inference problem of having three labor supply outcome measures by creating a single labor supply index, we still find a significant labor supply response to the treatment among females. In row 6, we also include Social Security claiming as a component of the index. Not surprisingly, this weakens the results because we found no treatment effects on claiming behavior, but we still find a marginally significant effect on the index of all four outcome variables for females ( $\mathrm{p}$-value 0.065).

The second way of accounting for the multiple inference problem is to calculate the probability that at least one hypothesis out of a family of hypotheses is falsely rejected. This probability is the family-wise error rate (FWER). We calculate the FWER using the Westfall and Young (1993) free stepdown resampling algorithm. ${ }^{15}$ When the family of hypotheses consists of all four primary outcome measures equaling zero, only the treatment effect on female labor force participation is statistically significant (FWER-adjusted p-value of 0.047). This implies that the treatment effect on female labor force participation remains significant even after

\footnotetext{
${ }^{15}$ We use 100,000 replications.
} 
accounting for the fact that we tested for a treatment effect in four outcome measures. Alternatively, one can control for the family-wise error rate by considering a family of two hypotheses: no treatment effect on the index of the three labor supply measures and no treatment effect on claiming behavior. In this case, the treatment effect on the index of labor supply measures remains significant for females (FWER-adjusted p-value of 0.044). Overall, we conclude from Panel B of Table 3 and the calculations of the FWER-adjusted p-values that the significant treatment effect on female labor supply holds up after accounting for the multiple inference problem.

Table 4 examines the robustness of the estimates in Table 3 to two alternative specifications: (i) the omission of control variables and (ii) a probit regression for binary outcome variables and a median regression for continuous outcome variables. Table 4 shows that the key finding of Table 3 - a positive treatment effect on female labor supply - is robust. The treatment effect on female labor force participation is statistically significant and similar in magnitude for all specifications. Similar to the findings in Table 3, the estimated effects on hours and earnings are positive and consistent in magnitude with the increase in labor force participation, but only occasionally statistically significant. Also in line with the findings of Table 3, we never detect a significant effect of our treatment on Social Security claiming behavior.

\section{Understanding the Results}

This section contains additional analysis and discussion of the results, with a focus on three questions: (i) what aspects of the intervention led to the behavioral responses; (ii) why were the experimental impacts limited to female sample members; and (iii) whether we would expect to see additional behavioral responses if we were able to measure outcomes after more time has passed.

\subsection{Which Aspects of the Intervention Led to the Behavioral Response?}

In designing this project, we and others we consulted with had significant doubts about whether the relatively mild intervention that was feasible given our resources could affect 
understanding about Social Security and alter behavior. ${ }^{16}$ We were particularly concerned that if we tested too weak an intervention and found no impact, we would have learned little - since it would always be possible that a slightly stronger intervention would have had an impact. We therefore decided to combine several different approaches to providing information in order to maximize the strength of the intervention, but did this subject to the constraint that the intervention had to be easily scalable, both in the cost per sample member and in the information delivery mechanism. Specifically, we offered each treatment-group sample member both an informational mailing and an online tutorial. Within each, we combined specific information about Social Security rules, more general information about the importance of taking steps to ensure adequate income during retirement, and vignettes in which actual retirees discussed their own experiences in ways that reinforced the more specific information.

The multi-faceted treatment raises the question of which aspects of the intervention led to the behavioral responses. Knowing the answer to this question is relevant if one were thinking of scaling up this intervention or of applying this finding to another policy domain. Would a mailing alone be sufficient? A web-tutorial alone? Or was the reinforcement through delivering the information through two different mechanisms critical? Similarly, was the specific knowledge about the program essential, or are vignettes the best way to communicate information in a salient manner? Are there interaction effects from presenting information in multiple ways?

Knowing the answers to these questions is important not only for learning how to scale up interventions at the least cost, but also for drawing normative policy recommendations from the findings. In particular, if the behavioral impact comes about because people now understand the program better and therefore make better decisions, then the normative implications are clear - we have made sample members better off by providing them with information. In contrast, if the intervention had its effect because it communicated an overall message of "continuing to work until older ages has benefits," then the normative implications are more complex. Such an intervention could persuade people to continue to work for whom it is not optimal. The policy dilemma in this latter case is analogous to that in the literature in behavioral economics about setting defaults. On the one hand, it seems innocuous to change or set a default, as long as

\footnotetext{
${ }^{16}$ Lusardi and Mitchell (2007) similarly caution that one should not expect meaningful impacts from one-time financial literacy interventions - not because the financial education is ineffective per se but because the "cure" is likely to be inadequate.
} 
people have an opportunity to opt out. On the other hand, if defaults are shown to affect outcomes, then there will likely be some people who are affected by the defaults in a way that makes them worse off. Indeed, the analogy to defaults is even more direct since Social Security already provides a significant amount of information about retirement incentives to the U.S. population. To the extent that the content of the information and the way in which it is presented affects people's choices, a proposal to alter what information is provided and how it is delivered is exactly analogous to altering a default.

Because our information delivery mechanism, unlike the caseworker approach, allows for complete researcher control over what information is provided, it would in theory be straightforward to do follow-up experiments to determine which components of the intervention are necessary to produce the behavioral response we observed. One would simply randomize people into different treatments each containing different subsets of the experimental intervention. In practice, one would have to be selective since sample size considerations would limit the number of different permutations that could be tested. In the current experiment, we followed a different path to learn about the mechanisms through which the intervention had its effects. We asked questions to measure whether the intervention changed the amount of knowledge sample members had about different aspects of Social Security.

Table 5 presents the effects on knowledge about the three main topics on which the information intervention focused: the likelihood that retirees live into their 90 s, the effects of working longer and claiming later on Social Security benefits, and the earnings test.

To assess knowledge about longevity, we asked respondents about (i) the likelihood that a typical 65 year-old individual of the same gender as the respondent lives to age 90 or beyond and (ii) the likelihood that at least one member of a typical 65 year-old couple lives to age 90 or beyond. Based on the 2005 life tables published by the National Center for Health Statistics, the correct answers to the first question is 21 percent for males and 33 percent for females, and the correct answer to the second question is 47 percent. Panel A of Table 5 shows that the respondents in the control group are too optimistic about survival probabilities. For example, respondents in the control group on average believe that the probability that at least one member of a 65 year-old couple lives to 90 or beyond is 65 percent. Our information intervention had no economically or statistically significant effects on the perceived survival probabilities. All point estimates are positive, consistent with respondents remembering the gestalt of our message 
("You may live longer than you think") rather than the longevity figures we provided, but the size of the treatment effect is 2 percentage points or less in all cases.

Panels B and C present the effects of our information treatment on incentives to work longer and on incentives to delay claiming Social Security benefits. The responses to the four questions related to work incentives from Social Security benefits are presented in Panel B. The first of these four questions is a multiple choice question that asks whether the respondent's Social Security benefits will be the same, higher, or lower if the respondent works fewer years, but keeps constant the age of claiming Social Security benefits. This is the exactly the same question as the one we analyzed in Liebman and Luttmer (2011), and, consistent with our previous findings, about two thirds of respondents in the control group believe that benefits increase with number of years worked. ${ }^{17}$ Row 3 shows that our information treatment had a very small positive but statistically insignificant effect on this response, which is perhaps not surprising given that the response was already correct on average in the control group. Row 4 analyzes the quantitative version of the same question, in which we ask respondents about the percentage change in their Social Security benefits per additional year worked (holding claim age constant). The mean response in the control group (5.2 percent increase per additional year worked) is similar to our earlier findings and, as we explain in Liebman and Luttmer (2009), overestimates the true return by about a factor of two for a typical worker. The information treatment has no economically meaningful or statistically significant effect on the quantitative answer to the perceived return. ${ }^{18}$

Because we were aware that our information intervention might have an effect on perceptions of incentives even when respondents' ability to quantify incentives precisely is limited, we also asked a question in a more intuitive format. We asked whether you get a "better deal" or "worse deal" from Social Security if you work fewer years, where we explain that a "better deal" means that "money saved by paying into Social Security for fewer years would be greater than the cut to [your] Social Security benefits." We pose this question to those

\footnotetext{
${ }^{17}$ Social Security rules dictate that extra years of work will either increase or not change a person's benefits, depending upon (i) whether or not the person claims solely on his or her own record and (ii) whether the additional year will be part of the 35 highest years that enter the AIME calculation. In Liebman and Luttmer (2011), we explain that it is plausible that the Social Security benefits to approximately one third of respondents would not be affected by a small change in number of years worked.

${ }^{18} \mathrm{We}$ also examined the effect of the information treatment on the variances of responses of variables that are measured on a continuous scale. We do not find significant treatment effects on the variance of responses, but our power to detect such effects is limited given the sensitivity of variances to outliers.
} 
respondents who believe that Social Security benefits increase with the number of years worked (recall that the size of this group was not affected by the information treatment). We analyze this question for all respondents in our sample (not only those who answered the follow-up question) by coding an individual as a 1 if they both report that Social Security benefits increase with years worked and that you get a "better deal" from working more years and coding an individual as a zero otherwise. Row 5 shows that 36.3 percent of control group respondents believe they get a better deal by working more years, and that the information treatment increases this fraction by 4.3 percentage points, significant at the 10 percent level. This effect is driven by female respondents, for whom the information treatment increases the fraction perceiving a better deal by 7.9 percentage points from a base of 34.6 percent. There is virtually no effect for male respondents. Thus, when the question about incentives to work for more years is asked in a more intuitive format, our information treatment had an economically sizeable and statistically significant positive effect on the perception of this incentive for females - the population subgroup that exhibited a behavioral labor supply response.

We also ask respondents a multiple choice question about which years of earnings determine one's Social Security benefits. In line with results in our earlier paper, just under 40 percent of individuals in the control group are aware that the benefits are based on their $X$ highest years of earnings (the other options for this multiple choice question were "most recent years of earnings," "earnings at particular ages," and "the number of years worked, but not the earnings in those years"). We ask them about the value of $X$, but in coding the answer as correct, we do not require them to correctly answer that $X$ is 35 . Row 6 shows that the information intervention significantly raises the fraction of respondents that answers that benefits are based on years with highest earnings by 5.5 percentage points. Again, the effect appears to be driven by female respondents, for whom the effect is 7.4 percentage points and statistically significant, although we cannot reject the hypothesis that the effect for men and women is the same.

Panel $\mathrm{C}$ examines the effect of the information treatment on perceptions of the effect of the age at which someone starts claiming Social Security benefits on benefit levels. We first ask respondents a multiple-choice question about the effect on their own benefits of claiming a year later than they were planning. Row 7 shows that about two thirds of the control group thinks their benefits would increase by claiming a year later, and that this fraction is not statistically significantly affected by our information intervention, though for the subgroup of female 
respondents the effect is positive and marginally statistically significant. To elicit the schedule of incentives at different claim ages (rather than just the respondent's own planned claim age), we then ask respondents to fill out a table that shows how benefits vary by claim age for a typical worker that would receive $\$ 1000$ in monthly benefits if he claimed at age 62. In this table, we elicit benefits for initial claim ages of 66,70, and 74. Based on the entries in this table, we can calculate for each of the three age ranges $(62-66,66-70$, and 70-74) whether (a) the respondent thinks benefits increase by delaying claiming in that age range and (b) the increase in benefits per year of delay in claiming as a percentage of the benefit level at the full-benefit retirement age (66 for our sample).

Rows 8 through 13 shows the results for these six variables. Clear majorities $(91 \%$ and $80 \%$ ) in the control group correctly respond that benefits increase with claim age in the 62-66 and the 66-70 age ranges, but only a minority (37\%) correctly responds that benefits don't depend on claim age in the 70-74 age range. The mean perceived increase in benefits per year of delayed claiming as a percentage of benefits at age 66 is quite accurate for the 62-66 age range (perception of $7.1 \%$ vs. actual value of 6.25\%), is too low for the 66-70 age range (perception of $3.1 \%$ vs. actual value of $8.0 \%$ ), and too high for the $70-74$ age range (perception of $3.4 \%$ vs. actual value of $0 \%$ ). The information treatment had no significant effects on these responses for the sample as a whole, though it increased the fraction of male respondents that perceive a positive return for delaying claiming between the ages of 66 and 70 by a statistically significant 5.6 percentage points. Consistent with this finding, the information treatment also has a positive and statistically significant effect on male respondents' perceptions of the percentage increase in benefits per year of delayed claiming.

The final area on which the information intervention focused was knowledge about the earnings test. A solid majority (62\%) of the respondents in the control group is aware that current Social Security benefits will be reduced for someone aged 64 who already claims benefits but has earnings that exceed a certain amount. The information intervention did not significantly raise this percentage. A minority (39\%) of the control group respondents who are aware of the earnings test also knows that any current reduction in benefits due to the earnings test is offset by an increase in benefits in the future. The information treatment increased this minority by a marginally statistically significant 5.9 percentage points, thus raising the perception in the treatment group of the returns to working after having started claiming benefits. 
Overall, we take away three points from Table 5. First, the information intervention generally increased awareness of the benefits of working longer and claiming later, even if many of the treatment effects are insignificant. This result suggests that at least part of the behavioral labor supply response may have occurred through a higher perceived return to working more years. Second, the treatment had a strong and significant effect on the perceived incentive for women to work more years, which closely matches our earlier finding that the labor supply response is driven primarily by female respondents. Third, the information intervention has a significant effect on men's perceptions of the return to delaying claiming between the ages of 66 and 70, which, as we will see later in Table 6, is consistent with the increase in planned Social Security claim ages among male respondents. Thus, while we cannot rule out that the "gestalt" of the information intervention may be partly or fully responsible for the observed responses in realized and planned behavior, Table 5 is consistent with a pathway in which the intervention affected behavior by changing perceptions of incentives.

\subsection{Why Are Behavioral Impacts Limited to Females?}

The labor supply impacts in Table 3 are accounted for almost entirely by female sample members, raising the question of why this is so. Male and female sample members were equally likely to recall the intervention, ruling out different exposure to the treatment as an explanation. One dimension, however, along which men and women have a striking difference is the length of their work history. Only $8.7 \%$ of the men in our sample have a work history of less than 35 years, whereas this figure is $36.5 \%$ for women. The returns to working an additional year drop sharply after 35 years of earnings because at that point an additional year of earnings generally replaces an earlier year of earnings (rather than a 0) when calculating the PIA, which is based on the 35 highest years of indexed earnings. Thus, women are four times more likely than men to have a year of additional earnings count fully in the determination of their PIA. This finding implies that a better understanding of the 35-year rule would have an impact on the perceived returns to working additional years that is stronger for women than for men. Table 5 demonstrated that our intervention significantly increased knowledge of the 35-year rule, both in the entire sample as well as in the subsample of women. We think it is plausible that the increased understanding of the 35-year rule in combination with the higher fraction of women with a work history less than 35 years caused a disproportionate increase among women in the 
perceived return to working longer.

If the differences in work history are responsible for the stronger treatment effects on perceived work incentives and on actual labor force participation for women, we expect the treatment effects to be concentrated among females with a work history of fewer than 35 years. This is indeed the case. The treatment effect on perceived labor supply incentives, as measured by the "better deal" question, is 0.119 (s.e. 0.064) for women with a work history less than 35 years but only 0.033 (s.e. 0.046) for those with a work history of 35 years or more. Though this difference is not statistically significant (p-value 0.203 ), the size and sign of the difference offer suggestive support for the notion that the gender difference in treatment effects can traced to differences in work history. Similarly, we would expect the treatment effect on labor force participation to be concentrated among women with a work history of fewer than 35 years. This is also the case. The treatment effect on labor force participation is 0.099 (s.e. 0.056) for women with less than 35 years of work but is 0.057 (s.e. 0.041) for those with a longer work history. While the difference in treatment effects is not statistically significant (p-value 0.560 ), its sign and size are consistent with the role of gender differences in earnings histories as an explanation for the stronger treatment effects on women.

The stronger treatment effects among women may have been further accentuated by an historical perception of women receiving low returns from additional work. We speculate that some women in our sample had believed that as secondary earners, they get little or no marginal Social Security benefits from additional work. This would have been true for most women who retired twenty or thirty years ago, but for women today who are working into their 60s, we estimate that 70 percent or more are receiving benefits based on their own earnings record. ${ }^{19}$ Females in the control group are indeed 3.9 percentage points less likely than males to think that the incremental benefits are enough to outweigh the incremental contributions (see Table 5, row

\footnotetext{
${ }^{19}$ To generate a rough estimate of the share of women receiving benefits on their own record, we analyzed SSA's 2004 Benefit and Earnings Public-Use File. To mimic the characteristics of our sample, we identified recent retirees who had been working when they were between the age of 60 and 65 and examined whether they were receiving only retired worker benefits or whether they were also (or only) receiving benefits based on the record of a current or former spouse. Specifically, we examined female Social Security beneficiaries who were between the age of 66 and 71 in 2004 and who had positive labor earnings in 1998 (when their ages ranged from 60 to 65). In this sample, 65 percent of the women were receiving benefits based only upon their own earnings record. However, this cohort (born around 1935) was born about 10 years earlier than our survey sample (born around 1945). Eckstein and Lifshitz (2009) show that female labor force participation rates rose by more than 10 percentage points at most ages between the 1935 and 1945 birth cohorts. Thus, it appears likely that the fraction in our sample who will receive benefits on their own record exceeds 70 percent. Moreover, $83 \%$ of the female respondents report that their benefits will be based only on their own earnings record.
} 
5). Though this difference is not statistically significant, its sign is consistent with the possibility that our intervention affected women by counteracting the notion that working women receive no meaningful benefit on the margin from Social Security.

The provision of information can improve decision making even if it does not change mean outcomes. In particular, if prior perceptions of labor supply incentives were centered around the true values, better knowledge could cause an equal number of people to increase and decrease their retirement dates. Liebman and Luttmer (2011) find that for many features of Social Security, median perceptions are quite close to the true values, even though there is a wide spread around the median. One possible interpretation of our results is that labor supply was broadly affected, but that only females had prior perceptions that were centered away from their true values, leading to a change in average behavior.

\subsection{Treatment Effects on Planned or Expected Behavior}

Because only just over one year elapsed between the administration of the information intervention and the collection of the follow-up data, the time span during which respondents could possibly change their behavior in response to the new information was limited. ${ }^{20}$ In an attempt to capture effects of the information intervention on future behavior, we also asked the respondents a number of questions about their planned future behavior. We think of these responses as more speculative than our responses on current behavior because the planned behavior measures are likely to be less reliable (cheap talk) and more noisy (respondents might not have firm plans yet or have thought future decisions through) than realized behavior. Keeping these caveats in mind, we nevertheless present the results for the planned outcome variables in Table 6.

The first variable about planned future behavior is the respondent's retirement status defined using the same two questions as in our baseline survey. According to this definition, the respondent is retired if she does not "currently work for pay (with at least \$2500 in annual earnings)" and does "not expect that in the future [she] will work for pay (with at least $\$ 2500$ in

\footnotetext{
${ }^{20}$ Delaying the administration of the follow-up survey beyond one year would have had the drawback of increasing attrition from the panel.
} 
annual earnings)." ${ }^{21}$ The first row of Table 6 shows that the information treatment had no significant effect on the retirement measure, though, consistent with our labor supply findings, the point estimates are negative for the sample as a whole and particularly for the female subsample.

We measure the respondent's "point estimate" of her expected or realized retirement age by a question in which we ask "at what age did you last work for pay (with at least $\$ 2500$ in annual earnings)" for those who reported being retired and "at what age do you plan to stop working for pay or to reduce your earnings to a minimal amount" for those reporting not being retired. We ask for the age in years and months. The second row reports that we find no significant effects on the expected or realized retirement age though, consistent with the first row, the point estimates are positive for the sample as a whole and the positive effects are concentrated in the subsample of female respondents.

In an attempt to capture uncertainty about future retirement plans and in the hope of measuring future retirement plans more precisely, we elicited the probability density function (pdf) of future retirement dates for non-retired respondents using the "bins and balls" question format from Delavande and Rohwedder (2008). ${ }^{22}$ The bins are centered on the respondent's point estimate of her retirement age, but with the restriction that the minimum age is at least as high as her current age. Row 3 of Table 6 reports the effect of the information treatment on the mean of the pdf of expected retirement dates from the bins-and-balls question for those not yet retired and the realized retirement age for those already retired. The results are very similar to those for the point estimate of the retirement age reported in the previous row, and none of the estimates are significant.

The information intervention could have helped respondents to decide when to retire without, on average, moving retirement dates forwards or backwards. We test for such effects by testing whether the information intervention altered the standard deviation of the pdf of future retirement dates. We assign a standard deviation of zero to respondents who are already retired

\footnotetext{
${ }^{21}$ Apart from the expected future labor supply component, this question differs from our main labor supply variable in that it specifies a minimal level of annual earnings and that it is less precise about the timing ("currently" here versus "in [the previous calendar month] of 2010 " for our main labor supply question").

${ }^{22}$ We first explain the format of the question using a hypothetical example of uncertainty regarding "temperatures in Boston tomorrow." We then present respondents with an interactive screen in which they are asked to allocate 20 balls over nine age bins and tell them the "more likely you think that you will retire at a given age, the more balls you should put in that age bin." The age bins each have a one-year age range except for the bottom bin, which is labeled "[minimum age] or earlier," and the top bin, which is labeled "[maximum age] or later."
} 
since their uncertainty about when to retire has been resolved. Row 4 of Table 6 shows that the information intervention raised the standard deviation for the full sample by a very small and statistically insignificant amount.

In row 5 of Table 6 , we report the effect of the information intervention on the respondents' subjective expectation of "working for pay at least part-time" after the respondent has started claiming Social Security benefits. This question is asked on a 4-point likert scale and, for ease of presentation, we code respondents answering "very likely" or "likely" as a one. Close to 70 percent reports being likely or very likely to work after claiming benefits, and the information treatment had no statistically significant impact on this percentage.

We ask respondents about their realized or planned age of starting to claim Social Security benefits, and, for those not claiming benefits, we also ask about their pdf of benefit claim ages using the bins-and-balls format. The nine bins run from "61 or earlier" to "69 or later." We use these questions to create three variables: the point estimate of the claim age, the mean of the pdf of the claim age, and the standard deviation of the claim age. We use the realized claim age for those already claiming benefits and assign them a zero standard deviation. We limit the sample to those not claiming benefits at the time of the baseline survey in 2008 because only those not claiming benefits in 2008 could possibly be affected by the information treatment.

Rows 6 and 7 show that the information treatment delayed the expected claim age by about a third of year for male respondents. This effect is statistically significant at the 10-percent level when we elicit claim age as a point estimate and significant at the 5-percent level when we measure it as the mean of the pdf. This finding is consistent with our earlier finding that the information intervention increased the perception among male respondents of the return to delaying claiming between the ages of 66 and 70 (rows 9 and 12 of Table 5). Indeed, we find that the delay in expected claiming among male respondents takes the form of more respondents planning to claim beyond the age of 66 ; in response to information treatment, male respondents put 8 percent more probability mass in the bins corresponding to ages 67 and higher, and this effect is significant at the 5-percent level. The information treatment, however, did not statistically significantly affect the expected claim ages among female respondents or in the entire sample, and we can reject the hypothesis that male and female respondents adjusted their claim age in the same way in response to the information treatment. As Row 8 shows, we do not 
find a significant effect of the information treatment on respondents' uncertainty about their expected claim age.

Overall, Table 6 shows that the information intervention generally had no significant effects on planned or expected outcomes. We suspect that this lack of statistically significant findings is partly due to the fact that expectations are not measured as precisely as realized outcomes. The one exception to the lack of statistically significant findings is that the information intervention increased the expected claim age among male respondents. This change in expected behavior closely matches our earlier finding that the information intervention increased the perceived return to delaying claiming among men. We take this close correspondence between changes in perceived incentives and changes in expected behavior as a further indication that the intervention may have worked at least partly through changing perceptions of incentives.

\section{Conclusion}

The field experiment described in this paper demonstrates that a relatively mild informational intervention can have important impacts on the labor force participation of older individuals. Moreover, we show that the intervention affected people's perceptions of the returns to remaining in the labor force and that both the labor supply impacts and the impacts on perceptions were concentrated in the same population subgroups - suggesting that the behavioral response may be attributable at least in part to updated information about Social Security. We do not, however, have a conclusive explanation for why the labor supply impacts were concentrated among female sample members. We speculate that the intervention may have countered perceptions that women receive little or no additional Social Security benefits from incremental labor effort, perceptions left over from an earlier era when most women received benefits based on their husbands' earnings records.

This study was designed to answer the threshold question of whether an easily scalable information intervention could alter behavior. The intervention therefore delivered information in several different mutually reinforcing ways. Before drawing policy implications from this intervention and other similar interventions in which information provision alters behavior, it will be important to learn more about the mechanisms through which such interventions produce their effects. To the extent that informational interventions affect behavior by educating sample 
members and allowing them to make better choices, such interventions unambiguously raise sample member welfare. In contrast, if interventions have their impact by delivering a general message such as "working to older ages is better," then the normative implications are more complicated since the message may or may not be accurate for a particular sample member. Because our experimental mechanism allows for complete researcher control over the message delivered to sample members, it would be straightforward to conduct a follow-up study that delivered only subsets of the intervention so as to determine the relative importance of each form of information as well as the existence of interaction effects from reinforcing the message by providing information in multiple ways. 


\section{References}

Acemoglu, Daron, and Amy Finkelstein. 2008. "Input and Technology Choices in Regulated Industries: Evidence from the Health Care Sector," Journal of Political Economy, 116(5), pp. 837-880.

Anderson, Michael L. 2008. "Multiple Inference and Gender Differences in the Effects of Early Intervention: A Reevaluation of the Abecedarian, Perry Preschool, and Early Training Projects," Journal of the American Statistical Association, 103(484), pp. 1481-1495.

Benítez-Silva, Hugo, Berna Demiralp, and Zhen Liu. 2009. "Social Security Literacy and Retirement Well-being." University of Michigan Retirement Research Center Working Paper 2009-210.

Bernheim, B. Douglas. 1988. "Social Security Benefits: An Empirical Study of Expectations and Realizations," in Rita Ricardo-Campbell and Edward P. Lazear (eds.), Issues in Contemporary Retirement, Stanford: Hoover Institution Press, pp. 312-345.

Bernheim, B. Douglas, and Antonio Rangel. 2009. "Beyond Revealed Preference: ChoiceTheoretic Foundations for Behavioral Welfare Economics," Quarterly Journal of Economics, 124(1), pp. 51-104.

Beshears, John, James J. Choi, David Laibson, and Brigitte C. Madrian. 2008. "How Are Preferences Revealed?” Journal of Public Economics, 92(8-9), pp. 1787-1794.

Brown, Jeffrey R., Arie Kapteyn, and Olivia S. Mitchell. 2011. "Framing Effects and Expected Social Security Claiming Behavior," NBER Working Paper 17018.

Chan, Sewin, and Ann Huff Stevens. 2008. "What You Don't Know Can't Help You: Pension Knowledge and Retirement Decision-Making," Review of Economics and Statistics, 90(2), pp. 253-266.

Chetty, Raj, Adam Looney, and Kory Kroft. 2009. "Salience and Taxation: Theory and Evidence”, American Economic Review, 99(4), pp. 1145-1177.

Chetty, Raj, and Emmanuel Saez. 2009. "Teaching the Tax Code: Earnings Responses to an Experiment with EITC Recipients," NBER Working Paper No. 14836.

Delavande, Adeline, and Susann Rohwedder. 2008. "Eliciting Subjective Expectations in Internet Surveys," Public Opinion Quarterly, 72(5), pp. 866-891.

Dominitz, Jeff, Angela Hung, and Arthur van Soest. 2007. "Future Beneficiary Expectations of the Returns to Delayed Social Security Benefit Claiming and Choice Behavior," Michigan Retirement Research Center Working Paper 2007-164.

Duflo, Esther, William Gale, Jeffrey Liebman, Peter Orszag, and Emmanuel Saez. 2006. "Savings Incentives for Low- and Middle-Income Families: Evidence from a Field Experiment with H\&R Block," Quarterly Journal of Economics, 121(4), pp. 1311-1346.

Eckstein, Zvi, and Osnat Lifshitz. 2009. "Dynamic Female Labor Supply.” CEPR Discussion Paper No. DP7548.

Gustman, Alan L., and Thomas L. Steinmeier. 2005. "Imperfect Knowledge of Social Security and Pensions," Industrial Relations, 44(2), pp. 373-97.

Hastings, Justine S. and Lydia Tejeda-Ashton. 2008. "Financial Literacy, Information, and Demand Elasticity: Survey and Experimental Evidence From Mexico," NBER Working Paper 14538.

Heckman, James, Seong Hyeok Moon, Rodrigo Pinto, Peter Savelyev, and Yavitz, Adam. 2010. "Analyzing Social Experiments as Implemented: A Reexamination of the Evidence from the HighScope Perry Preschool Program," Quantitative Economics, 1(1), pp. 1-46. 
Kling, Jeffrey R., Jeffrey B. Liebman, and Lawrence F. Katz. 2007. "Experimental Analysis of Neighborhood Effects," Econometrica, 75(1), pp. 83-119.

Kling, Jeffrey R., Sendhil Mullainathan, Eldar Shafir, Lee Vermeulen, and Marian V. Wrobel. 2011. "Comparison Friction: Experimental Evidence From Medicare Drug Plans." forthcoming in Quarterly Journal of Economics.

Liebman, Jeffrey B., Erzo F.P. Luttmer, and David G. Seif. 2009. "Labor Supply Responses to Marginal Social Security Benefits: Evidence from Discontinuities," Journal of Public Economics, 93(11-12), pp. 1119-1284.

Liebman, Jeffrey B., and Erzo F.P. Luttmer. 2011. “The Perception of Social Security Incentives for Labor Supply and Retirement: The Median Voter Knows More Than You'd Think." Forthcoming in Tax Policy and the Economy, Jeffrey R. Brown (ed.), Volume 26.

Liebman, Jeffrey B. and Richard J. Zeckhauser. 2004. "Schmeduling." Unpublished manuscript. Harvard University.

Liebman, Jeffrey B., and Richard J. Zeckhauser. 2008. "Simple Humans, Complex Insurance, Subtle Subsidies," in Using Taxes to Reform Health Insurance: Pitfalls and Promises, Henry J. Aaron and Leonard E. Burman (eds.), Washington D.C.: Brookings Institution Press, 230-252.

Lusardi, Annamaria, and Olivia Mitchell. 2007. "Financial Literacy and Retirement Preparedness. Evidence and Implications for Financial Education," Business Economics, 42(1), pp. 35-44.

Lusardi, Annamaria, and Olivia Mitchell. 2009. "How Ordinary Consumers Make Complex Economic Decisions: Financial Literacy and Retirement Readiness.” NBER working paper 15350.

Mastrobuoni, Giovanni. 2010. "The Role of Information for Retirement Behavior: Evidence based on the Stepwise Introduction of the Social Security Statement," Journal of Public Economics, 95(7-8), pp. 913-925.

Mitchell, Olivia S. 1988. "Worker Knowledge of Pension Provisions," Journal of Labor Economics, 6(1), pp. 21-39.

O’Brien, Peter C. 1984. "Procedures for Comparing Samples with Multiple Endpoints," Biometrics, 40(4), pp. 1079-1087.

Rohwedder, Susann, and Kristin J. Kleinjans. 2006. "Dynamics of Individual Information about Social Security." Unpublished Manuscript, RAND.

Westfall, Peter H., and S. Stanley Young. 1993. Resampling-Based Multiple Testing: Examples and Methods for p-Value Adjustment. New York: Wiley. 
Table 1: Summary Statistics

\begin{tabular}{|c|c|c|c|c|c|c|c|}
\hline & \multicolumn{3}{|c|}{ Women } & \multicolumn{3}{|c|}{ Men } & \multirow{2}{*}{$\begin{array}{c}\text { P-value on } \\
\text { t-test of } \\
\text { difference }\end{array}$} \\
\hline & $\mathrm{N}$ & Mean & S.D. & $\mathrm{N}$ & Mean & S.D. & \\
\hline \multicolumn{8}{|l|}{ Key outcome variables } \\
\hline Did paid work last month (2010) & 880 & 0.75 & 0.43 & 712 & 0.79 & 0.41 & 0.088 \\
\hline Hours worked for pay last month (2010) & 879 & 91 & 76 & 712 & 109 & 79 & 0.000 \\
\hline Earnings last month (2010), in dollars/month & 873 & 2888 & 4998 & 703 & 4248 & 5777 & 0.000 \\
\hline $\begin{array}{l}\text { Not receiving Social Security benefits in } 2010 \\
\text { (Asked if not claiming in '08 and aged } 60+\text { in '10) }\end{array}$ & 672 & 0.69 & 0.46 & 570 & 0.72 & 0.45 & 0.330 \\
\hline \multicolumn{8}{|c|}{ Demographics measured at the time of the baseline survey (2008) } \\
\hline Age in 2010 & 883 & 63.2 & 2.2 & 712 & 63.1 & 2.2 & 0.419 \\
\hline Non-Hispanic white & 883 & 0.88 & 0.32 & 712 & 0.90 & 0.30 & 0.257 \\
\hline Non-Hispanic black & 883 & 0.06 & 0.23 & 712 & 0.03 & 0.18 & 0.034 \\
\hline Other race/ethnicity & 883 & 0.06 & 0.24 & 712 & 0.07 & 0.25 & 0.749 \\
\hline High school dropout & 883 & 0.02 & 0.13 & 712 & 0.01 & 0.11 & 0.328 \\
\hline High school & 883 & 0.18 & 0.39 & 712 & 0.10 & 0.30 & 0.000 \\
\hline Some college & 883 & 0.33 & 0.47 & 712 & 0.32 & 0.47 & 0.582 \\
\hline Bachelor's degree or more & 883 & 0.47 & 0.50 & 712 & 0.57 & 0.50 & 0.000 \\
\hline Married & 883 & 0.55 & 0.50 & 712 & 0.78 & 0.41 & 0.000 \\
\hline Widowed & 883 & 0.07 & 0.26 & 712 & 0.02 & 0.14 & 0.000 \\
\hline Divorced & 883 & 0.27 & 0.44 & 712 & 0.11 & 0.31 & 0.000 \\
\hline Separated & 883 & 0.01 & 0.09 & 712 & 0.01 & 0.09 & 0.892 \\
\hline Never married & 883 & 0.06 & 0.25 & 712 & 0.05 & 0.22 & 0.344 \\
\hline Living apart & 883 & 0.03 & 0.18 & 712 & 0.03 & 0.18 & 0.977 \\
\hline Lives in the Northeast & 883 & 0.20 & 0.40 & 712 & 0.17 & 0.37 & 0.137 \\
\hline Lives in the Midwest & 883 & 0.26 & 0.44 & 712 & 0.25 & 0.43 & 0.511 \\
\hline Lives in the South & 883 & 0.28 & 0.45 & 712 & 0.32 & 0.47 & 0.078 \\
\hline Lives in the West & 883 & 0.26 & 0.44 & 712 & 0.26 & 0.44 & 0.913 \\
\hline Household size of one & 883 & 0.35 & 0.48 & 712 & 0.21 & 0.41 & 0.000 \\
\hline Household size of two & 883 & 0.49 & 0.50 & 712 & 0.57 & 0.50 & 0.001 \\
\hline Household size of three or more & 883 & 0.16 & 0.37 & 712 & 0.22 & 0.41 & 0.005 \\
\hline Household income: less than $25 \mathrm{k}$ & 883 & 0.09 & 0.28 & 712 & 0.05 & 0.21 & 0.002 \\
\hline Household income: 25k-50k & 883 & 0.25 & 0.44 & 712 & 0.15 & 0.35 & 0.000 \\
\hline Household income: 50k-75k & 883 & 0.25 & 0.43 & 712 & 0.22 & 0.42 & 0.167 \\
\hline Household income: 75k-100k & 883 & 0.21 & 0.41 & 712 & 0.19 & 0.40 & 0.437 \\
\hline Household income: $100 \mathrm{k}$ or more & 883 & 0.20 & 0.40 & 712 & 0.39 & 0.49 & 0.000 \\
\hline
\end{tabular}

Notes: Key outcome variables are measured in the April-J une 2010 Social Security Follow-Up Survey, designed by the authors and fielded by Knowledge Networks. The baseline demographics are the values in the standard demographic profile variables at the time of the baseline survey (November 2008). The standard demographic profile is collected by Knowledge Networks. Our sample is restricted to individuals working in November 2008 and heavily oversamples individuals between the ages of 60 and 65 in as of November 2008 . 
Table 2: Manipulation Checks

(3)

(4)

(5)

(6)

Entire Sample Control Treatment

Female Respondents Mean Effect Control Treatment

Male Respondents

Dependent Variable

[N of reg.] (S.E.)

$$
\text { Mean Effect }
$$

Control Treatment

[ $\mathrm{N}$ of reg.]

(S.E.)

Mean Effect

P-value on

1. Recall receiving our brochure about SS

0.048
$[1,595]$

$0.286 * * *$

0.040

$0.307 * * *$

[N of reg.]

(S.E.)

t-test of

2. Recall taking our web-tutorial on SS

$\begin{array}{cl}0.010 & 0.084 * * * \\ {[1,595]} & (0.011)\end{array}$

[883]

(0.024)

0.059

$0.256 * * *$

difference

2. Recall taking our web-tutorial on SS

$[1,595]$

0.012

[883]

$0.083 * * *$

[712]

(0.027)

0.761

(0.015)

0.009

$0.082 * * *$

(0.016)

Notes: Robust standard errors between parentheses. Number of observations in the regression sample in square brackets. $*$ significant at $10 \%, * *$ significant at $5 \%$ *** significant at $1 \%$. Treatment effects are estimated by an OLS regression with controls for age and age squared as well as demographics measured at the time of the baseline survey. The demographic control variables, measured at the time of the baseline survey consist ofgender, race/ethnicity dummies (non-hispanic white, nonhispanic black, other race/ethicity), education dummies (high school dropout, high school graduate, some college, college plus), marital status dummies (married, widowed, divorced, separated, never married, living apart), regional dummies (Northeast, Midwest, South, West), and household size dummies (one-person, twoperson, 3+ person household). See appendix C for the exact wording of the questions that define the outcome variables: Q8.4 and Q8.5. Column 7 reports the p-value on the test of the hypothesis that treatment effects are equal for females and males. 

(1)
(2)
(3)
(4)
(5)
(6)
(7)

Entire Sample

Female Respondents

Male Respondents

\begin{tabular}{ccccc} 
Control & Treatment & & Control & Treatment \\
Mean & Effect & & Mean & Effect \\
[N of reg.] & (S.E.) & & [N of reg.] & (S.E.) \\
\hline
\end{tabular}

Dependent Variable

\section{Panel A: Primary outcome measures}

1. Did paid work last month (2010)

$\begin{array}{cccccc}0.744 & 0.042^{* *} & 0.713 & 0.072 * * & 0.783 & 0.003 \\ {[1,592]} & (0.021) & {[880]} & (0.029) & {[712]} & (0.031) \\ 97.7 & 2.8 & 88.6 & 4.8 & 108.9 & 1.4 \\ {[1,591]} & (3.8) & {[879]} & (5.1) & {[712]} & (5.9) \\ 3258 & 388 & 2554 & 683 * * & 4146 & 168 \\ {[1,576]} & (263) & {[873]} & (336) & {[703]} & (443) \\ 0.712 & -0.007 & 0.711 & -0.032 & 0.713 & 0.022 \\ {[1,242]} & (0.023) & {[672]} & (0.033) & {[570]} & (0.033)\end{array}$

Control Treatment

P-value on

Mean Effect

t-test of

1. Did paid work last month (2010)

2. Hours worked for pay last month (2010)

[672]

$(0.033)$

[570]

$(0.033)$

difference

\section{Panel B: I ndices of outcome measures}

5. Index of labor market outcomes (stardardized

$\begin{array}{cccccc}1.000 & 0.082^{*} & 1.000 & 0.154^{* *} & 1.000 & 0.017 \\ {[1,592]} & (0.049) & {[880]} & (0.068) & {[712]} & (0.075) \\ 1.000 & 0.063 & 1.000 & 0.121^{*} & 1.000 & 0.016 \\ {[1,595]} & (0.048) & {[883]} & (0.066) & {[712]} & (0.073)\end{array}$

0.102

0.659

0.354

0.245 average of standardized values of (1), (2), and (3))

6. Index of all key outcomes (stardardized average of standardized values of (1), (2), (3), and (4))

Notes: Robust standard errors between parentheses. Number of observations in the regression sample in square brackets. * significant at $10 \%, * *$ significant at $5 \%, * * *$ significant at $1 \%$. The entire sample consists of 1,595 observations ( 883 females, 712 males), but some regressions may have smaller samples because of item non-response. The sample size for

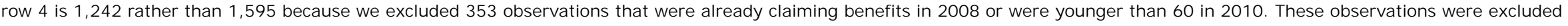
because the information treatment could not have possibly affected their claim status in 2010. The indices in rows 5 and 6 are standardized by the control group mean and standard deviation of the sample listed in the column. Treatment effects are estimated by an OLS regression with controls for age and age squared as well as demographics measured at the time of the baseline survey. See the note to Table 2 for a description of these demographic control variables. See appendix $C$ for the exact wording of the questions that define the four outcome variables: Q1.13, Q1.16, Q1.17, and Q1.2, respectively. Column 7 reports the p-value on the test of the hypothesis that treatment effects are equal for females and males. 


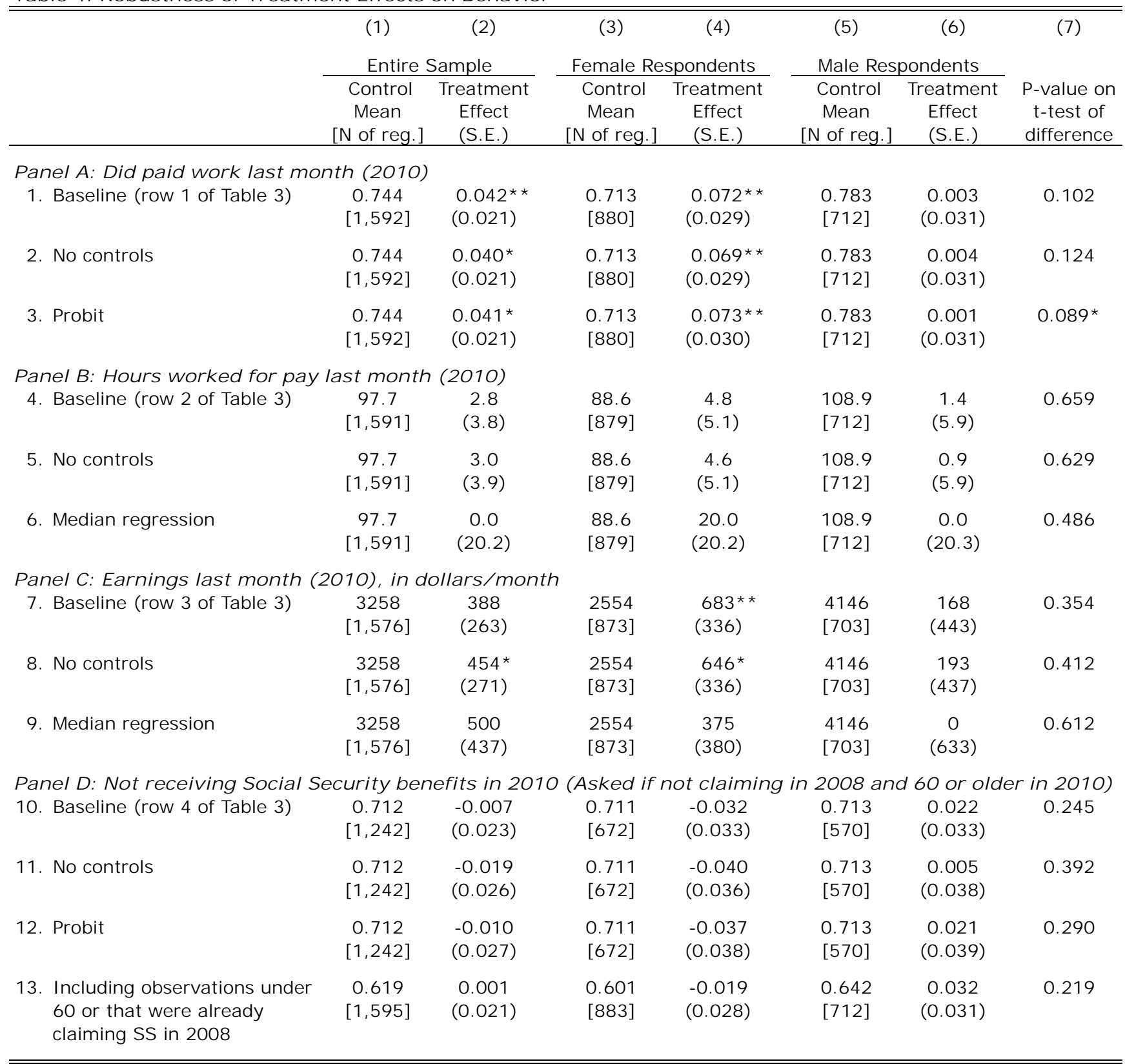

Notes: Robust standard errors between parentheses. Number of observations in the regression sample in square brackets. $*$ significant at $10 \%, * *$ significant at $5 \%, * * *$ significant at $1 \%$. The entire sample consists of 1,595 observations ( 883 females, 712 males), but some regressions may have smaller samples because of item non-response. The sample size rows 10-12 is 1,242 rather than 1,595 because we excluded 353 observations that were already claiming benefits in 2008 or were younger than 60 in 2010 . These observations were excluded because the information treatment could not have possibly affected their claim status in 2010 . Treatment effects are estimated by regressions that control for age and age squared as well as demographics measured at the time of the baseline survey. See the note to Table 2 for a description of these demographic control variables. The baseline specification is an OLS regression. The Probit specification reports marginal effects. See appendix $C$ for the exact wording of the questions that define the outcome variables: Q1.13, Q1.16, Q1.17, and Q1.2, respectively. Column 7 reports the p-value on the test of the hypothesis that treatn 


\begin{tabular}{|c|c|c|c|c|c|c|c|}
\hline \multirow[b]{2}{*}{ Dependent Variable } & (1) & (2) & (3) & (4) & (5) & (6) & (7) \\
\hline & $\begin{array}{c}\text { Entire S } \\
\text { Control } \\
\text { Mean } \\
\text { [N of reg.] }\end{array}$ & $\begin{array}{c}\text { Sample } \\
\text { Treatment } \\
\text { Effect } \\
\text { (S.E.) }\end{array}$ & $\begin{array}{c}\text { Female Res } \\
\text { Control } \\
\text { Mean } \\
\text { [N of reg.] }\end{array}$ & $\begin{array}{c}\text { spondents } \\
\text { Treatment } \\
\text { Effect } \\
\text { (S.E.) }\end{array}$ & $\begin{array}{c}\text { Male Resp } \\
\text { Control } \\
\text { Mean } \\
\text { [N of reg.] }\end{array}$ & $\begin{array}{c}\text { pondents } \\
\text { Treatment } \\
\text { Effect } \\
\text { (S.E.) }\end{array}$ & $\begin{array}{l}\text { P-value on } \\
\text { t-test of } \\
\text { difference }\end{array}$ \\
\hline \multicolumn{8}{|l|}{ Panel A: Knowledge about longevity } \\
\hline $\begin{array}{l}\text { 1. Subjective probability that a typical } 65 \text { y.o. } \\
\text { [man/women] lives to age } 90 \text { or beyond }\end{array}$ & $\begin{array}{c}0.583 \\
{[1,546]}\end{array}$ & $\begin{array}{c}0.008 \\
(0.011)\end{array}$ & $\begin{array}{l}0.654 \\
{[849]}\end{array}$ & $\begin{array}{c}0.002 \\
(0.014)\end{array}$ & $\begin{array}{l}0.496 \\
{[697]}\end{array}$ & $\begin{array}{c}0.015 \\
(0.017)\end{array}$ & 0.539 \\
\hline $\begin{array}{l}\text { 2. Subjective probability that at least one member of a } \\
\text { typical } 65 \text { y.o. couple lives to age } 90 \text { or beyond }\end{array}$ & $\begin{array}{c}0.650 \\
{[1,544]}\end{array}$ & $\begin{array}{c}0.013 \\
(0.011)\end{array}$ & $\begin{array}{l}0.680 \\
{[843]}\end{array}$ & $\begin{array}{c}0.009 \\
(0.014)\end{array}$ & $\begin{array}{l}0.613 \\
{[701]}\end{array}$ & $\begin{array}{l}0.020 \\
(0.017)\end{array}$ & 0.605 \\
\hline \multicolumn{8}{|c|}{ Panel B: Knowledge about incentives for working more years } \\
\hline $\begin{array}{l}\text { 3. SS increases with years worked ( } R \text { believes that SS } \\
\text { would be lower if R had worked fewer years) }\end{array}$ & $\begin{array}{c}0.678 \\
{[1,550]}\end{array}$ & $\begin{array}{c}0.005 \\
(0.024)\end{array}$ & $\begin{array}{l}0.699 \\
{[857]}\end{array}$ & $\begin{array}{c}0.001 \\
(0.032)\end{array}$ & $\begin{array}{l}0.653 \\
{[693]}\end{array}$ & $\begin{array}{c}0.012 \\
(0.036)\end{array}$ & 0.822 \\
\hline 4. Percent increase in SS per additional year worked & $\begin{array}{l}0.052 \\
{[1,531]}\end{array}$ & $\begin{array}{l}-0.001 \\
(0.003)\end{array}$ & $\begin{array}{l}0.056 \\
{[842]}\end{array}$ & $\begin{array}{c}-0.001 \\
(0.005)\end{array}$ & $\begin{array}{l}0.046 \\
{[689]}\end{array}$ & $\begin{array}{c}0.000 \\
(0.005)\end{array}$ & 0.931 \\
\hline 5. SS a better deal if working more years & $\begin{array}{c}0.363 \\
{[1,536]}\end{array}$ & $\begin{array}{c}0.043^{*} \\
(0.025)\end{array}$ & $\begin{array}{l}0.346 \\
{[848]}\end{array}$ & $\begin{array}{l}0.079 * * \\
(0.034)\end{array}$ & $\begin{array}{l}0.385 \\
{[688]}\end{array}$ & $\begin{array}{c}0.009 \\
(0.038)\end{array}$ & 0.167 \\
\hline $\begin{array}{l}\text { 6. Aware that SS benefits are based on some number of } \\
\text { years with the highest earnings }\end{array}$ & $\begin{array}{c}0.364 \\
{[1,528]}\end{array}$ & $\begin{array}{l}0.055^{* *} \\
(0.025)\end{array}$ & $\begin{array}{l}0.378 \\
{[842]}\end{array}$ & $\begin{array}{l}0.074 * * \\
(0.034)\end{array}$ & $\begin{array}{l}0.347 \\
{[686]}\end{array}$ & $\begin{array}{c}0.037 \\
(0.037)\end{array}$ & 0.458 \\
\hline \multicolumn{8}{|c|}{ Panel C: Knowledge about incentives for claiming later } \\
\hline 7. SS increases with own claim age & $\begin{array}{c}0.677 \\
{[1,559]}\end{array}$ & $\begin{array}{l}0.017 \\
(0.023)\end{array}$ & $\begin{array}{l}0.622 \\
{[866]}\end{array}$ & $\begin{array}{r}0.061 * \\
(0.032)\end{array}$ & $\begin{array}{l}0.744 \\
{[693]}\end{array}$ & $\begin{array}{l}-0.038 \\
(0.034)\end{array}$ & $0.035^{* *}$ \\
\hline $\begin{array}{l}\text { 8. SS increases for a typical worker for delaying } \\
\text { claiming between ages } 62 \text { and } 66\end{array}$ & $\begin{array}{l}0.906 \\
{[1,572]}\end{array}$ & $\begin{array}{c}0.012 \\
(0.014)\end{array}$ & $\begin{array}{l}0.888 \\
{[873]}\end{array}$ & $\begin{array}{c}0.020 \\
(0.021)\end{array}$ & $\begin{array}{l}0.928 \\
{[699]}\end{array}$ & $\begin{array}{c}0.004 \\
(0.020)\end{array}$ & 0.566 \\
\hline $\begin{array}{l}\text { 9. SS increases for a typical worker for delaying } \\
\text { claiming between ages } 66 \text { and } 70\end{array}$ & $\begin{array}{l}0.803 \\
{[1,572]}\end{array}$ & $\begin{array}{l}0.023 \\
(0.019)\end{array}$ & $\begin{array}{l}0.788 \\
{[873]}\end{array}$ & $\begin{array}{l}-0.005 \\
(0.028)\end{array}$ & $\begin{array}{l}0.823 \\
{[699]}\end{array}$ & $\begin{array}{l}0.056 * * \\
(0.026)\end{array}$ & 0.112 \\
\hline $\begin{array}{l}\text { 10. SS remains the same for a typical worker for delaying } \\
\text { claiming between ages } 70 \text { and } 74\end{array}$ & $\begin{array}{c}0.367 \\
{[1,572]}\end{array}$ & $\begin{array}{l}-0.013 \\
(0.024)\end{array}$ & $\begin{array}{l}0.360 \\
{[873]}\end{array}$ & $\begin{array}{l}-0.012 \\
(0.033)\end{array}$ & $\begin{array}{l}0.375 \\
{[699]}\end{array}$ & $\begin{array}{l}-0.012 \\
(0.037)\end{array}$ & 0.999 \\
\hline $\begin{array}{l}\text { 11. Percent increase in SS per year of delay in claiming } \\
\text { between ages } 62 \text { and } 66 \text { for a typical worker }\end{array}$ & $\begin{array}{c}0.071 \\
{[1,572]}\end{array}$ & $\begin{array}{l}-0.001 \\
(0.003)\end{array}$ & $\begin{array}{l}0.072 \\
{[873]}\end{array}$ & $\begin{array}{c}0.001 \\
(0.005)\end{array}$ & $\begin{array}{l}0.071 \\
{[699]}\end{array}$ & $\begin{array}{l}-0.003 \\
(0.004)\end{array}$ & 0.568 \\
\hline $\begin{array}{l}\text { 12. Percent increase in SS per year of delay in claiming } \\
\text { between ages } 66 \text { and } 70 \text { for a typical worker }\end{array}$ & $\begin{array}{c}0.031 \\
{[1,572]}\end{array}$ & $\begin{array}{c}0.008^{*} \\
(0.005)\end{array}$ & $\begin{array}{l}0.031 \\
{[873]}\end{array}$ & $\begin{array}{c}0.001 \\
(0.007)\end{array}$ & $\begin{array}{l}0.031 \\
{[699]}\end{array}$ & $\begin{array}{l}0.017 * * * \\
(0.006)\end{array}$ & $0.079 *$ \\
\hline $\begin{array}{l}\text { 13. Percent increase in SS per year of delay in claiming } \\
\text { between ages } 70 \text { and } 74 \text { for a typical worker }\end{array}$ & $\begin{array}{c}0.034 \\
{[1,572]}\end{array}$ & $\begin{array}{c}0.002 \\
(0.003)\end{array}$ & $\begin{array}{l}0.033 \\
{[873]}\end{array}$ & $\begin{array}{c}0.000 \\
(0.004)\end{array}$ & $\begin{array}{l}0.034 \\
{[699]}\end{array}$ & $\begin{array}{c}0.004 \\
(0.004)\end{array}$ & 0.487 \\
\hline \multicolumn{8}{|l|}{ Panel D: Knowledge about the earnings test } \\
\hline $\begin{array}{l}\text { 14. Aware of earnings test ( } R \text { believes benefits would be } \\
\text { reduced at age } 62 \text { if earning above some threshold } \\
\text { after claiming SS) }\end{array}$ & $\begin{array}{c}0.631 \\
{[1,547]}\end{array}$ & $\begin{array}{c}0.005 \\
(0.025)\end{array}$ & $\begin{array}{l}0.607 \\
{[856]}\end{array}$ & $\begin{array}{c}0.026 \\
(0.034)\end{array}$ & $\begin{array}{l}0.662 \\
{[691]}\end{array}$ & $\begin{array}{l}-0.019 \\
(0.037)\end{array}$ & 0.362 \\
\hline $\begin{array}{l}\text { 15. Aware that a reduction in SS from earnings test leads } \\
\text { to higher benefits later (only asked if aware of } \\
\text { earnings test) }\end{array}$ & $\begin{array}{l}0.392 \\
{[956]}\end{array}$ & $\begin{array}{c}0.059 * \\
(0.032)\end{array}$ & $\begin{array}{l}0.392 \\
{[514]}\end{array}$ & $\begin{array}{c}0.068 \\
(0.044)\end{array}$ & $\begin{array}{l}0.392 \\
{[442]}\end{array}$ & $\begin{array}{c}0.043 \\
(0.047)\end{array}$ & 0.699 \\
\hline
\end{tabular}

Notes: Robust standard errors between parentheses. Number of observations in the regression sample in square brackets. * significant at $10 \%, * *$ significant at $5 \%, * * *$ significant at $1 \%$. The entire sample consists of 1,595 observations ( 883 females, 712 males), but some regressions may have smaller samples because of item non-response. Rows 5 and 15 have smaller samples because the question was only asked to the relevant subsample of respondents. Treatment effects are estimated by an OLS regression with controls for age and age squared as well as demographics measured at the time of the baseline survey. See the note to Table 2 for a description of these demographic control variables. See appendix $C$ for the exact wording of the questions that define the outcome variables. Panel A: Q8.3 and Q8.4, respectively. Panel B: Q3.1, Q3.2, Q3.3 combined with Q3.1, and Q5.1, respectively. Panel C: Q4.1 for row 7, and Q4.2 for rows 8-13. Panel D: Q4.3 and Q4.4 for row 14, and Q4.5 for row 15. Percentage increases in Social Security per year of delay in claiming benefits are measured as a percentage of benefits at age 66 . Column 7 reports the p-value on the test of the hypothesis that treatment effects are equal for females and males. 
(2)

\begin{tabular}{cc}
\multicolumn{2}{c}{ Entire Sample } \\
\hline Control & Treatment \\
Mean & Effect
\end{tabular}

Dependent Variable

1. $R$ does not currently work (with at least $\$ 2500$ in annual earnings) and does not plan to work in the future (with at least $\$ 2500$ in annual earnings)

2. R's point estimate of the expected or realized retirement age (in years)

3. The mean of R's pdf of expected or realized retirement age (in years)

4. The standard deviation of R's pdf of expected or realized retirement age (in years)

0.193

$[1,592]$

$-0.005$

-0.005
$(0.020)$

67.4

$[1,576]$

0.12

67.5

$(0.27)$

$[1,535]$

0.07
$(0.27)$

0.75

0.03

$[1,535]$

$(0.03)$

0.685

0.008

. R reports being likely or very likely to work for pay at

least part-time after starting to collect Social Security

$[1,587]$

$(0.023)$

65.5

0.07

claim age (if not claiming in 2008)

$[1,307]$

(0.13)

7. The mean of R's pdf of the expected or realized SS claim age (if not claiming in 2008)

8. The S.D. of R's pdf of the expected or realized SS claim age (if not claiming in 2008)

$$
65.5
$$

0.08

0.58

(0.11)

$[1,203]$

$(0.03)$

(3) (4)

Female Respondents

Control Treatment

Mean Effect

[N of reg.] (S.E.)

0.228

$-0.017$

(0.028) [712]

[883]

(5)

(6)

(7)

Male Respondents

Control Treatment

P-value on

$\begin{array}{ll}0.150 & 0.007\end{array}$

difference

$\begin{array}{cc}67.0 & 0.25 \\ {[870]} & (0.34) \\ 67.1 & 0.17 \\ {[849]} & (0.33) \\ 0.69 & 0.07 \\ {[849]} & (0.04)\end{array}$

67.9

(0.027)

0.537

$0.679 \quad 0.018$

$(0.032)$

[706]

$-0.16$

(0.44)

67.9

$-0.15$

[686]

(0.42)

$0.82-0.02$

[686] (0.05)

0.133

[878]

0.692

[709]

$-0.006$

(0.035)

$\begin{array}{llll}65.6 & -0.15 & 65.4 & 0.33^{*}\end{array}$

[698]

(0.20)

[609]

(0.18)

$\begin{array}{llll}65.5 & -0.11 & 65.5 & 0.34 * *\end{array}$

$\begin{array}{llll}647 & (0.15) & 65.5 & 0.34 * *\end{array}$

$\begin{array}{llll}0.53 & 0.04 & 0.63 & -0.01\end{array}$

[647] (0.04)

[556]

(0.04)

0.461

0.558

0.605

0.069*

$0.037 * *$

0.371

Notes: Robust standard errors between parentheses. Number of observations in the regression sample in square brackets. * significant at $10 \%, * *$ significant at $5 \%, * * *$ significant at $1 \%$. The entire sample consists of 1,595 observations ( 883 females, 712 males), but some regressions may have smaller samples because of item non-response. Rows $6-8$ have smaller samples because the question was only asked to the relevant subsample of respondents. Treatment effects are estimated by an OLS regression with controls for age and age squared as well as demographics measured at the time of the baseline survey. See the note to Table 2 for a description of these demographic control variables. Retirement age is defined as the age at which R stops working for pay (with at least $\$ 2500$ in annual earnings) and has no plans to work in the future (with at least $\$ 2500$ ) in annual earnings. See appendix $C$ for the exact wording of the questions that define the outcome variables: Q1.9 and Q1.10. for row 1, Q1.11 for row 2, Q1.34 for rows 3 and 4, Q7.1 for row 5 , Q1.8 for row 6, and Q1.33 for rows 7 and 8 . Column 7 reports the p-value on the test of the hypothesis that treatment effects are equal for females and males. 


\begin{tabular}{|c|c|c|c|c|c|}
\hline & \multirow{2}{*}{$\begin{array}{c}2008 \text { Current } \\
\text { Population Survey: } \\
\text { workers age } 60-65 \\
\text { Mean }\end{array}$} & \multicolumn{2}{|c|}{$\begin{array}{l}\text { Experimental group } \\
\text { (treatment and control) }\end{array}$} & \multicolumn{2}{|c|}{$\begin{array}{l}\text { Respondents to } \\
\text { follow-up survey }\end{array}$} \\
\hline & & Mean & $\begin{array}{l}\text { Difference } \\
\text { with CPS }\end{array}$ & Mean & $\begin{array}{l}\text { Difference with } \\
\text { exp. group }\end{array}$ \\
\hline Age in 2008 & 61.99 & 61.71 & $-0.285 * * *$ & 61.78 & 0.073 \\
\hline Female & 0.470 & 0.555 & $0.085 * * *$ & 0.554 & -0.001 \\
\hline Non-Hispanic white & 0.805 & 0.851 & $0.047 * * *$ & 0.889 & $0.038 * * *$ \\
\hline Non-Hispanic black & 0.077 & 0.059 & $-0.019 * * *$ & 0.046 & $-0.013^{*}$ \\
\hline Other race/ethnicity & 0.118 & 0.090 & $-0.028 * * *$ & 0.065 & $-0.025 * * *$ \\
\hline High school dropout & 0.075 & 0.025 & $-0.050 * * *$ & 0.014 & $-0.010 * *$ \\
\hline High school & 0.283 & 0.169 & $-0.114 * * *$ & 0.146 & $-0.023 * *$ \\
\hline Some college & 0.274 & 0.337 & $0.063 * * *$ & 0.326 & -0.011 \\
\hline Bachelor's degree or more & 0.368 & 0.469 & $0.101 * * *$ & 0.513 & $0.045^{* * *}$ \\
\hline Married & 0.709 & 0.642 & $-0.066 * * *$ & 0.653 & 0.010 \\
\hline Widowed & 0.059 & 0.058 & -0.001 & 0.050 & -0.008 \\
\hline Divorced & 0.161 & 0.197 & $0.036 * * *$ & 0.195 & -0.002 \\
\hline Separated & 0.018 & 0.011 & $-0.007 * *$ & 0.009 & -0.002 \\
\hline Never married & 0.054 & 0.056 & 0.003 & 0.060 & 0.003 \\
\hline Living with a partner &.. & 0.035 & & 0.034 & -0.002 \\
\hline Lives in the Northeast & 0.185 & 0.188 & 0.003 & 0.183 & -0.005 \\
\hline Lives in the Midwest & 0.226 & 0.259 & $0.033^{* * *}$ & 0.255 & -0.004 \\
\hline Lives in the South & 0.368 & 0.298 & $-0.070 * * *$ & 0.299 & 0.001 \\
\hline Lives in the West & 0.221 & 0.255 & $0.034 * * *$ & 0.263 & 0.008 \\
\hline Household size of one & 0.190 & 0.286 & $0.096 * * *$ & 0.292 & 0.006 \\
\hline Household size of two & 0.575 & 0.522 & $-0.053 * * *$ & 0.523 & 0.001 \\
\hline Household size of three or more & 0.236 & 0.193 & $-0.043 * * *$ & 0.186 & -0.007 \\
\hline Household income: less than $25 \mathrm{k}$ & 0.084 & 0.077 & -0.007 & 0.069 & -0.008 \\
\hline Household income: 25k-50k & 0.199 & 0.229 & $0.030 * * *$ & 0.206 & $-0.023 *$ \\
\hline Household income: 50k-75k & 0.209 & 0.236 & $0.027 * * *$ & 0.238 & 0.002 \\
\hline Household income: 75k-100k & 0.166 & 0.191 & $0.025 * * *$ & 0.203 & 0.011 \\
\hline Household income: $100 \mathrm{k}$ or more & 0.342 & 0.267 & $-0.075 * * *$ & 0.285 & 0.017 \\
\hline Number of observations & 5279 & & & & 1595 \\
\hline
\end{tabular}

Notes: * significant at $10 \%, * *$ significant at $5 \%, * * *$ significant at $1 \%$. The 2008 Current Population Survey sample has the same sample restrictions as our experimental sample: age 60 to 65 and working. CPS results are weighted by person weights. The experimental sample consists of the Knowledge Network panelists that were eligible for our information intervention. To be eligible, the respondent had to be working and we heavily oversampled respondents between the ages of 60 and 65 as of the date of the baseline survey (November 2008 ). The respondents to the follow-up survey are those members from the experimental group that were still part of the Knowledge Networks panel as of April 2010 and responded to our follow-up survey. The demographic characteristics are the values in the standard demographic profile variables at the time of the baseline survey (November 2008). The standard demographic profile is collected by Knowledge Networks. 


\title{
Appendix Table 2: Balance of Treatment and Control Group
}

\author{
Panel A: J oint Significance of Baseline Demographics in Predicting Treatment Status \\ F-statistic $(28,1566)$ on joint significance: 0.80 \\ P-value of the F-statistic: \\ 0.759
}

Panel B: Significance of Pairwise Differences in Baseline Demographics

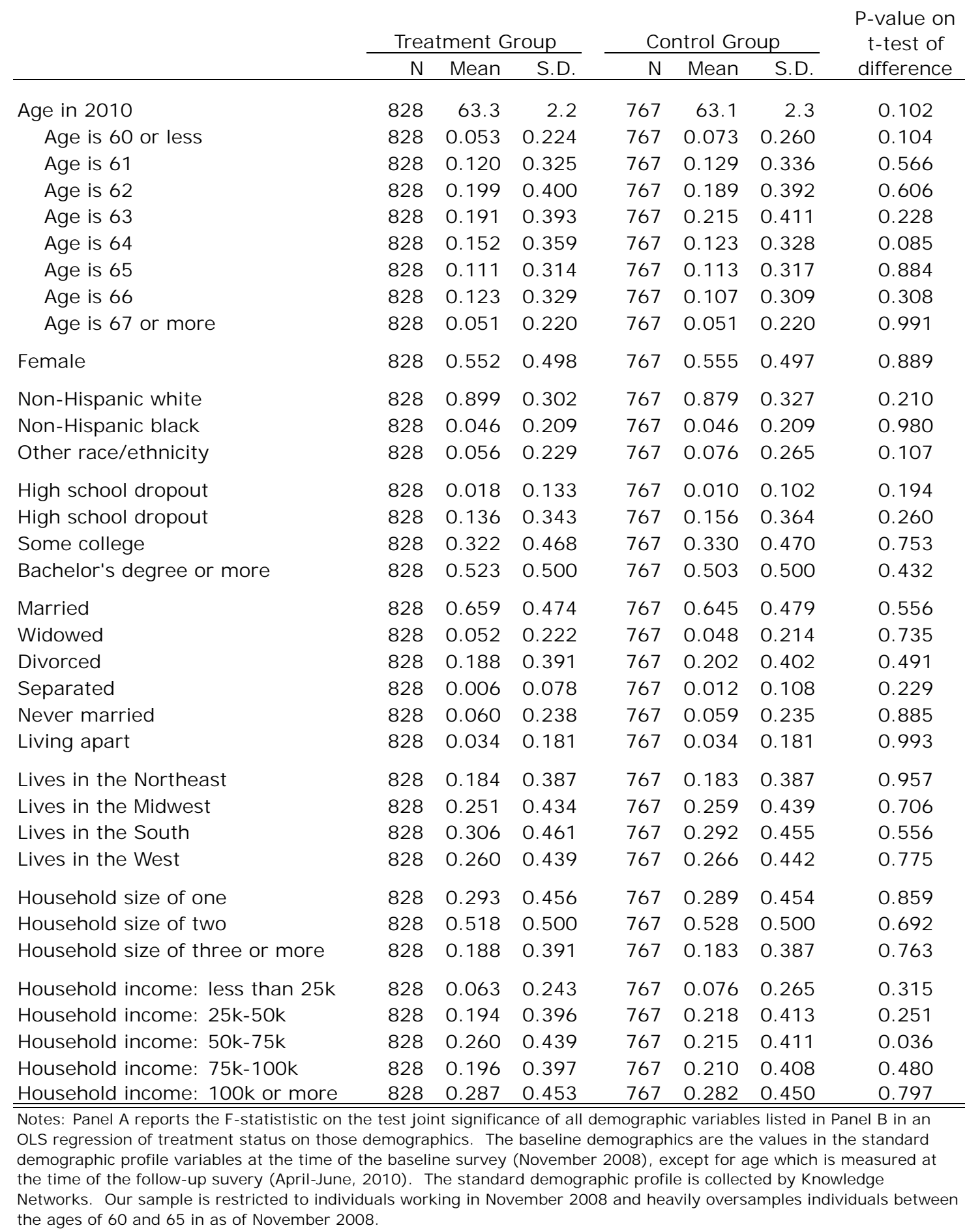




\section{Appendix Figure A1 Analysis Sample Flow Chart}

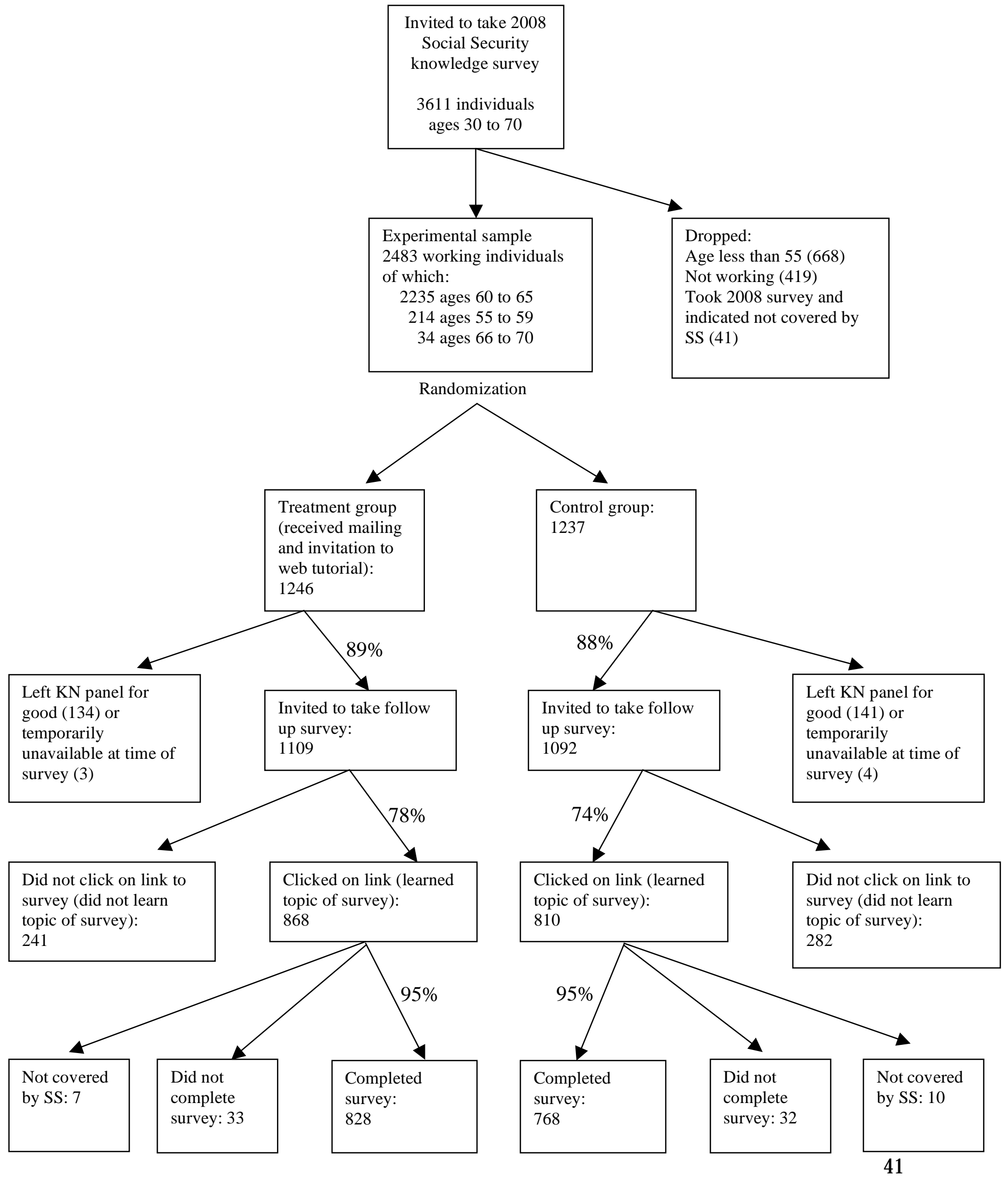




\section{FOR ONLINE PUBLICATION}

APPENDIX A - BROCHURE MAILED TO TREATMENT GROUP

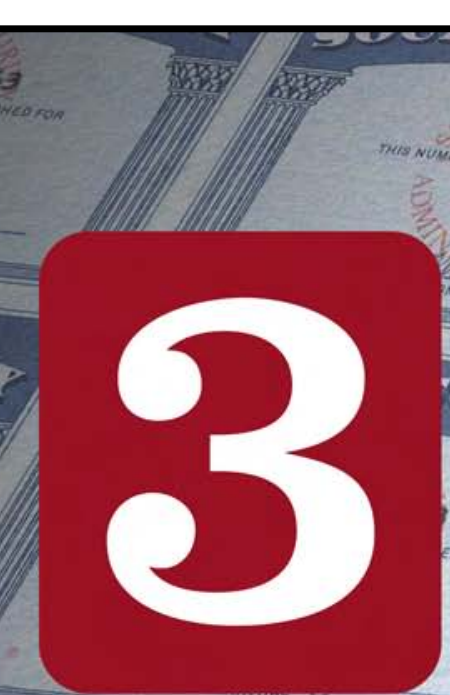

SOCLUV SLE
$63078-463$

$630-18 \pi 443$

Worex?

SOCUNGS:

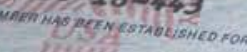
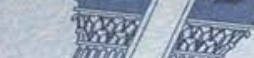

(1) 52

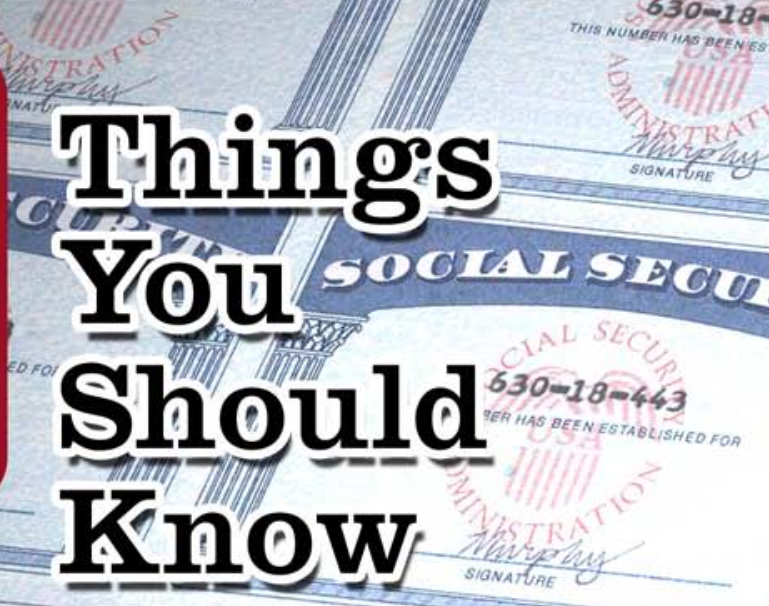

Should

Know

Albout

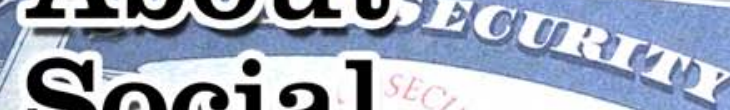

Social

Solal

Security

-

SECQR:

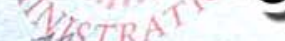

SIONATUAE

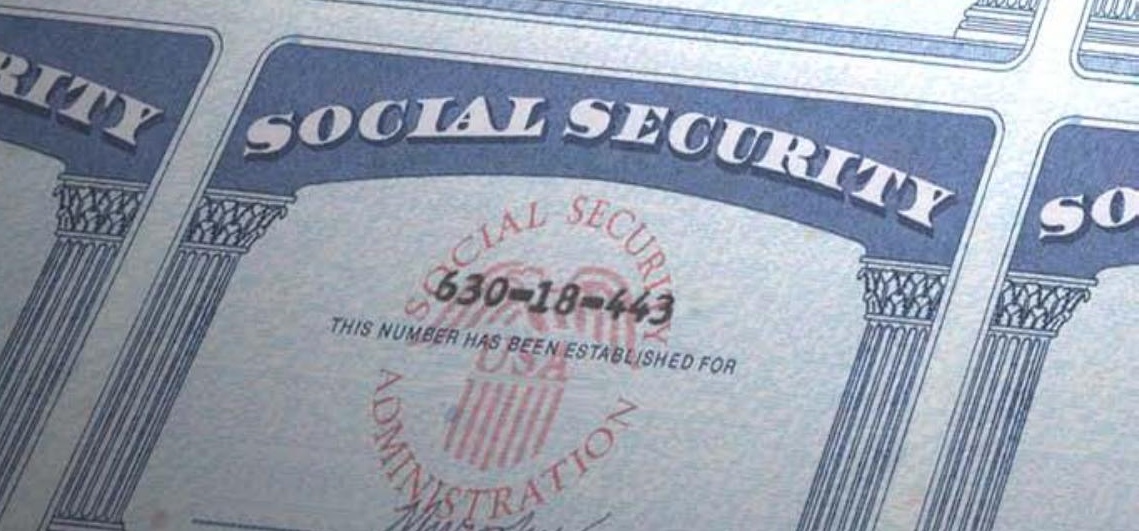




\section{You may live longer than you think.}

You might have already started saving money for retirement, but have you thought about how many years you'll need to cover?

- According to the National Center for Health Statistics, out of all 65-year-olds in America today, about one in four will live to age 90.

- For the average 65-year-old couple living in America today, there is a $47 \%$ chance that at least one spouse will live to age 90.

With many people living into their 90s, savings often need to last for a long time after retirement. As you're approaching retirement, you'll need to make some important decisions. Proper planning can mean the difference between living comfortably and just covering your basic needs. There are a few simple things you can do to make sure you're prepared for your retirement, and we'll talk about some of them in this brochure.

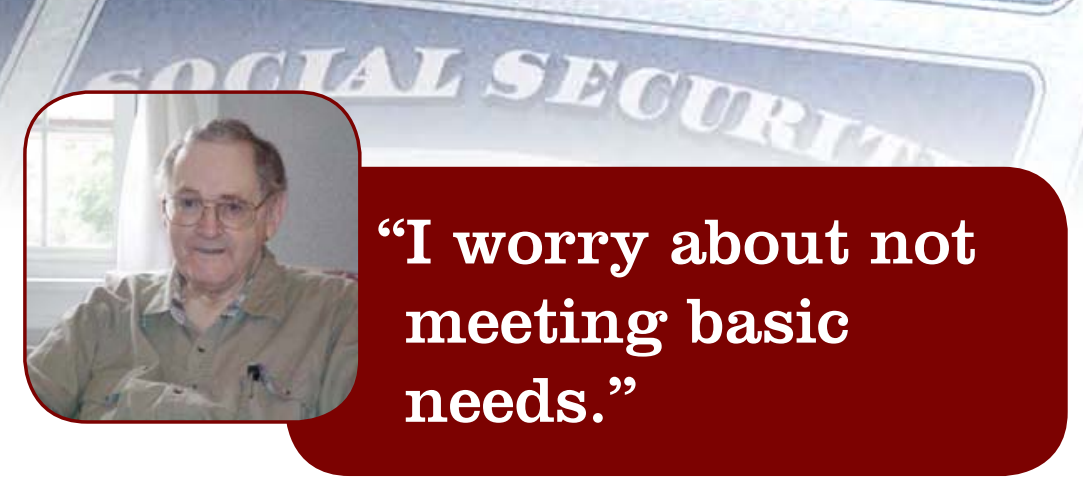

Consider the following story about Mr. Reichson, who regrets retiring when he did. Mr. Reichson worked as a software engineer and retired at age 57. He didn't save for retirement and is feeling constrained by his current financial situation. In his own words, "I worry about not meeting basic needsclothing, grooming accessories.. It's too much money to go on outings or things like that.. I can't afford it." If he could do it all over again, he would retire "as late as possible...To keep getting an income by working-it's a much larger income than Social Security benefits."

Mr. Reichson is right. If he had worked longer, he would have had more money to enjoy his retirement. But he may not have realized that a longer work history usually also translates into higher Social Security benefits, as we'll see in the next section. 


\section{(2) Postponing your retirement typically means more money for a more comfortable retirement.}

Many people decide to retire early without carefully considering the pros and cons of their retirement age. Here are three reasons why it can benefit you to wait a few extra years before retiring:

- Working longer will help you put away more money for retirement. If you work a few more years, you'll not only add to your existing savings, but you'll avoid spending the money you've already saved in the meantime.

- Social Security benefits generally go up the longer you wait to claim them, up until age 70. For each year you postpone claiming, your retired worker benefits increase by about $9.5 \%$ of the amount you'd get at age 62. For instance, a worker who would get $\$ 1000$ in monthly retired worker benefits if he claimed at age 62 could expect about $\$ 1330$ in benefits claiming at age 66, while postponing claiming until age 70 would translate into about $\$ 1760$ in monthly benefits (see graph on next page).

- In addition to the increase from delayed claiming, working a few more years generally raises your Social Security benefits because most people's benefits depend on their work history.

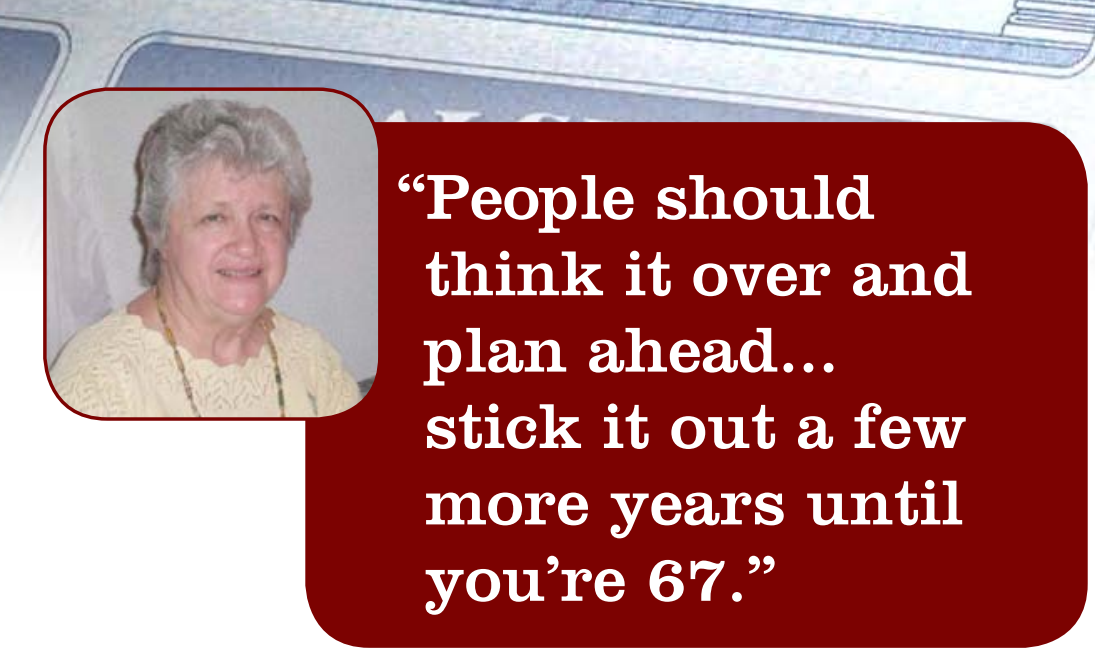

The following is a story about J ean, who wishes she had prepared more for retirement. J ean worked as a housekeeper for 12 years, but she didn't plan for her retirement. According to J ean, "I never watched my finances that well...I should have done it differently, worked." She urges people nearing retirement to wait until their full retirement age before retiring: "People should think it over and plan ahead.. stick it out a few more years until you're 67."

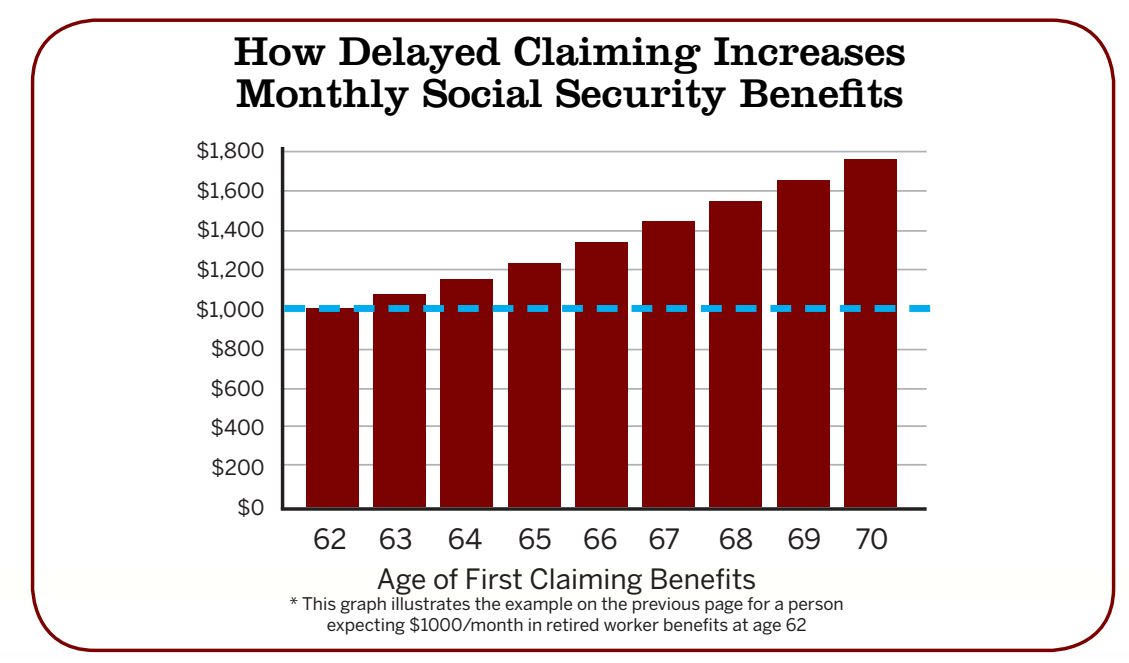


It pays to work,

3 even while you're receiving Social Security benefits.

Some people who claim benefits at age 62 stop working between ages 62 and 66 because they fear they will lose their benefits. In truth, if your benefits are reduced from working, the money is not actually lost. Instead, the reduction is returned to you later in the form of increased benefits. This complicated provision is called the Earnings Test. Here's how it works:

- Working longer will help you put away more money for retirement. If you work a few more years, you'll not only add to your existing savings, you will also avoid spending the money you've already saved in the meantime.

- If you do claim before full retirement age, your monthly benefits will be reduced if you earn more than certain threshold per year; in 2009, that amount is $\$ 14,160$.

- Once you reach your full retirement age, your benefits are never reduced, no matter how much you earn.

- If your benefits were ever lowered from working, they are recalculated to a higher amount when you reach full retirement age-meaning that the total benefits you can expect to receive over your lifetime are not really cut, even if they might be temporarily reduced.

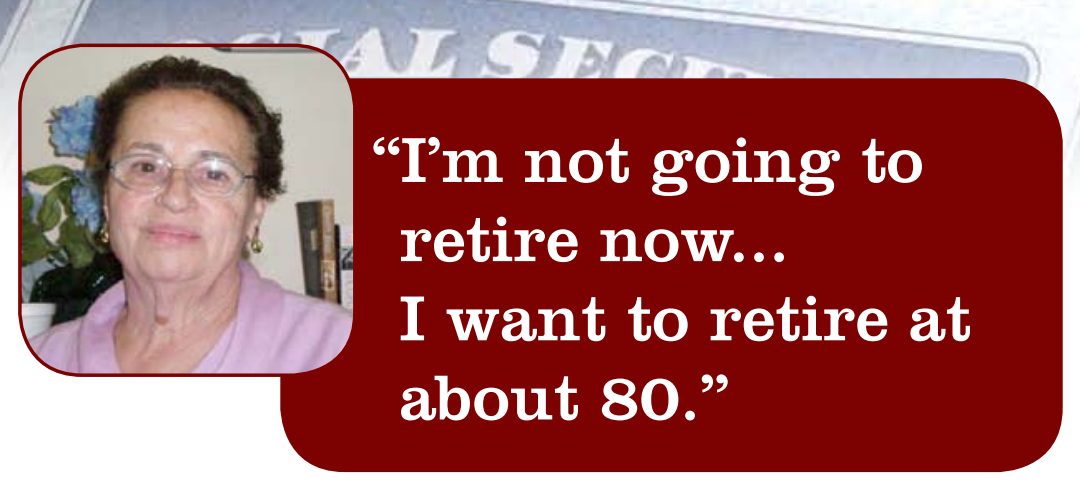

Giulia, 72, understands the advantage of working while receiving Social Security. Even though she first claimed benefits at age 62 , she still works nights in a restaurant kitchen for the added financial security.

Giulia worries about making rent payments and uses the extra income to support her grandchildren. She often talks to other seniors about the benefits of working. "That's why old people started to work again...in the senior center...85-year-olds and they are still working." Giulia does not regret her decision to work and plans to continue for a few more years: "I'm not going to retire now... I want to stay for another 6-7years; I want to retire at about 80."

For many seniors like Giulia who are already receiving Social Security benefits, the extra income from working can create a better financial situation. A few hours of work each week can help make ends meet, especially for those with little or no savings. 
This study is conducted by professors Liebman and Luttmer at Harvard's Kennedy School of Government. If you have any questions about this study, feel free to contact professor Luttmer at the address listed below: *

\section{Prof. Erzo Luttmer}

Associate Professor of Public Policy

J ohn F. Kennedy School of Government

Harvard University

79 J FK Street, Mailbox 25

Cambridge, MA 02138

erzo luttmer@harvard.edu

* Contacting the researchers directly would likely expose your identity to those conducting the study. For any questions related to your selection and participation in this panel, please call the Knowledge Networks panel relations group at 1-800-782-6899.
We have also listed a number of resources below in case you have further questions about Social Security.

\section{The U.S. Social Security Administration} http:// www.ssa.gov/

1-800-772-1213

The American Association of Retired Persons (AARP) http:/ / www.aarp.org/money/ social security/

1-888-OUR-AARP (1-888-687-2277)

USA.gov: Senior Citizens' Resources http:// www.usa.gov/ Topics/ Seniors.shtml 1-800-FED-INFO (1-800-333-4636) 

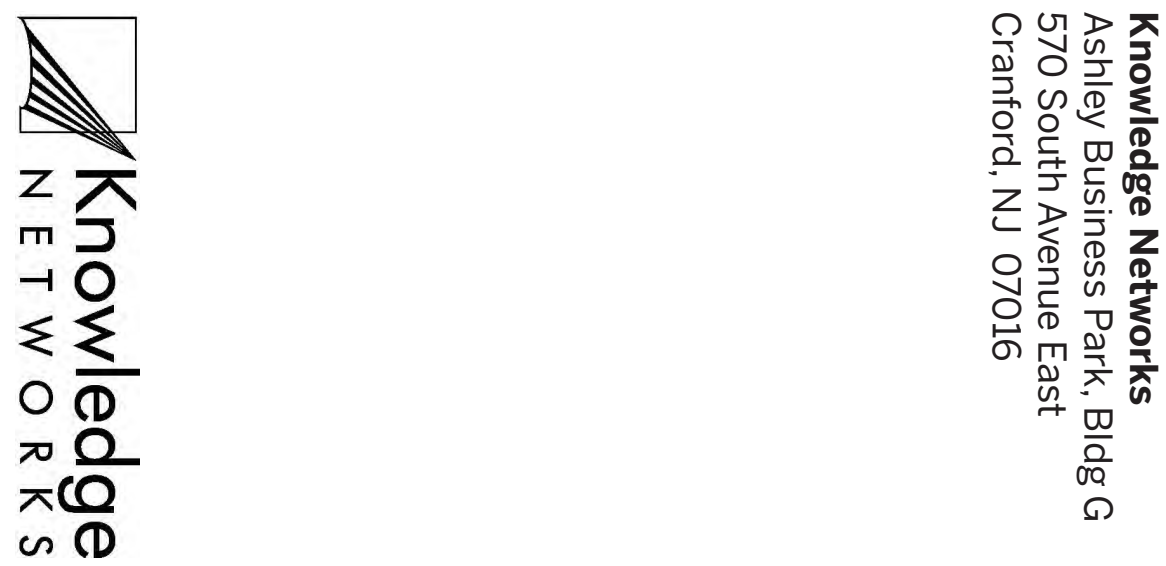


\section{APPENDIX B -WEB-TUTORIAL ON SOCIAL SECURITY}

\section{$\underline{\text { A note about the "syntax" of this questionnaire }}$}

Example questions:

Q1.2: [BROCH_REC] Whether or Not Respondent Received Brochure

Did you receive the informational brochure in the mail?

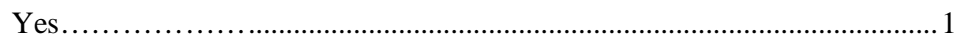

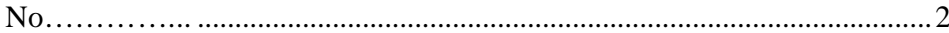

Q1.9: [Longevity Introduction] Background Information about Living Longer

When planning your retirement, it's important to budget for more years than you may realize because Americans are living longer than ever before.

[SHOW IF XGENDER==1 (MALE RESPONDENT)]

Out of all the 65-year-old men in America today, about one in five will live to the age of 90 or beyond, and about one in ten will live to the age of 95 or beyond.

[SHOW IF XGENDER==2 (FEMALE RESPONDENT)]

Out of all the 65-year-old women in America today, about one in three will live to the age of 90 or beyond, and about one in six will live to the age of 95 or beyond.

[SHOW IF XMARIT ==1 (i.e., married)]

You should also think about your [SPOUSE]'s financial situation when planning for retirement. For the average 65-year-old couple living in America today, there is a 47\% chance that at least one spouse will live to age 90 or beyond.

\section{Explanation:}

- Q1.2: [BROCH_REC] Whether or Not Respondent Received Brochure denotes (i) the question number, (ii) the variable name, and (iii) a description of the question. None of this appears on the screen for the respondents.

- $\quad$ Remarks between square brackets are just for the programmer.

- Variables are denoted in all capitals. E.g. XGENDER is a variable.

- Any programming remarks before the question name apply to the whole question. Variable names that should be replaced by the string they hold are indicated in all capitals between square brackets. E.g. [SPOUSE] is replaced by the string "husband" or "wife", which is the content of the variable SPOUSE.

- The solid lines indicate that a new screen should be shown.

- The numbers in parentheses in front of the selections boxes do not appear on the screen; they only indicate the value the variable will take if the relevant selection box is checked.

The following data-only variables are created for all respondents:

XGENDER denotes gender, 1: Male, 2: Female

CREATE A NEW DATA ONLY VARIABLE SPOUSE:

SET SPOUSE = "husband" IF XGENDER $==2$

SET SPOUSE = "wife" IF XGENDER==1

CREATE A NEW DATA ONLY VARIABLE ILL_HISHER:

SET ILL_HISHER = "his" IF XGENDER==1

SET ILL_HISHER = "her" IF XGENDER==2

CREATE A NEW DATA ONLY VARIABLE ILL_HESHE:

SET ILL_HESHE = "he" IF XGENDER==1

SET ILL_HESHE $=$ "she" IF XGENDER $==2$

CREATE A NEW DATA ONLY VARIABLE ILL_HIMHER:

SET ILL_HIMHER = "him" IF XGENDER==1

SET ILL_HIMHER = "her" IF XGENDER==2

CREATE A NEW DATA ONLY VARIABLE TOM_ANN: 


\section{Section 1: Longevity}

\section{Q1.1: [General Introduction] Introduction to the Online Module, No Specific SS Rules Yet}

We are researchers at Harvard University who are interested in understanding the amount of Social Security benefits that people receive or expect to receive. Recently, we invited you to take an online survey. Since several respondents told us that they would like additional information about Social Security rules, we sent an informational brochure to you.

This online module is designed to complement the brochure because it provides additional information and is tailored to your situation. Participation in this online module will help create clearer and easier-to-understand materials about the Social Security program.

\section{Q1.2: [BROCH_REC] Whether or Not Respondent Received Brochure}

Did you receive the informational brochure in the mail?

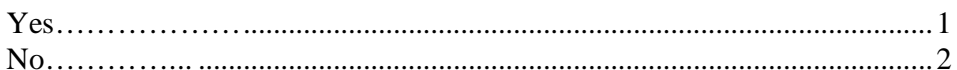

[Ask if BROCH_REC==1 AND XMARIT $\neq 1$ (i.e. not married)] Q1.3: [BROCH_READ1] Whether or Not Respondent Read Brochure

Did you read the brochure?

Yes, I read the brochure. 1

No, I did not read the brochure $\ldots \ldots \ldots \ldots \ldots \ldots \ldots \ldots \ldots \ldots \ldots \ldots \ldots \ldots \ldots \ldots \ldots \ldots \ldots \ldots . . .2$

\section{[Ask if BROCH_REC $==1$ AND XMARIT $==1$ (i.e., married)]} Q1.4: [BROCH_READ2] Whether or Not Respondent or Spouse Read Brochure

Did you or your [SPOUSE] read the brochure?

Yes, I read the brochure. 1

Yes, my [SPOUSE] read the brochure .......................................... 2

Yes, both my [SPOUSE] and I read the brochure........................ 3

No, neither of us read the brochure...................................................... 4

\section{Q1.5: Confirming Age of the Respondent}

In order for us to provide you with the most accurate information about Social Security, we need to know your date of birth. Knowledge Networks has your date of birth listed as [XBMONTH] [XBDAY], [XBYEAR].

Is this correct?

Please enter your date of birth.

Here is an example of how to enter in a date: if you were born on August 23, 1954, you would enter the number 8 for month, 23 for day, and 1954 for year. 
Type in the numbers to answer

MM _ D _ _ _ YYYY

[Create new variable BIRTHYEAR=XBYEAR.

If XBDAY==1 AND XBMONTH==1, SET BIRTHYEAR $=($ XBYEAR -1$)$. $]$

[SHOW IF XBMONTH==1 AND XBDAY ==1]

Q1.7: [JAN_BIRTH] Follow-Up for Respondents Born January 1

When calculating benefits, Social Security treats people born on January 1 as though they were born during the previous year. Since you were born on January 1st in [XBYEAR], your benefits are calculated as if you were born in [BIRTHYEAR]. Therefore, for the remainder of this survey, we will give you examples for a typical person born in [BIRTHYEAR].

[For all respondents: Drop the following variables: XBYEAR, XBMONTH, XBDAY]

Q.1.8: [WHOSE_RECORD] Type of Social Security benefits the person expects to claim

We also need to know the type of Social Security benefits you claim or expect to claim.

On whose earnings record do you think your benefits are based? They are based ...

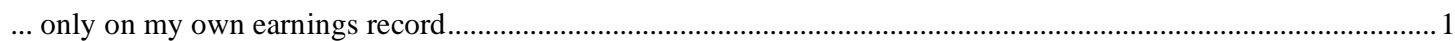

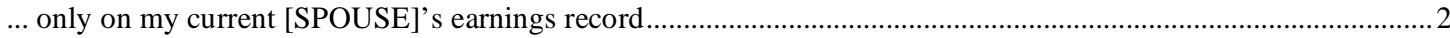

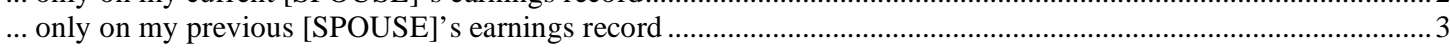

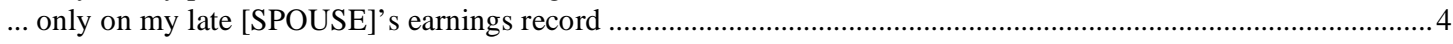

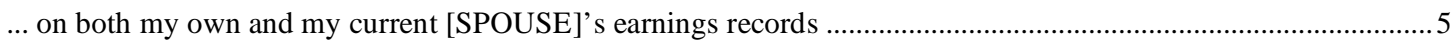

$\ldots$ on both my own and my previous [SPOUSE]'s earnings records ....................................................................

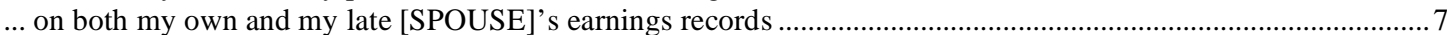

\section{Q1.9: [Longevity Introduction] Background Information about Living Longer}

When planning your retirement, it's important to budget for more years than you may realize because Americans are living longer than ever before.

[SHOW IF XGENDER==1 (MALE RESPONDENT)]

Out of all the 65-year-old men in America today, about one in five will live to the age of 90 or beyond, and about one in ten will live to the age of 95 or beyond.

\section{[SHOW IF XGENDER==2 (FEMALE RESPONDENT)]}

Out of all the 65-year-old women in America today, about one in three will live to the age of 90 or beyond, and about one in six will live to the age of 95 or beyond.

[SHOW IF XMARIT ==1 (i.e., married)]

You should also think about your [SPOUSE]'s financial situation when planning for retirement. For the average 65-year-old couple living in America today, there is a 47\% chance that at least one spouse will live to age 90 or beyond.

\section{Q1.10: [Longevity Story] Story about Living Longer}

Among those nearing retirement age, it's common to worry about future finances, and for good reason: retirees must grapple with the reality of paying for living expenses for years to come. However, with a bit of planning, retirees can live comfortably well beyond retirement age. The following is a story about 91-year-old Leon, who says, "I'm the other side of 91." 


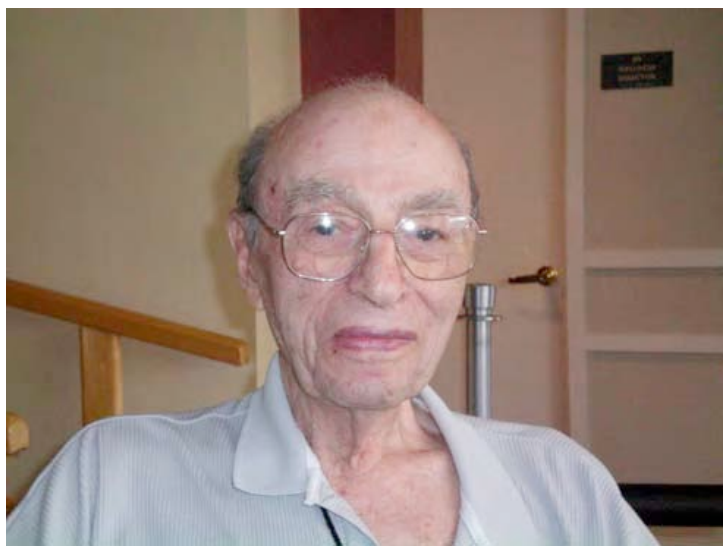

Leon worked as a chemistry teacher for 26 years before retiring at age 70 . Each year, he put aside the maximum amount out of his paycheck toward his pension. He also knew that waiting until age 70 to claim Social Security would increase his monthly benefits. Leon says that his current financial situation is "better than I've ever had. Between my pension and my Social Security...I don't worry about anything." According to Leon, people approaching retirement should continue to work as long as they're healthy.

\section{Q1.11: [LONG_PLAN] 'Plan B,” Being Stuck without Savings}

How would you cover your expenses if you live longer than anticipated, and your savings run low? Check all that apply.

[Show check boxes for each; allow multiple picks]

[Q.1.11_A] I'm not worried about running out of money because I have adequate savings

[Q.1.11_B] My pension benefits would be enough to cover living expenses

[Q.1.11_C] My Social Security benefits would suffice

[Q.1.11_D] I would eliminate my future travel plans

[Q.1.11_E] I would cut back on extra expenses, like movies and eating out

[Q.1.11_F] I would reduce my spending on food and clothing

[Q.1.11_G] I would move in with children/relatives

[Q.1.11_H] I would rely on public housing or government assistance

Q1.12: [LIV_EXP] How People Generally Cover Living Expenses when They Retire ("Plan A")

Would you consider any of the following to make sure that you have enough money to cover many years after your retirement? Check all that apply.

[Show check boxes for each; allow multiple buttons to be selected]

[Q1.12_A] Claiming Social Security benefits later so that my monthly benefits are higher

[Q1.12_B] Working more years to build my savings to a more comfortable level

[Q1.12_C] Delaying retirement so that my monthly Social Security benefits are higher

[LET Q1.12_A take on a value of 1 if not selected and a value of 2 if selected. Similarly for the other two radio buttons]

Q1.13: [Living Expenses Follow-Up] Follow-Up to Living Expenses Question ("Plan A")

[SHOW IF Q1.12_A==2 AND Q1.12_B==2 AND Q1.12_C==2 (Respondent would consider all possibilities)]

You just answered that you'd consider all three ways to ensure you have enough money for retirement:

- $\quad$ Claiming Social Security benefits later so that my monthly benefits are higher

- Working more years to build my savings to a more comfortable level

- $\quad$ Delaying retirement so that my monthly Social Security benefits are higher

We're going to take a look at each of these choices in more detail throughout this survey. During the process, we'll be giving you a lot of information, and you may learn something new that you didn't already know about Social Security.

[SHOW IF Q1.12_A==1 OR Q1.12_B==1 OR Q1.12_C==1 (Respondent would not consider all possibilities)]

You just answered that you would not consider all three ways to ensure you have enough money for retirement:

- Claiming Social Security benefits later so that my monthly benefits are higher 
- Working more years to build my savings to a more comfortable level

- Delaying retirement so that my monthly Social Security benefits are higher

We're going to take a look at each of these choices in more detail throughout this survey. During the process, we'll be giving you a lot of information, and you may learn something new that you didn't already know about Social Security.

Section 2: Higher Benefits from Claiming Later, Working Longer, and Saving More

[IF Q1.8==4 OR Q1.8==7, SKIP TO SECTION 3 (Respondent expects to claim widow/widower benefits; Only a couple percent are widows, so going through the trouble of explaining widow benefits, which are rather complicated, is not worth it)]

Q.2.1: [Claim Age Introduction] Benefits to waiting until full retirement age

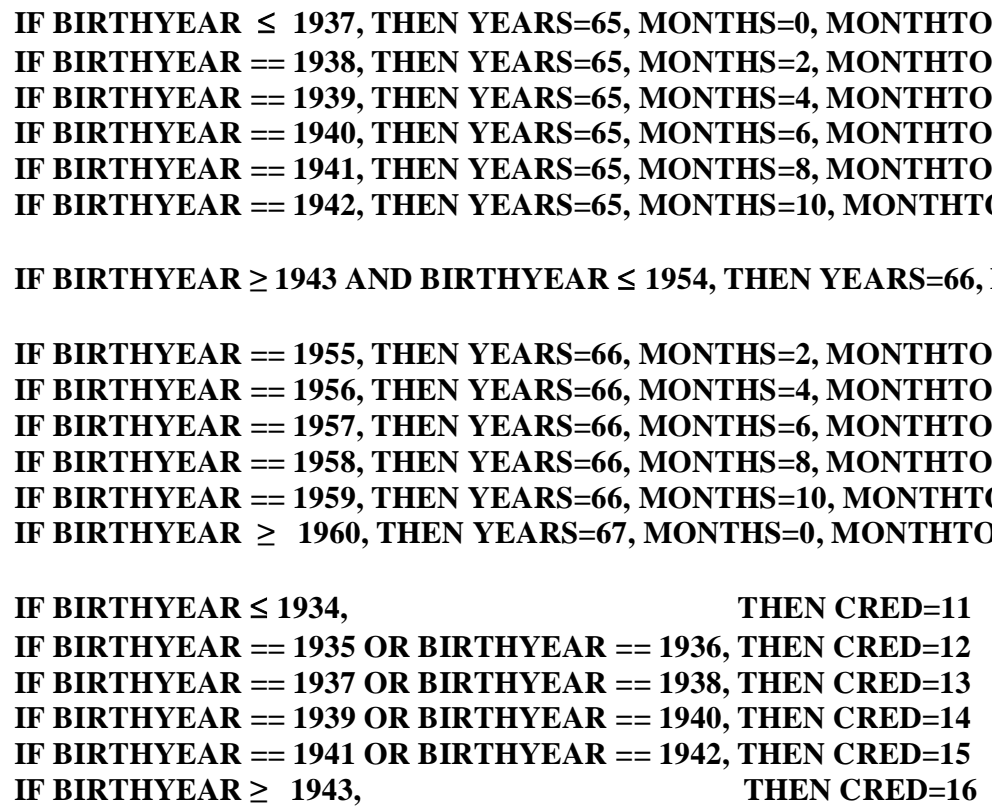

[RETIREMENT Benefits at age $\mathrm{XX}$ as a percentage of benefits at full-benefit age] BEN62 = $100-36 *(5 / 9)-($ MONTHTOT -36$) *(5 / 12)$

BEN64 = $100-($ MONTHTOT -24$) *(5 / 9)$

IF MONTHTOT $\geq 48$, THEN BEN66=100 - (MONTHTOT-48)*(5/9)

IF MONTHTOT< 48, THEN BEN66=100 + (48-MONTHTOT)*CRED/24

BEN68 $=100+($ 72-MONTHTOT $) *$ CRED/24

BEN70 $=100+(96-\text { MONTHTOT })^{*}$ CRED/24

[Percentage increase relative to benefit at age 62 for own RETIREMENT benefit]

PCT_FULL $=100 *(100$ / BEN62 - 1 $)$

PCT64 $=100 *($ BEN64 / BEN62 - 1 $)$

PCT66 $=100 *($ BEN66 $/$ BEN62 - 1 $)$

PCT68 $=100 *($ BEN68 $/$ BEN62 -1$)$

PCT70 $=100 *($ BEN70 $/$ BEN62 - 1 $)$

[SPOUSE Benefits at age $\mathrm{XX}$ as a percentage of benefits at full-benefit age]

SP_BEN62 $=100-36 *(25 / 36)-($ MONTHTOT-36 $) *(5 / 12)$

SP_BEN64 $=100$ - $($ MONTHTOT-24 $) *(25 / 36)$

IF MONTHTOT $\geq 48$, THEN SP_BEN66=100 - $($ MONTHTOT -48$) *(25 / 36)$ IF MONTHTOT $<48$, THEN SP_BEN66=100

[Percentage increase relative to benefit at age 62 for own SPOUSE benefit] SP_PCT_FULL $=100 *(100$ /SP_BEN62 - 1 $)$

SP_PCT64 $=100 *($ SP_BEN64 $/$ SP_BEN62 -1$)$

SP_PCT66 $=100 *\left(S_{-} \_\right.$BEN66 $/$SP_BEN62 -1$)$ 
[SHOW IF XAGE < 62 AND (Q1.8==1 OR Q1.8==Refused) (Respondent is younger than the earliest claim age, plans to claim on own earnings record)]

If you're like many people nearing retirement age, you've probably already thought about when you're going to start collecting Social Security benefits. You can start collecting retirement benefits as early as age 62 or as late as age 70 . Your Social Security benefits go up the longer you wait to claim them, up until age 70.

For a person born in [BIRTHYEAR], full retirement age is [YEARS] years, [MONTHS] months old. If you start claiming retirement benefits at your full retirement age, your benefits will be [PCT_FULL]\% higher than what you would receive if you started claiming at 62. Waiting until age 70 to claim retirement benefits would give you [PCT_70]\% higher benefits than what you would receive at age 62 .

[SHOW IF XAGE < 62 AND (Q1.8==2 OR Q1.8==3 OR Q1.8==5 OR Q1.8==6) (Respondent is younger than the earliest claim age, plans to claim on spouse's earnings record)]

If you're like many people nearing retirement age, you've probably already thought about when you're going to start collecting Social Security benefits. You answered before that you plan to claim at least part of your benefits based on the earnings history of your current or previous [SPOUSE]. You can start collecting Social Security spouse benefits as early as age 62. Your Social Security spouse benefits go up the longer you wait to claim them, up until full retirement age.

For a person born in [BIRTHYEAR], full retirement age is [YEARS] years, [MONTHS] months old. If you start claiming your spouse benefits at your full retirement age, your benefits will be [SP_PCT_FULL]\% higher than what you would receive if you started claiming at 62 .

[SHOW IF 62<= XAGE AND (Q1.8==1 OR Q1.8==Refused) (Respondent has reached earliest claim age, plans to claim based on own earnings record)]

If you're like many people age [XAGE], you might have already begun collecting Social Security benefits or considered when you're going to first claim benefits. People can start collecting retirement benefits as early as age 62 or as late as age 70 . Your Social Security benefits go up the longer you wait to claim them, up until age 70 .

For a person born in [BIRTHYEAR], full retirement age is [YEARS] years, [MONTHS] months old. If you start claiming retirement benefits at your full retirement age, your benefits will be [PCT_FULL]\% higher than what you would receive if you started claiming at 62. Waiting until age 70 to claim retirement benefits would give you [PCT_70]\% higher benefits than what you would receive at age 62 .

[SHOW IF 62<=XAGE AND (Q1.8==2 OR Q1.8==3 OR Q1.8==5 OR Q1.8==6) (Respondent has reached earliest claim age, plans to claim based on spouse's earnings record)]

If you're like many people age [XAGE], you might have already begun collecting Social Security benefits or considered when you're going to first claim benefits. You answered before that you plan to claim at least part of your benefits based on the earnings history of your current of previous [SPOUSE]. You can start collecting Social Security spouse benefits as early as age 62. Your Social Security spouse benefits go up the longer you wait to claim them, up until full retirement age.

For a person born in [BIRTHYEAR], full retirement age is [YEARS] years, [MONTHS] months old. If you start claiming your spouse benefits at your full retirement age, your benefits will be [SP_PCT_FULL]\% higher than what you would receive if you started claiming at 62 .

\section{[SHOW FOR ALL RESPONDENTS AT BOTTOM OF THE SCREEN IN SMALLER FONT]}

These numbers are taken from the actual figures used by the Social Security Administration. For more information about how benefits are calculated, please refer to the resources provided at the end of this survey.

[NUMBER BOX, RANGE: 0-3000]

Q.2.2: [BEN_EX] Example using hypothetical earnings

\section{[SHOW IF XAGE < 62]}

Let's see how claiming Social Security benefits at different ages affects how much you'd receive each month in benefits. To illustrate what this means for someone like you, type in your expected monthly benefit at age 62 .

[SHOW IF XAGE $\geq 62]$

Let's see how claiming Social Security benefits at different ages affects how much you'd receive each month in benefits. To illustrate what this means for someone like you, type in the benefit you received or might have received at age 62.

[SHOW IF XAGE < 62]

I expect to receive $\$ \_\_$in monthly benefits at age 62.

[SHOW IF XAGE $\geq 62]$ 
Q.2.3: [BEN_TAB] Example using hypothetical earnings, table

Again, your full retirement age is [YEARS] years, [MONTHS] months.

[SHOW IF (Q1.8==2 OR Q1.8==3 OR Q1.8==5 OR Q1.8==6) AND Q.2.2==NOT Refused]

Because you said your benefits are based in part on the earnings record of a current or previous [SPOUSE], the table below shows how Social Security spouse benefits vary with age of first claiming:

\begin{tabular}{|c|c|c|}
\hline If you first claim at age: & $\begin{array}{l}\text {...your monthly benefit level would } \\
\text { total: }\end{array}$ & $\begin{array}{l}\text { Percent increase relative to } \\
\text { claiming at age 62: }\end{array}$ \\
\hline 62 & $\$\left[\mathrm{BEN} \_\mathrm{EX}\right]$ & $0 \%$ \\
\hline 64 & $\$\left[B E N \_E X^{*}(1+\right.$ SP_PCT64/100)] & [SP_PCT64]\% \\
\hline 66 & $\$\left[B E N \_E X^{*}(1+\right.$ SP_PCT66/100)] & [SP_PCT66]\% \\
\hline 68 & $\$\left[B E N \_E X^{*}\left(1+S P \_P C T \_F U L L / 100\right)\right]$ & [SP_PCT_FULL]\% \\
\hline 70 & \$[BEN_EX*(1+SP_PCT_FULL/100)] & [SP_PCT_FULL]\% \\
\hline
\end{tabular}

(All amounts are in today's dollars)

[SHOW IF (Q1.8==1 OR IF Q1.8==Refused) AND Q.2.2==NOT Refused]

Because you said your benefits are based your own earnings record, the table below shows how Social Security retirement benefits vary with age of first claiming:

\begin{tabular}{|l|l|l|}
\hline If you first claim at age: & $\begin{array}{l}\text {...your monthly benefit level would } \\
\text { total: }\end{array}$ & $\begin{array}{l}\text { Percent increase relative to } \\
\text { claiming at age 62: }\end{array}$ \\
\hline 62 & $\$\left[\mathrm{BEN} \_E X\right]$ & $0 \%$ \\
\hline 64 & $\$\left[\mathrm{BEN} \_E X^{*}(1+\mathrm{PCT} 64 / 100)\right]$ & {$[\mathrm{PCT} 64] \%$} \\
\hline 66 & $\$\left[\mathrm{BEN} \_E X^{*}(1+\mathrm{PCT} 66 / 100)\right]$ & {$[\mathrm{PCT} 66] \%$} \\
\hline 68 & $\$\left[\mathrm{BEN} \_E X^{*}(1+\mathrm{PCT} 68 / 100)\right]$ & {$[\mathrm{PCT} 68] \%$} \\
\hline 70 & $\$\left[\mathrm{BEN} \_\mathrm{EX} *(1+\mathrm{PCT} 70 / 100)\right]$ & {$[\mathrm{PCT} 70] \%$} \\
\hline
\end{tabular}

(All amounts are in today's dollars)

\section{Q.2.4: [CLAIM_AGE] "Pretend" question about claim age}

\section{[SHOW IF Q1.8==2 OR Q1.8==3 OR Q1.8==5 OR Q1.8==6]}

We just saw how the age at which you start claiming benefits can affect your future benefit levels. Consider a worker born in [BIRTHYEAR] deciding when to first claim Social Security benefits based at least in part on [ILL_HISHER] [SPOUSE]'s earnings history. At what age should [ILL_HESHE] claim so that [ILL_HESHE] will receive the highest first-time benefit?

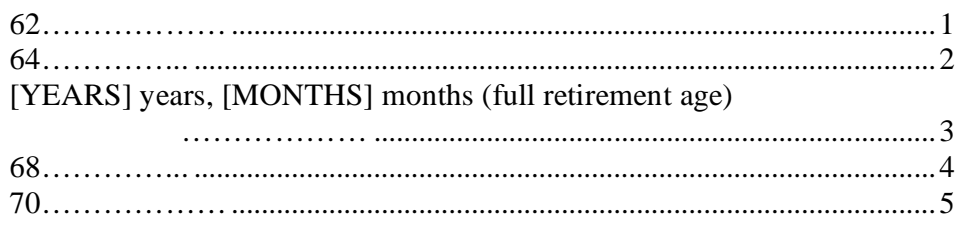

\section{[SHOW IF Q1.8==1 OR IF Q1.8==Refused]}

We just saw how the age at which you start claiming benefits can affect your future benefit levels. Consider a worker born in [BIRTHYEAR] deciding when to first claim Social Security benefits based on [ILL_HISHER] own earnings history. At what age should [ILL_HESHE] claim so that [ILL_HESHE] will receive the highest first-time benefit?

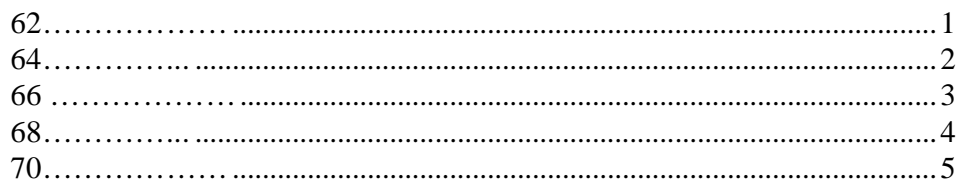

Q.2.5: [CLAIM_AGE follow-up] Follow-up to "pretend" question about claim age

[SHOW IF (Q1.8==2 OR Q1.8==3 OR Q1.8==5 OR Q1.8==6) AND Q.2.4 = NOT REFUSED] 
You answered that this worker can expect the highest first-time benefit if [ILL_HESHE] claimed at age [IF CLAIM_AGE==1, INSERT: 62; IF CLAIM_AGE==2, INSERT: 64; IF CLAIM_AGE==3, INSERT: [YEARS] years, [MONTHS] months; IF CLAIM_AGE==4, INSERT: 68; IF CLAIM_AGE==5, INSERT: 70].

Up until [ILL_HISHER] full retirement age of [YEARS] years and [MONTHS] months, [ILL_HISHER] spouse benefits are increased each year by about [SP_PCT_FULL / (MONTHTOT/12)]\% of the amount [ILL_HESHE] would receive at age 62. For instance, assume that a worker would receive $\$ 1000$ in monthly spouse benefits at age 62. [ILL_HESHE] could expect:

Age $62 \rightarrow$ [YEARS] Years, [MONTHS] Months

$\$ 1000 \quad \$[1000 *(1+$ SP_PCT_FULL/100)]

Therefore, this worker could expect the highest first-time benefit if [ILL_HESHE] waited to claim until [ILL_HESHE] reached [ILL_HISHER] full retirement age.

[SHOW IF CLAIM_AGE $\neq 5$ AND (Q1.8==1 OR IF Q1.8==Refused $)$ AND Q.2.4 = NOT REFUSED]

You answered that this worker can expect the highest first-time benefit if [ILL_HESHE] claimed at age [IF CLAIM_AGE==1, INSERT: 62; IF CLAIM_AGE==2, INSERT: 64; IF CLAIM_AGE==3, INSERT: 66; IF CLAIM_AGE==4, INSERT: 68$]$.

Retirement benefits are increased each year by about [PCT_70/8]\% of the amount [ILL_HESHE] would receive at age 62. For instance, assume that a worker would receive $\$ 1000$ in monthly retirement benefits at age 62. [ILL_HESHE] could expect:

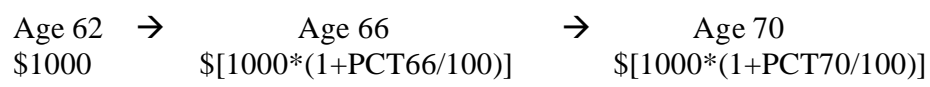

Therefore, this worker could expect the highest first-time benefit if [ILL_HESHE] claimed at age 70.

[SHOW IF CLAIM_AGE == 5 AND (Q1.8==1 OR IF Q1.8==Refused $)]$

You are correct; this worker can expect the highest first-time benefit if [ILL_HESHE] claimed at age 70.

Retirement benefits are increased each year by about [PCT_70/8]\% of the amount [ILL_HESHE] would receive at age 62. For instance, assume that a worker would receive $\$ 1000$ in monthly retirement benefits at age 62. [ILL_HESHE] could expect:

$\begin{array}{llcc}\text { Age } 62 & \rightarrow & \text { Age } 66 & \text { Age } 70 \\ \$ 1000 & \$[1000 *(1+\mathrm{PCT} 66 / 100)] & \$[1000 *(1+\mathrm{PCT} 70 / 100)]\end{array}$

Therefore, this worker could expect the highest first-time benefit if [ILL_HESHE] claimed at age 70.

\section{Q2.6: [Introduction to Working Longer]}

We talked about how Americans are living longer than ever, and we discussed how the age at which you first claim Social Security benefits can affect your future benefit levels. Now we'd like to talk about your retirement age (the age at which you stop working) and how the number of years you're in the workforce can build your savings and affect your benefits.

\section{Q.2.7: [Story about Working Longer \& Savings]}

When it comes to putting money away for retirement, it's a fact that working longer will increase overall savings. The following is a true story about 66-year-old Elena, who was forced out of the workforce early. She wasn't able to save while she was working, and as a result, she relies entirely on Social Security to cover her basic living expenses. According to Elena, it's "not enough money for the things I need. I can't buy clothes, I can't go on trips..., all I can do is buy the basic needs - and even then I have to cut corners.” Her advice to those approaching retirement is to "Save your money as much as you can, save your money. Don't retire too early, wait a while, as long as you possibly can." 


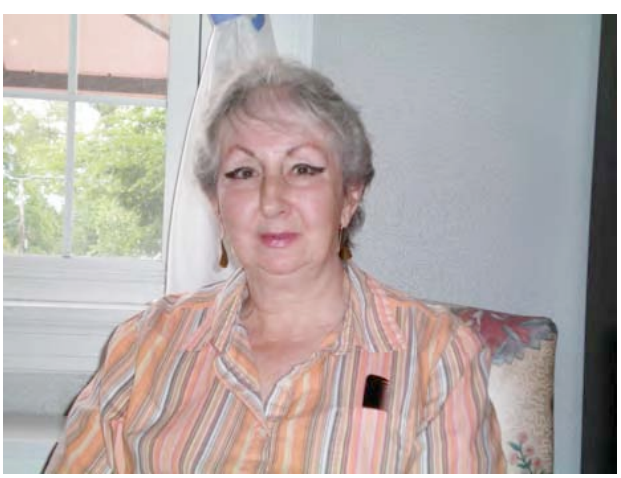

\section{Q.2.8: [BEN_WORK] Benefits to Working Longer}

What do you think is the most important benefit of working longer?

I will build my savings if I work longer......... 1

I can receive higher Social Security benefits with a better earnings history .....................................................................

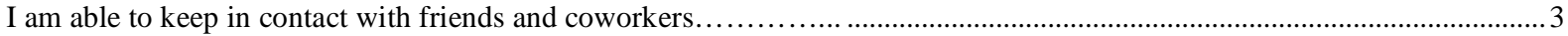

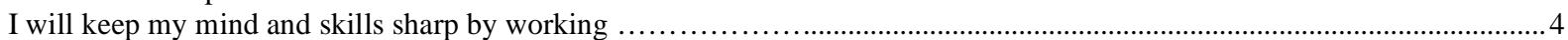

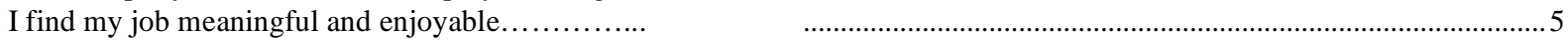

None of the above

\section{Q.2.9: [Explanation of 35-Year Rule]}

It's also important to understand how your workforce participation affects the Social Security benefits you receive.

The Social Security Administration uses the 35 years with your highest indexed earnings to determine your retirement benefits (earnings are indexed relative to average wages in that year). In other words, your benefits are affected by not only the number of years you work but also how much you earn while working. This fact plays into retirement planning in two important ways:

1. You're likely to have some of your highest-earning years close to retirement age, so working a few years longer can increase your benefits.

2. If you have a work history that is shorter than 35 years, or if you have a few low-earning years on your record, your benefits will be lower if you retire early than if you had continued to work.

\section{Q.2.10: [35_YEAR_RULE] 35-Year Rule Follow-Up}

Suppose you had planned to retire at age 62, but instead work an extra year and retire at 63 . Do you think this extra year of earnings would be among your highest 35 years?

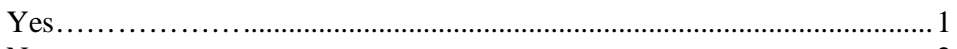

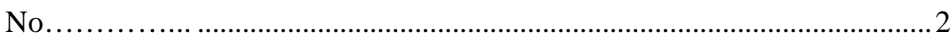

[There is no Q.2.11]

\section{Q.2.12a: [Savings Illustration]: Payoff from Higher Savings}

Imagine that you have a friend named [TOM_ANN] who is approaching retirement, and [ILL_HESHE] asks you for advice about retirement. [TOM_ANN] just turned 61 years old, so [ILL_HESHE] has one more year before [ILL_HESHE] can start receiving Social Security benefits. Over the years [TOM_ANN] managed to save a total of \$50,000. [TOM_ANN] currently has a good job with earnings that are about 50\% higher than the average earnings in America. [TOM_ANN] thinks that [ILL_HESHE] can save about $15 \%$ of [ILL_HISHER] current yearly earnings.

One of the first decisions [TOM_ANN] will have to make is when to stop working. Because [TOM_ANN] doesn't want to outlive [ILL_HISHER] savings, [ILL_HESHE] decided to only spend the interest income from [ILL_HISHER] savings, but not the savings themselves.

Q.2.12b: [Savings Illustration]: Payoff from Higher Savings, continued

Suppose [TOM_ANN]'s savings give [ILL_HIMHER] 4\% interest per year. Let's see what monthly income [TOM_ANN] can expect from [ILL_HISHER] savings if [ILL_HESHE] retires at age 62, 66, or 70:

[Information appears in three columns with the arrows lining up] 
Retire at $<$ in yellow $>62<$ in yellow $>\rightarrow<$ in yellow $>$ One $</$ in yellow $>$ more year to add to savings $\rightarrow<$ in yellow $>\$ 413</$ in yellow $>$ in interest income per month

Retire at $<$ in yellow $>66<$ in yellow $>\rightarrow<$ in yellow $>$ Five $<$ /in yellow $>$ more years to add to savings $\rightarrow<$ in yellow $>$ \$767 $<$ in yellow $>$ in interest income per month

Retire at $<$ in yellow $>70<$ in yellow $>\rightarrow<$ in yellow $>$ Nine $<$ in yellow $>$ more years to add to savings $\rightarrow<$ in yellow $>\$ 1180<$ in yellow $>$ in interest income per month

\section{Q.2.13a: [Benefits Illustration]: Higher SS from Claiming Later/More Earnings}

In addition to [ILL_HISHER] concerns about having enough savings, [TOM_ANN] is confused about [ILL_HISHER] Social Security benefits. [TOM_ANN] knows that benefits are calculated based on a formula, but [ILL_HESHE] isn't sure what goes into the calculation. After telling you [ILL_HISHER] work history, [TOM_ANN] wants your advice about Social Security.

[TOM_ANN] has worked for a total of 30 years. When [ILL_HESHE] started working, [ILL_HESHE] earned 50\% less than the average earnings in the U.S. at the time. Over the years, [ILL_HESHE] received steady pay increases, and currently [ILL_HESHE] earns 50\% more than the average American worker. [TOM_ANN] expects that [ILL_HISHER] earnings will not rise any further in the future.

[TOM_ANN] also tells you that the Social Security mailing [ILL_HESHE] received this past year said that if [ILL_HESHE] claims benefits at age <in yellow $>62</$ in yellow>, [ILL_HESHE] will get <in yellow $>\$ 1025<$ /in yellow $>$ per month.

\section{Q.2.13b: [Benefits Illustration2]: Higher SS from Claiming Later/More Earnings, continued}

Let's see what happens if [TOM_ANN] delays retirement for a few more years:

\begin{abstract}
Claim benefits at age $<$ in yellow $>66</$ in yellow $>$ :
\end{abstract}

Claim benefits at age $<$ in yellow $>70<$ in yellow $>$ : extra $<$ in yellow $>\$ 335</$ in yellow> per month (from claiming at a later date)

extra $<$ in yellow $>\$ 770</$ in yellow $>$ per month (from claiming at a later date)

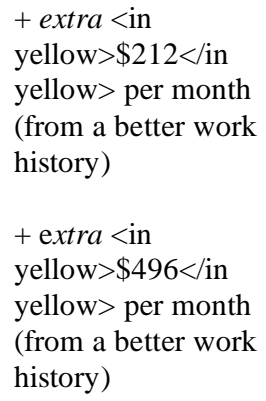

$=<$ in yellow $>\$ 1572</$ in yellow $>$ per month in total benefits

$=<$ in yellow $>\$ 2291<$ in yellow $>$ per month in total benefits

Q.2.14: [TOM_RET1]: [TOM_ANN] illustration, continued

Here are [TOM_ANN]'s options:

\begin{tabular}{|c|c|c|c|}
\hline $\begin{array}{l}\text { Retire and claim } \\
\text { benefits at age: }\end{array}$ & $\begin{array}{c}\text { Monthly Social } \\
\text { Security benefits }\end{array}$ & $\begin{array}{l}\text { Monthly income } \\
\text { from own savings }\end{array}$ & $\begin{array}{l}\text { Total Monthly } \\
\text { Income }\end{array}$ \\
\hline $\begin{array}{c}<\text { in yellow }>62</ \text { in } \\
\text { yellow }>\end{array}$ & $\begin{array}{c}<\text { in } \\
\text { yellow }>\$ 1025<\text { in } \\
\text { yellow }>\end{array}$ & $\begin{array}{c}<\text { in yellow }>\$ 413</ \text { in } \\
\text { yellow }>\end{array}$ & $\begin{array}{c}<\text { in } \\
\text { yellow }>\$ 1438<\text { in } \\
\text { yellow }>\end{array}$ \\
\hline 64 & $\$ 1271$ & $\$ 583$ & $\$ 1854$ \\
\hline $\begin{array}{c}<\text { in yellow }>66</ \text { in } \\
\text { yellow }>\end{array}$ & $\begin{array}{c}<\text { in } \\
\text { yellow }>\$ 1572<\text { in } \\
\text { yellow }>\end{array}$ & $\begin{array}{c}<\text { in yellow }>\$ 767</ \text { in } \\
\text { yellow }>\end{array}$ & $\begin{array}{c}<\text { in } \\
\text { yellow }>\mathbf{\$ 2 3 3 9}</ \text { in } \\
\text { yellow }>\end{array}$ \\
\hline 68 & $\$ 1930$ & $\$ 965$ & $\$ 2895$ \\
\hline$<$ in yellow $>70$ & $\begin{array}{c}\text { in } \\
\text { yellow }>\$ 2291<\text { in } \\
\text { yellow }>\end{array}$ & $\begin{array}{c}\text { in } \\
\text { yellow }>\$ 1180<\text { in } \\
\text { yellow }>\end{array}$ & $\begin{array}{c}\text { in } \\
\text { yellow }>\$ 3471<\text { in } \\
\text { yellow }>\end{array}$ \\
\hline
\end{tabular}

(All amounts are in today's dollars)

Given what you just saw, at which age would you advise [TOM_ANN] to retire? 
Q.2.15:[TOM_RET3]: Second Follow-up to [TOM_ANN] illustration

To calculate [TOM_ANN]'s monthly benefits, the Social Security Administration uses a complicated formula. Which of the following is true about [TOM_ANN]'s benefit calculation? Check all that apply.

\section{[ALLOW RESPONDENT TO PICK MULTIPLE OPTIONS]}

[Q2_15A] [TOM_ANN]'s earnings are indexed for inflation

[Q2_15B] [TOM_ANN]'s highest 35 years of earnings are used

[Q2_15C] [TOM_ANN]'s most recent 35 years of earnings are used

[Q2_15D] The total number of years with earnings is used

[Q2_15E] The sum of all earnings over [ILL_HISHER] lifetime is used

[LET Q2_15A take on a value of 1 if not selected and a value of 2 if selected. Similarly for the other four radio buttons]

Q.2.16: [TOM_RET4]: Follow-up to Benefit Calculation Question

[SHOW IF Q2_15A==2 AND Q2_15B==2 AND Q2_15C==1 AND Q2_15D==1 AND Q2_15E==1]

You are correct; when the Social Security Administration determines [TOM_ANN]'s benefit levels, [ILL_HISHER] earnings are indexed for inflation, and [ILL_HISHER] highest 35 years of earnings are used to calculate [ILL_HISHER] benefits.

[SHOW IF Q2_15A==1 OR Q2_15B==1 OR Q2_15C==2 OR Q2_15D==2 OR Q2_15E==2]

In truth, when the Social Security Administration determines [TOM_ANN]'s benefit levels, [ILL_HISHER] earnings are indexed for inflation, and [ILL_HISHER] highest 35 years of earnings are used to calculate [ILL_HISHER] benefits.

\section{Section 3: The Earnings Test}

\section{Q.3.1a: [The Earnings Test, Explained]}

Now we'd like to talk about work and collecting Social Security benefits. Some people who claim benefits at age 62 stop working between ages 62 and 66 because they fear they will lose their benefits. In truth, if your benefits are reduced from working, the money is not actually lost. Instead, the reduction is returned to you later in the form of increased benefits. This provision is called the Earnings Test.

Q.3.1b: [The Earnings Test, Continued]

Here's how the Earnings Test works

If you work while receiving Social Security benefits beginning at age 62, your benefits are reduced by $\$ 1$ for every $\$ 2$ you earn above the yearly earnings limit. In 2009 , that limit is $\$ 14,160$.

After you reach your full retirement age of [YEARS] years, [MONTHS] months, your benefits are never reduced no matter how much you earn from working.

However, once you reach your full retirement age, your benefits are recalculated to a higher amount based on how much your benefits were reduced before full retirement age. In other words, your benefits are never really cut, even if they might be temporarily reduced.

\section{Q.4.2: [EARNTEST_ILL]}

Suppose [TOM_ANN] claimed Social Security at age 63 and worked until age 66. As a result, [ILL_HISHER] benefits were reduced over this period by a total of $\$ 7200$ ( $\$ 200$ per month for 36 months).

In terms of Social Security benefits, how much out of this reduction would [TOM_ANN] receive back over [ILL_HISHER] lifetime, assuming [ILL_HESHE] lives as long as the typical person?

[ILL_HESHE] would receive $\$ 7,200$ back, with interest, over [ILL_HISHER] lifetime.............................................

[ILL_HESHE] would receive between $\$ 5,000$ - \$7,200 back over [ILL_HISHER] lifetime .....................................

[ILL_HESHE] would receive between $\$ 2,500$ - \$5,000 back over [ILL_HISHER] lifetime ......................................... 3

[ILL_HESHE] would receive less than $\$ 2,500$ back over [ILL_HISHER] lifetime ............................................. 4

[ILL_HESHE] would not receive any of the reduction back over [ILL_HISHER] lifetime .....................................5

Q.4.3: [The Earnings Test, Illustration Follow-Up] 


\section{[SHOW IF EARNTEST_ILL $\neq 1$ 1]}

You just answered that out of the $\$ 7200$ reduction in benefits from working, [TOM_ANN] would receive [IF EARNTEST_ILL==2, INSERT: "between $\$ 5,000$ and \$7,200"; IF EARNTEST_ILL==3, INSERT: "between $\$ 2,500$ and $\$ 5,000 "$ IF EARNTEST_ILL==4, INSERT: "less than \$2,500"; IF EARNTEST_ILL==5, INSERT: "none of the reduction"] back over [ILL_HISHER] lifetime.

[TOM_ANN] could actually expect to receive the full \$7,200 back in benefits over [ILL_HISHER] lifetime.

\section{[SHOW IF EARNTEST_ILL==1]}

You just answered that out of the $\$ 7,200$ reduction in benefits from working, [TOM_ANN] would receive $\$ 7,200$ back, with interest, over [ILL_HISHER] lifetime. That is correct; [TOM_ANN] would receive the full $\$ 7,200$ back in benefits over [ILL_HISHER] lifetime.

\section{[SHOW FOR ALL RESPONDENTS]}

To illustrate how this works, assume [TOM_ANN]'s Social Security benefits at age 63 totaled $\$ 800$ per month.

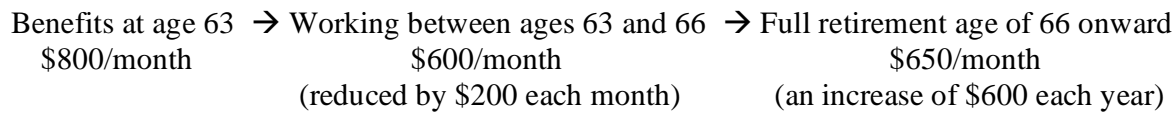

Assuming that [ILL_HESHE] lived at least another 12 years, [TOM_ANN] received the full $\$ 7,200(=12$ years $\times \$ 600 /$ year $)$ back over the course of [ILL_HISHER] lifetime.

\section{Q4.4: [SS_INDEX] Awareness of How Social Security is Indexed with Inflation}

Many people rely on Social Security to cover their basic living expenses, even if they have other forms of income like pension benefits or a retirement account (401K or IRA). What is a major benefit of Social Security relative to retirement accounts? Check all that apply.

[Show check boxes for each; allow multiple buttons to be selected]

[Q4.4_A] You cannot outlive Social Security - you will receive benefits as long as you live.

[Q4.4_B] Social Security benefits are indexed with inflation and increase as the price levels go up.

[Q4.4_C] Social Security is not affected by market shocks, so benefit levels remain steady even during times of economic downturn.

[LET Q4.3_A take on a value of 1 if not selected and a value of 2 if selected. Similarly for the other two radio buttons]

\section{Q4.5: [SS_INDEX2] Follow-Up to SS Indexing Question}

[SHOW IF Q4.4_A ==1 OR Q4.4_B ==1 OR Q4.4_C ==1]

In truth, all three of the answers apply to Social Security benefits:

- You cannot outlive Social Security - you will receive benefits as long as you live.

- Social Security benefits are indexed with inflation and increase as the price levels go up.

- Social Security is not affected by market shocks, so benefit levels remain steady even during times of economic downturn.

[SHOW IF Q4.4_A ==2 AND Q4.4_B ==2 AND Q4.4_C ==2]

You just answered that all the options are major benefits of Social Security relative to savings and retirement accounts such as IRAs and $401 \mathrm{Ks}$. That is correct; all three components together describe the advantages of Social Security over other sources of retirement savings.

\section{Section 5: Conclusion, General Questions}

\section{Q.5.1: [Conclusion]}

Now we'd like to ask you a few general questions so we can have a better idea of your plans for retirement.

\section{[NUMBER BOX: RANGE: 0-120]}

Q.5.2: [RET_AGE] Retirement Age

At what age did you last work for pay or do you plan to stop working for pay (with at least $\$ 2500$ in annual earnings)?

At age:

$\square$ I never worked for pay 
[NUMBER BOX: RANGE: 0-120]

Q.5.3: [CLAIM_AGE] Social Security benefits claim age

At what age did you start receiving or do you plan to start receiving Social Security benefits?

At age:

$\underline{\text { Section } 6 \text {-Standard Close }}$

\section{QF1}

[INSERT THE KN STANDARD CLOSE HERE (THIS QUESTION IS AN OPEN-ENDED QUESTION THAT KNOWLEDGE NETWORKS ASKS AT THE END OF EACH SURVEY AND IN WHICH RESPONDENTS CAN MAKE ANY COMMENT ABOUT THE SURVEY THEY HAVE JUST TAKEN)]

[PLEASE LINK TO THIS QUESTION AFTER QF1]

Q.6.2: [Further Resources]

Thank you for participating in our study. The survey is now complete, and you have been rerouted to this page in case you have further questions about Social Security benefits.

We have listed a number of resources below.

The U.S. Social Security Administration

http://www.ssa.gov/

$1-800-772-1213$

The American Association of Retired Persons: Social Security Page http://www.aarp.org/money/social_security/

1-888-OUR-AARP (1-888-687-2277)

USA.gov: Senior Citizens' Resources

http://www.usa.gov/Topics/Seniors.shtml

1-800-FED-INFO (1-800-333-4636)

Century Foundation: The Social Security Network

http://www.socsec.org/

National Center for Policy Analysis: Daily Social Security Policy Digest

http://www.ncpa.org/sub/dpd/index.php?Article_Category=39 


\section{APPENDIX C - INSTRUMENT FOR FOLLOW-UP SURVEY}

\section{A note about the "syntax" of this questionnaire}

Example question:

[Ask if MARRIED==1 AND SS_STATUS_S $\neq 3$ ]

Q.1.18: [CLAIM_AGE_S] Spouse's Social Security benefits claim age

[Show if SS_STATUS_S==1 (receiving benefits)]

At what age did your [SPOUSE] start receiving Social Security benefits?

At age:

[Show if SS_STATUS_S==2 (not receiving benefits yet)]

At what age does your [SPOUSE] plan to start collecting Social Security benefits?

At age:

Explanation:

- “Q.1.18: [CLAIM_AGE_S] Spouse's Social Security benefits claim age” denotes (i) the question number, (ii) the variable name, and (iii) a description of the question. None of this appears on the screen for the respondents.

- $\quad$ Remarks between square brackets are just for the programmer.

- Variables are denoted in all capitals. E.g. MARRIED and SPOUSE are variables.

- Any programming remarks before the question name apply to the whole question. E.g., in this question, if MARRIED equals 0, the whole question should be skipped.

- Variable names that should be replaced by the string they hold are indicated in all capitals between square brackets. E.g. [SPOUSE] is replaced by "husband" or "wife", which are the string contents of the variable SPOUSE.

- The solid lines indicate that a new screen should be shown.

- The numbers in parentheses in front of the selections boxes do not appear on the screen; they only indicate the value the variable will take if the relevant selection box is checked.

\section{Design File}

We will provide you with a Stata dataset with for each observation in the target population (2483 observations):

CASEID Caseid number from the Nov/Dec 2008 Social Security Main Survey (including non-respondents)

XRET_CHG Number of years earlier the respondent stopped working in section 3, equal to 1, 2, or 5 years

XCLM_CHG Whether claim age is moved forward or backward.

XDEP_V Version for whether benefits depend on claim age (1=reference age is 62, $2=$ reference age is 66)

XEARNTST The age for which the earnings test question in section 5 is asked (64 or 68)

XBINBALL The type of example given for the bins/balls question

Please merge these variables before administering the survey because skip patterns depend on these variables.

\section{The following data-only variables are created for all respondents:}

Note that the following two variables are collected by the research company prior to each respondent's participation: PPMARIT denotes marital status, 1 corresponds to "married"

PPGENDER denotes gender, 1: Male, 2: Female

CREATE A NEW DATA ONLY VARIABLE MARRIED:

SET MARRIED $=0$ IF PPMARIT $\neq 1$

SET MARRIED = 1 IF PPMARIT $==1$

CREATE A NEW DATA ONLY VARIABLE SPOUSE:

SET SPOUSE $=$ "HUSBAND" IF MARRIED ==1 AND PPGENDER==2

SET SPOUSE = "WIFE" IF MARRIED ==1 AND PPGENDER==1

CREATE A NEW DATA ONLY VARIABLE SP_HISHER:

SET SP_HISHER $=$ "HIS" IF MARRIED $==1$ AND PPGENDER $==2$

SET SP_HISHER = "HER" IF MARRIED $==1$ AND PPGENDER==1

CREATE A NEW DATA ONLY VARIABLE PREV_MONTH:

SET PREV_MONTH = "JANUARY" IF INTERVIEW TAKES PLACE IN FEBRUARY

SET PREV_MONTH = "FEBRUARY" IF INTERVIEW TAKES PLACE IN MARCH

SET PREV_MONTH = "MARCH" IF INTERVIEW TAKES PLACE IN APRIL

SET PREV_MONTH = “APRIL” IF INTERVIEW TAKES PLACE IN MAY 


\section{Section 1A: Own and Spousal Social Security and Retirement Plans}

\section{Q.1.1: [INTRODUCTION]}

We are researchers at Harvard University who are interested in understanding the work and retirement behavior of Americans, and the role that Social Security plays in these decisions.

In this survey, we sometimes ask questions that may be hard to answer exactly. Please take time to consider the questions and give us your best guess even if you do not know the exact answer. Having your best guess will be very helpful to us.

Thank you very much for your help.

\section{Q.1.2: [SS_STATUS] Social Security Status}

What best describes you:

(1) $\square$ I currently receive Social Security benefits.

(2) $\square$ I don't currently receive Social Security benefits but expect to receive them at some time in the future.

(3) $\square$ I will never receive Social Security benefits.

In answering this question, please include benefits you yourself receive from the Social Security program whether these benefits are retired worker benefits, spouse benefits, survivor benefits, or disability benefits.

[IF SS_STATUS ==MISSING: PROMPT]

[IF SS_STATUS ==MISSING AFTER PROMT: GO TO STANDARD CLOSE]

\section{[ASK IF SS_STATUS==3]}

Q.1.3: [SS_ELIG] Social Security Eligibility

Why do you think you will never receive Social Security benefits?

(1) $\square$ My main job was/is not covered by Social Security ................................................................. 1

(2) I don't have or will not have a sufficient work history to receive benefits.............................................2

(3) $\square$ I do not think Social Security will be around by the time I would start claiming benefits........................... 3

\section{[SHOW IF SS_STATUS==3 AND SS_ELIG==3]}

\section{[SET SS_STATUS=2 IF SS_STATUS==3 AND SS_ELIG==3]}

Q.1.4: [SSEL_AROUND]

Please assume for the remainder of this survey that Social Security will be around when you start claiming benefits.

\section{[ASK IF SS_STATUS==3 AND SS_ELIG==1]}

\section{Q.1.5: [SSEL_SECTOR]}

In what kind of business or industry is the job where you worked the most years? (For example: hospital, auto repair shop, mail order company, state government, elementary school).

\section{[ASK IF SS_STATUS==3 AND IF SS_ELIG==2]}

Q.1.6: [SSEL_QUALIF]

Approximately how many years have you worked for pay? years

[ASK IF SS_STATUS==3 AND (SS_ELIG $\neq$ 3) AND (PPMARIT $\neq 5$ )]

[Note: PPMARIT=5 corresponds to "never married" and SS_ELIG=3 corresponds to those who thought Social Security would no longer exist]

\section{Q.1.7: [SSEL_SPOUSE]}

Individuals who are not eligible for Social Security based on their own work history are often eligible to receive Social Security benefits based on the earnings history of their spouse, late spouse, or ex-spouse.

Do you think you will be able to receive benefits based on the earnings history of your [SPOUSE], late [SPOUSE], or ex-[SPOUSE]?

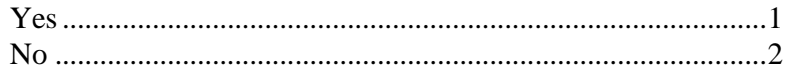

[IF SSEL_SPOUSE==1 AND SS_STATUS==3: SET SS_STATUS=2 AND CONTINUE WITH SURVEY]

[IF SSEL_SPOUSE==2 AND SS_STATUS==3: GO TO STANDARD CLOSE] 
[ASK IF SS_STATUS==1 (RECEIVING BENEFITS):]

At what age did you start receiving Social Security benefits?

At age: years and months.

[ASK IF SS_STATUS==2 (NOT RECEIVING BENEFITS YET):]

At what age do you plan to start collecting Social Security benefits?

At age: years and months.

Note: Allow values 0-11 in the month box.

[ALWAYS: (THE CODE BELOW ENSURES CLAIM_AGE WILL NEVER BE MISSING)]

[SET CLAIM_AGE_ORIG=CLAIM_AGE]

[SET CLAIM_AGE=MAX(PPAGE+1, 62) IF CLAIM_AGE=MISSING AND SS_STATUS==2]

[SET CLAIM_AGE=MIN(PPAGE-1, 62) IF CLAIM_AGE=MISSING AND SS_STATUS==1]

Q.1.9: [WORK_NOW] Current Work Status

What best describes you:

I currently work for pay

(with at least $\$ 2500$ in annual earnings) .................................1

I do not currently work for pay (with at least \$2500 in annual

earnings) 2

[ASK IF WORK_NOW==2]

Q.1.10: [WORK_FUT] Expected Future Work Status

What best describes you:

I expect that in the future I will work for pay (with at least $\$ 2500$ in annual earnings)

I do not expect that in the future I will work for pay (with at least

$\$ 2500$ in annual earnings)

\section{[CREATE A NEW DATA ONLY VARIABLE: “RETIRED”. SET RETIRED TO “0”] \\ [SET RETIRED=1 IF WORK_NOW==2 AND WORK_FUT==2] \\ Q.1.11: [RET_AGE, RET_MTH] Retirement Age}

[SHOW IF RETIRED==1]

At what age did you last work for pay (with at least $\$ 2500$ in annual earnings)?

At age: years and months.

$\square$ I never worked for pay

We will refer to this age in the rest of this survey as your "retirement age".

[IF RESPONDENT CHECK THE BOX "I NEVER WORKED FOR PAY", SET RET_AGE=0]

[SHOW IF RETIRED==0]

At what age do you plan to stop working for pay or to reduce your earnings to a minimal amount?

At age: years and months.

We will refer to this age in the rest of this survey as your expected "retirement age".

Allow values 0-11 in the month box.

[ASK IF RET_AGE $\neq 0$ AND RETIRED==1 AND RET_AGE <65 (R HAS SOME WORK HISTORY AND STOPPED WORKING BEFORE THE AGE OF 65)]

Q.1.12: [DISABLE] Stopped working because of a disability

After you stopped working, did you receive disability benefits?

Yes, I received Social Security Disability Insurance (SSDI) .........1

Yes, I received Supplemental Security Income (SSI) ....................2

Yes, I received both SSDI and SSI ................................................ 3

Yes, I received disability benefits, but don't know from which program .............................................................................4

No, I did not receive disability benefits........................................

[CREATE NEW VARIABLE SKIPDIS=0. -IF Q1_12==1 OR Q1_12==2 OR Q1_12==3 OR Q1_12==4, SET SKIPDIS=1] 
[SET RET_AGE=MAX(PPAGE+1, 62) IF RET_AGE=MISSING AND RETIRED==0]

[SET RET_AGE=MIN(PPAGE-1, 62) IF RET_AGE=MISSING AND RETIRED==1]

\section{Q.1.13: [PAID_WORK] Work Information from [Previous calendar Month] of 2010}

Next, we would like to ask you some questions about your work during [PREV_MONTH] of 2010.

During [PREV_MONTH] of 2010, did you do any work that earned some money?

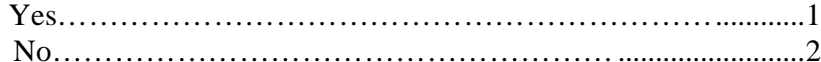

\section{[ASK IF PAID_WORK==2]}

Q.1.14: [NOWORK_RES] Reason For No Paid Work during [Previous calendar Month] of 2010

What is the main reason you did not do any paid work during [PREV_MONTH] of 2010?

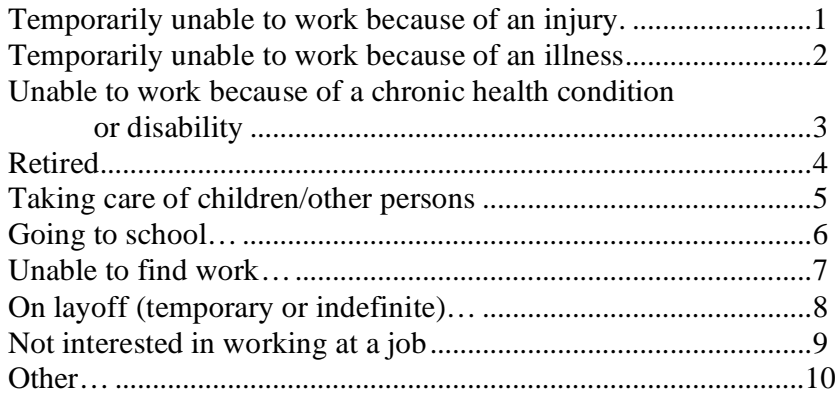

\section{[ALLOW R TO SELECT ONLY ONE CHOICE]} s ? .8 9 10

[ASK IF PAID_WORK==1]

Q.1.15: [PAIDWORK_TYPE] Type of Paid Work During [Previous calendar Month] of 2010

What was the type of paid work that you did during [PREV_MONTH] of 2010?

Employed by someone.. 1

Self-Employed............................................................................2

Both employed by someone and self-employed ……….................. 3

Other ...........................................................................................

[ALLOW R TO SELECT ONLY ONE CHOICE]

[ASK IF PAID_WORK==1]

Q.1.16: [PAIDWORK_HRS] Number of Hours Worked for Pay during [Previous calendar month] of 2010

As your best guess, how many hours in total did you do paid work during [PREV_MONTH] of 2010?

1-9 hours in total during [PREV_MONTH] (about 1 hour/week)
$10-29$ hours in total during [PREV_MONTH] (about 5 hours/week)
$30-49$ hours in total during [PREV_MONTH] (about 10 hours/week)
$50-69$ hours in total during [PREV_MONTH] (about 15 hours/week)
$70-89$ hours in total during [PREV_MONTH] (about 20 hours/week)
$90-109$ hours in total during [PREV_MONTH] (about 25 hours/week)
$110-129$ hours in total during [PREV_MONTH] (about 30 hours/week)
$130-149$ hours in total during [PREV_MONTH] (about 35 hours/week)
$150-169$ hours in total during [PREV_MONTH] (about 40 hours/week)
$170-189$ hours in total during [PREV_MONTH] (about 45 hours/week)
$190-209$ hours in total during [PREV_MONTH] (about 50 hours/week)
$210-229$ hours in total during [PREV_MONTH] (about 55 hours/week)
$230-249$ hours in total during [PREV_MONTH] (about 60 hours/week)
250 or more hours in total during [PREV_MONTH] (about 65 or more hours/week)

[ALLOW R TO SELECT ONLY ONE CHOICE]

[ASK IF PAID_WORK==1]

Q.1.17: [PAIDWORK_AMT] Own Gross Earnings during [Previous Calendar Month] of 2010

As your best guess, what was the total gross amount (i.e., before taxes and deductions) that you earned from your paid work in [PREV_MONTH] of 2010? 


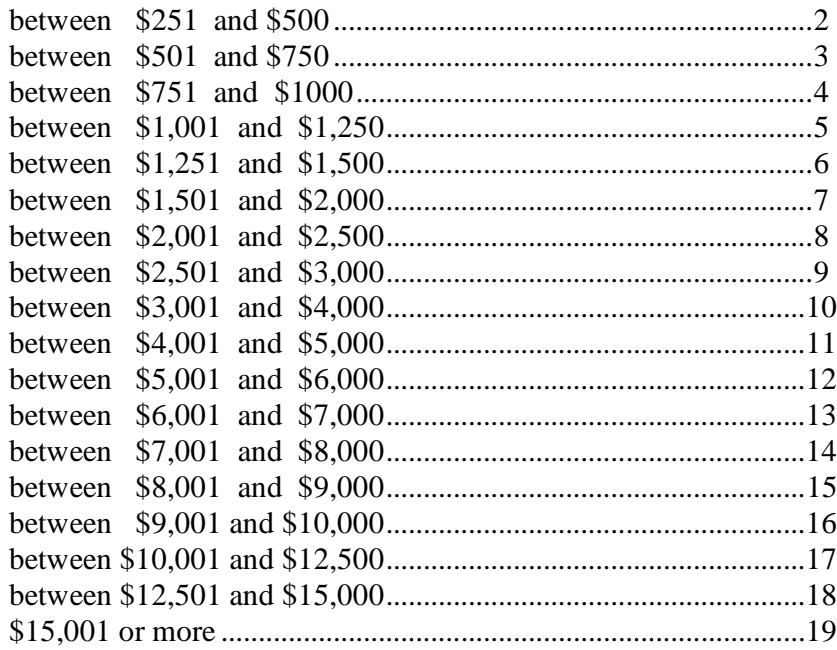

\title{
[ALLOW R TO SELECT ONLY ONE CHOICE]
}

\author{
[ASK IF MARRIED==1] \\ Q.1.18: [AGE_S] Spouse's current age \\ What is your [SPOUSE]'s current age (in years)? \\ years. \\ D N/A, I am not married. \\ [IF THE RESPONDENT CHECKS THE BOX N/A, THEN SET MARRIED=0]

\section{[ASK IF MARRIED==1] \\ Q.1.19: [SS_STATUS_S] Spouse Social Security Status} \\ What best describes your [SPOUSE]:
}
My [SPOUSE] currently receives Social Security benefits. ..........1
My [SPOUSE] doesn't currently receive Social Security benefits but expects to receive them at some time in the future..................2

My [SPOUSE] will never receive Social Security benefits. .......... 3

\section{[SHOW IF PPGENDER==1 (MALE RESPONDENT)]}

In answering this question, please include benefits your wife herself receives from the Social Security program whether these benefits are retired worker benefits, spouse benefits, or disability benefits.

\section{[SHOW IF PPGENDER==2 (FEMALE RESPONDENT)]}

In answering this question, please include benefits your husband himself receives from the Social Security program whether these benefits are retired worker benefits, spouse benefits, or disability benefits.

\section{[ASK IF MARRIED==1 AND SS_STATUS_S==3] \\ [ONLY ASK CODE 3 IF PILOT TEST] \\ Q.1.20: [SS_ELIG_S] Spouse's Social Security Eligibility}

Why do you think your [SPOUSE] will never receive Social Security benefits?

My [SPOUSE]'s main job was/is not covered by Social Security.

My [SPOUSE] doesn't have or will not have a sufficient work history

to receive benefits. ......................................................................

Another reason:

\footnotetext{
[ASK IF MARRIED==1 AND SS_STATUS_S==3]

Q.1.21: [SSEL_SPOUSE_S]

Individuals who are not eligible for Social Security based on their own work history are often eligible to receive Social Security benefits based on the earnings history of their spouse.

Do you think your [SPOUSE] will be able to receive benefits based on your earnings history?

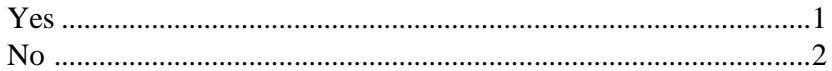

[IF SSEL_SPOUSE_S==1, SET SS_STATUS_S=2]

\section{[ASK IF MARRIED==1 AND SS_STATUS_S $\neq 3$ ] \\ Q.1.22: [CLAIM_AGE_S, CLAIM_MTH_S] Spouse's Social Security benefits claim age}


[SHOW IF SS_STATUS_S==1 (RECEIVING BENEFITS)]

At what age did your [SPOUSE] start receiving Social Security benefits?

At age: years and months.

[SHOW IF SS_STATUS_S==2 (NOT RECEIVING BENEFITS YET)]

At what age does your [SPOUSE] plan to start collecting Social Security benefits?

At age: years and months.

[AlWAYS: (THE CODE BELOW ENSURES CLAIM_AGE_S WILL NEVER BE MISSING)]

[SET CLAIM_AGE_S_ORIG=CLAIM_AGE_S]

[SET CLAIM_AGE_S=MAX(AGE_S+1, 62) IF CLAIM_AGE_S=MISSING AND SS_STATUS_S==2 AND MARRIED==1]

[SET CLAIM_AGE_S=MIN(AGE_S-1, 62) IF CLAIM_AGE_S=MISSING AND SS_STATUS_S==1 AND MARRIED==1]

[SET CLAIM_AGE_S=62 IF AGE_S=MISSING AND CLAIM_AGE_S=MISSING AND SS_STATUS_S==1 AND MARRIED==1]

[SET CLAIM_AGE_S=62 IF CLAIM_AGE_S=MISSING AND SS_STATUS_S=MISSING]

Allow Values 0-11 in THE MONTH BOX.

\section{[ASK IF MARRIED==1]}

Q.1.23: [WORK_NOW_S] Spouse's Current Work Status

What best describes your [SPOUSE]:

My [SPOUSE] currently works for pay (with at least $\$ 2500$ in annual earnings) .......................................................................... 1

My [SPOUSE] does not currently work for pay (with at least $\$ 2500$

in annual earnings)

.2

[ASK IF MARRIED==1 AND WORK_NOW_S==2]

Q.1.24: [WORK_FUT_S] Spouse's Expected Future Work Status

What best describes your [SPOUSE]:

I expect that in the future my [SPOUSE] will work for pay (with at least $\$ 2500$ in annual earnings) ..............................................1

I do not expect that in the future my [SPOUSE] will work for pay

(with at least \$2500 in annual earnings).

.2

[ASK IF MARRIED==1]

[CREATE A NEW VARIABLE: RETIRED_S=0 IF MARRIED==1]

[SET RETIRED_S=1 IF MARRIED==1 AND WORK_NOW_S==2 AND WORK_FUT_S==2]

Q.1.25: [RET_AGE_S, RET_MTH_S] Spouse's Retirement Age

[SHOW IF RETIRED_S==1]

At what age did your [SPOUSE] last work for pay (with at least $\$ 2500$ in annual earnings)?

At age: years and months.

口 My [SPOUSE] never worked for pay

We will refer to this age in the rest of this survey as your [SPOUSE]'s "retirement age".

[IF R CHECKS THE BOX "MY SPOUSE NEVER WORKED FOR PAY", SET RET_AGE_S=0]

[SHOW IF RETIRED_S==0]

As your best guess, at what age does your [SPOUSE] plan to stop working for pay or to reduce [SP_HISHER] earnings to a minimal amount? At age: years and months.

We will refer to this age in the rest of this survey as your [SPOUSE]'s expected "retirement age".

Allow values 0-11 in the month box

[ALWAYS: (THE CODE BELOW ENSURES RET_AGE_S WILL NEVER BE MISSING)]

[SET RET_AGE_S_ORIG=RET_AGE_S]

[SET RET_AGE_S=MAX(AGE_S $+1,62)$ IF RET_AGE_S=MISSING AND RETIRED_S==0 AND MARRIED==1]

[SET RET_AGE_S=MIN(AGE_S-1, 62) IF RET_AGE_S=MISSING AND RETIRED_S==1 AND MARRIED==1]

[ASK IF MARRIED==1]

Q.1.26: [PAID_WORK_S] Spouse's Work Information from [Previous calendar Month] of 2010

Next, we would like to ask you some questions about your [SPOUSE]'s work during [PREV_MONTH] of 2010.

During [PREV_MONTH] of 2010, did your [SPOUSE] do any work that earned some money?

Yes......................................................... 1

No..................................................... 2 


\section{[ASK IF PAID_WORK_S==2]}

Q.1.27: [NOWORK_RES_S] Spouse's Reason For No Paid Work during [Previous calendar Month] of 2010

What is the main reason your [SPOUSE] did not do any paid work during [PREV_MONTH] of 2010?

Temporarily unable to work because of an injury. ........................1

Temporarily unable to work because of an illness..........................2

Unable to work because of a chronic health condition

(1)

Taking care of children/other persons .........................................

Going to school.....................................................................

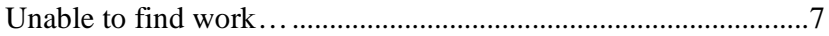

On layoff (temporary or indefinite) ... ................................... 8

Not interested in working at a job .............................................. 9

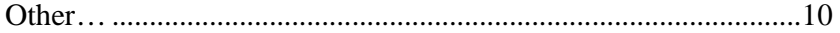

\section{[ALLOW R TO SELECT ONLY ONE CHOICE]}

[ASK IF PAID_WORK_S==1]

Q.1.28: [PAIDWORK_TYPE_S] Spouse's Type of Paid Work During [Previous calendar Month] of 2010

What was the type of paid work that your [SPOUSE] did during [PREV_MONTH] of 2010?

(1) Employed by someone …....................................................

(2) Self-Employed ......................................................................

(3) Both employed by someone and self-employed ........................

(4) Other .................................................................................

[ALLOW R TO SELECT ONLY ONE CHOICE]

[ASK IF PAID_WORK_S $==1]$

Q.1.29: [PAIDWORK_HRS_S] Number of Hours Worked for Pay during [Previous calendar month] of 2010

As your best guess, how many hours in total did your [SPOUSE] do paid work during [PREV_MONTH] of 2010?

$\begin{aligned} 1-9 \text { hours in total during [PREV_MONTH] } & \text { (about } 1 \text { hour/week) } \\ 10-29 \text { hours in total during [PREV_MONTH] } & \text { (about } 5 \text { hours/week) } \\ 30-49 \text { hours in total during [PREV_MONTH] } & \text { (about } 10 \text { hours/week) } \\ 50-69 \text { hours in total during [PREV_MONTH] } & \text { (about } 15 \text { hours/week) } \\ 70-89 \text { hours in total during [PREV_MONTH] } & \text { (about } 20 \text { hours/week) }\end{aligned}$

[ALLOW R TO SELECT ONLY ONE CHOICE]

[ASK IF PAID_WORK_S==1]

Q.1.30: [PAIDWORK_AMT_S] Spouse's Gross Earnings during [Previous Calendar Month] of 2010

As your best guess, what was the total gross amount (i.e., before taxes and deductions) that your [SPOUSE] earned from paid work in [PREV_MONTH] of 2010?

\begin{tabular}{|c|c|}
\hline between & $\$ 251$ and $\$ 500$. \\
\hline between & $\$ 501$ and $\$ 750$. \\
\hline between & $\$ 751$ and $\$ 1000$. \\
\hline between & $\$ 1,001$ and $\$ 1,250 \ldots$. \\
\hline between & $\$ 1,251$ and $\$ 1,500 \ldots \ldots$ \\
\hline between & $\$ 1,501$ and $\$ 2,000 \ldots$ \\
\hline between & 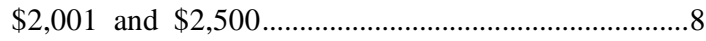 \\
\hline etween & 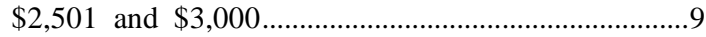 \\
\hline
\end{tabular}




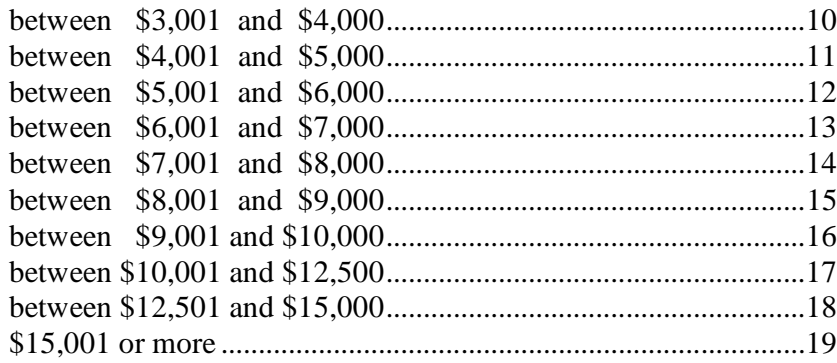

\section{[ALLOW R TO SELECT ONLY ONE CHOICE]}

\section{Section 1B: Subjective Distributions of Claim Age and Retirement Age}

\section{[ASK IF SS_STATUS==2 OR RETIRED==0 (NOT RECEIVING BENEFITS OR NOT RETIRED)]} Q.1.31: [BINBALL_EXPLAIN] Explanation of the Bins and Balls format

\section{[SHOW IF SS_STATUS==2 AND RETIRED==0 (NOT RECEIVING BENEFITS AND NOT RETIRED)]}

In the next few questions, we ask you to think about future decisions about retiring and claiming Social Security benefits. Even though people aren't completely sure about the future, they still have an idea of the chances that they will retire at a certain age or claim Social Security benefits at a certain age.

To help you answer these questions about future plans, we will show you 20 balls that you can put in nine different age bins. The more likely you think it is that you will retire at a certain age or claim benefits at a certain age, the more balls you should put in that age bin. To see how this works, an example is shown on the next screen.

[SHOW IF SS_STATUS==2 AND RETIRED==1 (NOT RECEIVING BENEFITS AND RETIRED)] In the next question, we ask you to think about future decisions about claiming Social Security benefits. Even though people aren't completely sure about the future, they still have an idea of the chances that they will claim Social Security benefits at a certain age.

To help you answer this question about future plans, we will show you 20 balls that you can put in nine different age bins. The more likely you think it is that you will claim Social Security benefits at a certain age, the more balls you should put in that age bin. To see how this works, an example is shown on the next screen.

[SHOW IF SS_STATUS==1 AND RETIRED==0 (RECEIVING BENEFITS AND NOT RETIRED)]

In the next question, we ask you to think about future decisions about retiring. Even though people aren't completely sure about the future, they still have an idea of the chances that they will retire at a certain age.

To help you answer this question about future plans, we will show you 20 balls that you can put in nine different age bins. The more likely you think it is that you will retire at a certain age, the more balls you should put in that age bin. To see how this works, an example is shown on the next screen.

\section{[SHOW IF SS_STATUS==2 OR RETIRED==0 (NOT RECEIVING BENEFITS, OR, NOT RETIRED)]}

\section{Q.1.32: [BINBALL_EXAMPLE] Example about using the Bins and Balls format}

This is an example that shows what we think the temperature will be in Boston at noon tomorrow. We don't know for sure how hot or cold it will get, but we have some guesses. The more likely we think that it will be a given temperature, the more balls we put in that bin.

[SHOW IF XBINBALL==1]

We are sure that the temperature will not reach $40{ }^{\circ} \mathrm{F}$ (or higher) or drop to $24^{\circ} \mathrm{F}$ (or lower) at noon, so we don't put any balls in those bins. We think that there is a 20 percent chance ( 4 out of 20) that it will be $25-29^{\circ} \mathrm{F}$, so we put 4 out of 20 balls in that bin. We think that there is a 50 percent chance ( 10 out of 20 ) that it will be $30-34^{\circ} \mathrm{F}$, so we put 10 out of 20 balls in that bin. We think that there is a 30 percent chance ( 6 out of 20) that it will be $35-39^{\circ} \mathrm{F}$, so we put 6 out of 20 balls in that bin.

[SHOW IF XBINBALL==2]

We are sure that the temperature will not reach $60^{\circ} \mathrm{F}$ (or higher) at noon, so we don't put any balls in that bin. We think that there is a 25 percent chance ( 5 out of 20) that it will be $35-39^{\circ} \mathrm{F}$, so we put 5 out of 20 balls in that bin. We think that there is a 15 percent chance ( 3 out of 20 ) that it will be $30-34^{\circ} \mathrm{F}$, so we put 3 out of 20 balls in that bin. We think that there is a 10 percent chance (2 out of 20$)$ that the temperature will fall in each of the remaining bins, so we put 2 balls in each of the remaining bins.

[ASK IF SS_STATUS==2 (NOT RECEIVING BENEFITS)] Q.1.33: [PDF_CLAIM_AGE] Subjective Probability Distribution of Own Claim Age Earlier you answered that you plan to start collecting Social Security benefits at age [CLAIM_AGE]. In this question, we ask you to think 
about the chances that you might claim Social Security benefits at each of the ages listed below.

You have 20 balls that you can put in nine different age bins. The more likely you think it is that you will claim Social Security benefits at a given age, the more balls you should put in that age bin.

Use the (+) button to add balls to a bin and use the (-) button to remove balls from a bin

[PROMPT RESPONDENT TO ALLOCATE ALL 20 BALLS INTO A BIN, IF THEY FAIL TO DO SO]

[CREATE NINE BINS: 61 OR EARLIER, 62, 63, 64, 65, 66, 67, 68, 69 OR LATER].

[CREATE NINE VARIABLES FOR THE NUMBER OF BALLS IN EACH BIN].

[ASK IF RETIRED==0 (NOT RETIRED)]

Q.1.34: [PDF_RET_AGE] Subjective Probability Distribution of Own Retirement Age

Earlier you answered that you plan to retire at age [RET_AGE]. In this question, we ask you to think about the chances that you might retire at each of the ages listed below.

You have 20 balls that you can put in nine different age bins. The more likely you think it is that you will retire at a given age, the more balls you should put in that age bin.

Use the (+) button to add balls to a bin and use the (-) button to remove balls from a bin

[SHOW 9 AGE CATEGORIES CENTERED AROUND [RET_AGE]. THE LOWEST AGE LISTED MUST BE AS HIGH AS THE RESPONDENT'S CURRENT AGE. SO THE AGE OF THE LOWEST AGE-BIN IS GIVEN BY:

BIN_MIN = MAX(PPAGE, RET_AGE-4)

THE AGE FOR THE SECOND AGE-BIN IS: BIN_MIN+1, ..., , AND THE AGE FOR THE HIGHEST AGE-BIN IS BIN_MIN+8]

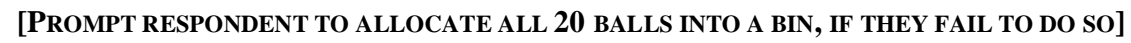

[PLeASE SAVE BIN_MIN, AND CREATE NINE VARIABLES FOR THE NUMBER OF BALlS IN EACH BIN].

[ASK IF RETIRED==1 AND SS_STATUS==1 AND MARRIED=1 AND (RETIRED_S==0 OR SS_STATUS_S==2)]

Q.1.35: [BINBALL_EXPLAIN_S] Explanation of Bins and Balls Format to Married Respondents Who Did Not See Q.1.31

[SHOW IF SS_STATUS_S==2 AND RETIRED_S==0 ([SPOUSE] NOT RECEIVING BENEFITS AND NOT RETIRED)]

In the next few questions, we ask you to think about your [SPOUSE]'s future decisions about retiring and claiming Social Security benefits. Even though people aren't completely sure about the future, they still have an idea of the chances that their [SPOUSE] will retire at a certain age or claim Social Security benefits at a certain age.

To help you answer these questions about your [SPOUSE]'s future plans, we will show you 20 balls that you can put in nine different age bins. The more likely you think it is that your [SPOUSE] will retire at a certain age or claim benefits at a certain age, the more balls you should put in that age bin. To see how this works, an example is shown on the next screen.

[SHOW IF SS_STATUS_S==2 AND RETIRED_S==1 ([SPOUSE] NOT RECEIVING BENEFITS AND RETIRED)]

In the next question, we ask you to think about your [SPOUSE]'s future decisions about claiming Social Security benefits. Even though people aren't completely sure about the future, they still have an idea of the chances that their [SPOUSE] will claim Social Security benefits at a certain age.

To help you answer this question about your [SPOUSE]'s future plans, we will show you 20 balls that you can put in nine different age bins. The more likely you think it is that your [SPOUSE] will claim Social Security benefits at a certain age, the more balls you should put in that age bin. To see how this works, an example is shown on the next screen.

[SHOW IF SS_STATUS_S==1 AND RETIRED_S==0 ([SPOUSE] RECEIVING BENEFITS AND NOT RETIRED)]

In the next question, we ask you to think about your [SPOUSE]'s future decisions about retiring. Even though people aren't completely sure about the future, they still have an idea of the chances that their [SPOUSE] will retire at a certain age.

To help you answer this question about your [SPOUSE]'s future plans, we will show you 20 balls that you can put in nine different age bins. The more likely you think it is that your [SPOUSE] will retire at a certain age, the more balls you should put in that age bin. To see how this works, an example is shown on the next screen.

[SHOW IF RETIRED==1 AND SS_STATUS==1 AND MARRIED=1 AND (RETIRED_S==0 OR SS_STATUS_S==2)] Q.1.36: [BINBALL_EXAMPLE_S] Example about using the Bins and Balls format for Respondents who did not see Q.1.32

This is an example that shows what we think the temperature will be in Boston at noon tomorrow. We don't know for sure how hot or cold it will get, but we have some guesses. The more likely we think that it will be a given temperature, the more balls we put in that bin. 
[SHOW IF XBINBALL $==1$ ]

We are sure that the temperature will not reach $40{ }^{\circ} \mathrm{F}$ (or higher) or drop to $24{ }^{\circ} \mathrm{F}$ (or lower) at noon, so we don't put any balls in those bins. We think that there is a 20 percent chance ( 4 out of 20) that it will be $25-29^{\circ} \mathrm{F}$, so we put 4 out of 20 balls in that bin. We think that there is a 50 percent chance ( 10 out of 20 ) that it will be $30-34^{\circ} \mathrm{F}$, so we put 10 out of 20 balls in that bin. We think that there is a 30 percent chance $(6$ out of 20) that it will be $35-39^{\circ} \mathrm{F}$, so we put 6 out of 20 balls in that bin.

[SHOW IF XBINBALL==2]

We are sure that the temperature will not reach $60^{\circ} \mathrm{F}$ (or higher) at noon, so we don't put any balls in that bin. We think that there is a 25 percent chance ( 5 out of 20 ) that it will be $35-39^{\circ} \mathrm{F}$, so we put 5 out of 20 balls in that bin. We think that there is a 15 percent chance ( 3 out of 20 ) that it will be $30-34^{\circ} \mathrm{F}$, so we put 3 out of 20 balls in that bin. We think that there is a 10 percent chance (2 out of 20$)$ that the temperature will fall in each of the remaining bins, so we put 2 balls in each of the remaining bins.

[ASK IF MARRIED==1 AND SS_STATUS_S==2 ([SPOUSE] NOT RECEIVING BENEFITS)]

Q.1.37: [PDF_CLAIM_AGE_S] Subjective Distribution of Spousal Claim Age

You answered before that you think your [SPOUSE] plans to claim Social Security benefits at age [CLAIM_AGE_S]. In this question, we ask you to think about the chances that your [SPOUSE] might claim Social Security benefits at each of the ages listed below.

As before, you have 20 balls that you can put in nine different age bins. The more likely you think it is that your [SPOUSE] will claim Social Security benefits at a given age, the more balls you should put in that age bin.

Use the (+) button to add balls to a bin and use the (-) button to remove balls from a bin

[Prompt RESPONDENT TO ALLOCATE ALL 20 BALLS INTO A BIN, IF THEY FAIL TO DO SO]

[PLEASE CREATE NINE VARIABLES FOR THE NUMBER OF BALLS IN EACH BIN].

[ASK IF MARRIED==1 AND RETIRED_S==0 ([SPOUSE] NOT RETIRED) Q.1.38: [PDF_RET_AGE_S] Subjective Distribution of Spousal Retirement Age

You answered before that you think your [SPOUSE] plans to retire at age [RET_AGE_S]. In this question, we ask you to think about the chances that your [SPOUSE] might retire at each of the ages listed below.

As before, you have 20 balls that you can put in nine different age bins. The more likely you think it is that your [SPOUSE] will retire at a given age, the more balls you should put in that age bin.

Use the (+) button to add balls to a bin and use the (-) button to remove balls from a bin

SHOW 9 AGE CATEGORIES CENTERED AROUND [RET_AGE_S]. THE LOWEST AGE LISTED MUST BE AS HIGH AS THE RESPONDENT'S [SPOUSE]'S CURRENT AGE.

SO THE AGE OF THE LOWEST AGE-BIN IS GIVEN BY:

BIN_MIN_S = MAX(AGE_S, RET_AGE_S-4)

THE AGE FOR THE SECOND AGE-BIN IS: BIN_MIN_S+1，..., AND THE AGE FOR THE HIGHEST AGE-BIN IS BIN_MIN_S+8.

[PROMPT RESPONDENT TO ALLOCATE ALL 20 BALLS INTO A BIN, IF THEY FAIL TO DO SO]

[SAVE BIN_MIN_S, AND CREATE NINE VARIABLES FOR THE NUMBER OF BALLS IN EACH BIN].

Section 2: Perceived Total and Marginal Social Security Benefits

Q.2.1: [BEN_LEVEL] Social Security Benefits Level

[SHOW IF SS_STATUS==1 (RECEIVING BENEFITS)]

Approximately how much are your monthly Social Security benefits?

Even if you do not know exactly, please give your best guess.

(As before, please report any Social Security benefits paid to you yourself, not benefits paid to any other member in your household).

$\$$ per month.

[SHOW IF SS_STATUS==2 AND RETIRED==1 (NOT RECEIVING BENEFITS, BUT RETIRED)] 
How much do you expect your monthly Social Security benefits to be if you start collecting Social Security at age [CLAIM_AGE]?

Even if you do not know exactly, please give your best guess.

(As before, please report any Social Security benefits paid to you yourself, not benefits paid to any other member in your household. Also, please give your answer in today's dollars, and ignore any inflation that may occur between today and when you collect benefits).

$\$$ per month.

[SHOW IF SS_STATUS==2 AND RETIRED==0 (NOT RECEIVING BENEFITS, NOT RETIRED)]

How much do you expect your monthly Social Security benefits to be if you stop working for pay at age [RET_AGE] and start collecting Social Security at age [CLAIM_AGE]?

Even if you do not know exactly, please give your best guess.

(As before, please report any Social Security benefits paid to you yourself, not benefits paid to any other member in your household. Also, please give your answer in today's dollars, and ignore any inflation that may occur between today and when you collect benefits).

\$_____ per month.

[FOR ALL RESPONDENTS: CREATE A NEW VARIABLE BEN_ORIG = BEN_LEVEL]

[ASK IF BEN_LEVEL=MISSING OR BEN_LEVEL==0]

Q.2.2: [BEN_LEVEL2] Benefits Level Follow-up A

We understand this is a hard question to answer. We would really like to have your best guess, even if this guess is not exactly right.

[SHOW IF SS_STATUS==1 (RECEIVING BENEFITS)]

As your best guess, how much are your monthly Social Security benefits?

(As before, please report any Social Security benefits paid to you yourself, not benefits paid to any other member in your household).

$\$$ per month.

[IF BEN_LEVEL2 $\neq$ MISSING, SET BEN_LEVEL=BEN_LEVEL2]

[SHOW IF SS_STATUS==2 AND RETIRED==1 (NOT RECEIVING BENEFITS, BUT RETIRED)]

As your best guess, how much do you expect your monthly Social Security benefits to be if you start collecting Social Security at age [CLAIM_AGE]?

(As before, please report any Social Security benefits paid to you yourself, not benefits paid to any other member in your household. Also, please give your answer in today's dollars, and ignore any inflation that may occur between today and when you collect benefits).

$\$$ per month.

[IF BEN_LEVEL2 $\neq$ MISSING, SET BEN_LEVEL=BEN_LEVEL2]

[SHOW IF SS_STATUS==2 AND RETIRED==0 (NOT RECEIVING BENEFITS, NOT RETIRED)]

As your best guess, how much do you expect your monthly Social Security benefits to be if you stop working for pay at age [RET_AGE] and start collecting Social Security at age [CLAIM_AGE]?

(As before, please report any Social Security benefits paid to you yourself, not benefits paid to any other member in your household. Also, please give your answer in today's dollars, and ignore any inflation that may occur between today and when you collect benefits).

$\$$ per month.

[IF BEN_LEVEL2 $\neq$ MISSING, SET BEN_LEVEL=BEN_LEVEL2]

[ASK IF BEN_LEVEL>3500]

Q.2.3: [BEN_LEVEL3] Benefits Level Follow-up B

Social Security benefits are never higher than $\$ 3500$ per month.

[SHOW IF SS_STATUS==1 (RECEIVING BENEFITS)]

Given that monthly benefits are less than $\$ 3500$, how much are your monthly Social Security benefits?

(As before, please report any Social Security benefits paid to you yourself, not benefits paid to any other member in your household).

$\$$ per month.

[IF BEN_LEVEL3 $\neq$ MISSING, SET BEN_LEVEL=BEN_LEVEL3]

[SHOW IF SS_STATUS==2 AND RETIRED==1 (NOT RECEIVING BENEFITS, BUT RETIRED)] 
Given that monthly benefits are less than $\$ 3500$, how much do you expect your monthly Social Security benefits to be if you start collecting Social Security at age [CLAIM_AGE]?

(As before, please report any Social Security benefits paid to you yourself, not benefits paid to any other member in your household. Also, please give your answer in today's dollars, and ignore any inflation that may occur between today and when you collect benefits).

$\$$ per month.

[IF BEN_LEVEL3 $\neq$ MISSING, SET BEN_LEVEL=BEN_LEVEL3]

[SHOW IF SS_STATUS==2 AND RETIRED==0 (NOT RECEIVING BENEFITS, NOT RETIRED)]

Given that monthly benefits are less than $\$ 3500$, how much do you expect your monthly Social Security benefits to be if you stop working for pay at age [RET_AGE] and start collecting Social Security at age [CLAIM_AGE]?

(As before, please report any Social Security benefits paid to you yourself, not benefits paid to any other member in your household. Also, please give your answer in today's dollars, and ignore any inflation that may occur between today and when you collect benefits).

$\$$ per month.

[IF BEN_LEVEL3 $\neq$ MISSING, SET BEN_LEVEL=BEN_LEVEL3]

\section{[SHOW IF BEN_LEVEL=MISSING] \\ [IF BEN_LEVEL=MISSING, SET BEN_LEVEL=1000] \\ Q.2.4: [BEN_DEFAULT] Benefits Level Follow-up C}

[SHOW IF SS_STATUS==1 (RECEIVING BENEFITS)]

Please assume for the remainder of the survey that your Social Security benefits are $\$ 1000$ per month.

[SHOW IF SS_STATUS==2 AND RETIRED==1 (NOT RECEIVING BENEFITS, BUT RETIRED)]

Please assume for the remainder of the survey that if you start collecting Social Security at age [CLAIM_AGE], your Social Security benefits will be $\$ 1000$ per month.

[SHOW IF SS_STATUS==2 AND RETIRED==0 (NOT RECEIVING BENEFITS, NOT RETIRED)]

Please assume for the remainder of the survey that if you stop working for pay at age [RET_AGE] and start collecting Social Security at age [CLAIM_AGE], your Social Security benefits will be $\$ 1000$ per month.

\section{[SHOW IF BEN_LEVEL>3500] \\ [IF BEN_LEVEL>3500, SET BEN_LEVEL=3500] \\ Q.2.5: [BEN_MAX] Benefits Level Follow-up D}

[SHOW IF SS_STATUS==1 (RECEIVING BENEFITS)]

Please assume for the remainder of the survey that your Social Security benefits are $\$ 3500$ per month.

[SHOW IF SS_STATUS==2 AND RETIRED==1 (NOT RECEIVING BENEFITS, BUT RETIRED)]

Please assume for the remainder of the survey that if you start collecting Social Security at age [CLAIM_AGE], your Social Security benefits will be $\$ 3500$ per month.

[SHOW IF SS_STATUS==2 AND RETIRED==0 (NOT RECEIVING BENEFITS, NOT RETIRED)]

Please assume for the remainder of the survey that if you stop working for pay at age [RET_AGE] and start collecting Social Security at age [CLAIM_AGE], your Social Security benefits will be $\$ 3500$ per month.

[SHOW IF MARRIED==1 AND SS_STATUS_S $\neq 3$ ]

Q.2.6: [BEN_LEVEL_S] Expected Spouse's Social Security Benefits Level

[SHOW IF SS_STATUS_S==1 (RECEIVING BENEFITS)]

Approximately how much are your [SPOUSE]'s monthly Social Security benefits?

Even if you do not know exactly, please give your best guess.

(Please report any Social Security benefits paid to your [SPOUSE], not benefits paid to you or other members in your household).

$\$$ per month.

[SHOW IF SS_STATUS_S==2 AND RETIRED_S==1 (NOT RECEIVING BENEFITS, BUT RETIRED)] How much do you expect your [SPOUSE]'s monthly Social Security benefits to be if your [SPOUSE] starts collecting benefits at age [CLAIM_AGE_S]?

Even if you do not know exactly, please give your best guess. 
(Please report any Social Security benefits paid to your [SPOUSE], not benefits paid to you or other members in your household. Also, please give your answer in today's dollars, and ignore any inflation that may occur between today and when your [SPOUSE] collects benefits).

$\$$ per month.

[SHOW IF SS_STATUS_S==2 AND RETIRED_S==0 (NOT RECEIVING BENEFITS, NOT RETIRED)]

How much do you expect your [SPOUSE]'s monthly Social Security benefits to be if your [SPOUSE] stops working for pay at age [RET_AGE_S] and starts collecting benefits at age [CLAIM_AGE_S]?

Even if you do not know exactly, please give your best guess.

(Please report any Social Security benefits paid to your [SPOUSE], not benefits paid to you or other members in your household. Also, please give your answer in today's dollars, and ignore any inflation that may occur between today and when your [SPOUSE] collects benefits).

$\$$ per month.

[FOR ALL RESPONDENTS: CREATE A NEW VARIABLE BEN_ORIG_S = BEN_LEVEL_S]

[ASK IF (BEN_LEVEL_S=MISSING OR BEN_LEVEL_S==0) AND MARRIED==1 AND SS_STATUS_S $\neq 3$ ]

Q.2.7: [BEN_LEVEL2_S] Spouse Benefits Level Follow-up A

We understand this is a hard question to answer. We would really like to have your best guess, even if this guess is not exactly right.

[SHOW IF SS_STATUS_S==1 (RECEIVING BENEFITS)]

As your best guess, approximately how much are your [SPOUSE]'s monthly Social Security benefits?

Even if you do not know exactly, please give your best guess.

(Please report any Social Security benefits paid to your [SPOUSE], not benefits paid to you or other members in your household).

$\$$ per month.

[IF BEN_LEVEL2_S $\neq$ MISSING, SET BEN_LEVEL_S=BEN_LEVEL2_S]

[SHOW IF SS_STATUS_S==2 AND RETIRED_S==1 (NOT RECEIVING BENEFITS, BUT RETIRED)]

As your best guess, how much do you expect your [SPOUSE]'s monthly Social Security benefits to be if your [SPOUSE] starts collecting benefits at age [CLAIM_AGE_S]?

Even if you do not know exactly, please give your best guess.

(Please report any Social Security benefits paid to your [SPOUSE], not benefits paid to you or other members in your household. Also, please give your answer in today's dollars, and ignore any inflation that may occur between today and when your [SPOUSE] collects benefits).

$\$$ per month.

[IF BEN_LEVEL2_S $\neq$ MISSING, SET BEN_LEVEL_S=BEN_LEVEL2_S]

[SHOW IF SS_STATUS_S==2 AND RETIRED_S==0 (NOT RECEIVING BENEFITS, NOT RETIRED)]

As your best guess, how much do you expect your [SPOUSE]'s monthly Social Security benefits to be if your [SPOUSE] stops working for pay at age [RET_AGE_S] and starts collecting benefits at age [CLAIM_AGE_S]?

Even if you do not know exactly, please give your best guess.

(Please report any Social Security benefits paid to your [SPOUSE], not benefits paid to you or other members in your household. Also, please give your answer in today's dollars, and ignore any inflation that may occur between today and when your [SPOUSE] collects benefits).

$\$$ per month.

[IF BEN_LEVEL2_S $\neq$ MISSING, SET BEN_LEVEL_S=BEN_LEVEL2_S]

[ASK IF BEN_LEVEL_S>3500 AND MARRIED==1 AND SS_STATUS_S $\neq 3$ ]

Q.2.8: [BEN_LEVEL3_S] Spouse Benefits Level Follow-up B

Social Security benefits are never higher than $\$ 3500$ per month.

[SHOW IF SS_STATUS_S==1 (RECEIVING BENEFITS)]

Given that monthly benefits are less than $\$ 3500$, how much are your [SPOUSE]'s monthly Social Security benefits?

Even if you do not know exactly, please give your best guess.

(Please report any Social Security benefits paid to your [SPOUSE], not benefits paid to you or other members in your household).

$\$$ per month.

[IF BEN_LEVEL3_S $\not$ MISSING, SET BEN_LEVEL_S=BEN_LEVEL3_S] 
[SHOW IF SS_STATUS_S==2 AND RETIRED_S==1 (NOT RECEIVING BENEFITS, BUT RETIRED)]

Given that monthly benefits are less than $\$ 3500$, how much do you expect your [SPOUSE]'s monthly Social Security benefits to be if your [SPOUSE] starts collecting benefits at age [CLAIM_AGE_S]?

Even if you do not know exactly, please give your best guess.

(Please report any Social Security benefits paid to your [SPOUSE], not benefits paid to you or other members in your household. Also, please give your answer in today's dollars, and ignore any inflation that may occur between today and when your [SPOUSE] collects benefits).

$\$$ per month.

[IF BEN_LEVEL3_S $\neq$ MISSING, SET BEN_LEVEL_S=BEN_LEVEL3_S]

[SHOW IF SS_STATUS_S==2 AND RETIRED_S==0 (NOT RECEIVING BENEFITS, NOT RETIRED)]

Given that monthly benefits are less than $\$ 3500$, how much do you expect your [SPOUSE]'s monthly Social Security benefits to be if your [SPOUSE] stops working for pay at age [RET_AGE_S] and starts collecting benefits at age [CLAIM_AGE_S]?

Even if you do not know exactly, please give your best guess.

(Please report any Social Security benefits paid to your [SPOUSE], not benefits paid to you or other members in your household. Also, please give your answer in today's dollars, and ignore any inflation that may occur between today and when your [SPOUSE] collects benefits).

$\$$ per month.

[IF BEN_LEVEL3_S $\neq$ MISSING, SET BEN_LEVEL_S=BEN_LEVEL3_S]

\section{[SHOW IF (BEN_LEVEL_S=MISSING OR BEN_LEVEL_S==0) AND MARRIED==1 AND SS_STATUS_S $\neq 3$ ] \\ [IF BEN_LEVEL_S=MISSING, SET BEN_LEVEL_S=1000] \\ Q.2.9: [BEN_DEFAULT_S] Spouse Benefits Level Follow-up C}

[SHOW IF SS_STATUS_S==1 (RECEIVING BENEFITS)]

Please assume for the remainder of the survey that your [SPOUSE]'s Social Security benefits are $\$ 1000$ per month.

[SHOW IF SS_STATUS_S==2 AND RETIRED_S==1 (NOT RECEIVING BENEFITS, BUT RETIRED)]

Please assume for the remainder of the survey that if your [SPOUSE] starts collecting Social Security at age [CLAIM_AGE_S], [SP_HISHER]

Social Security benefits will be $\$ 1000$ per month.

[SHOW IF SS_STATUS_S==2 AND RETIRED_S==0 (NOT RECEIVING BENEFITS, NOT RETIRED)]

Please assume for the remainder of the survey that if your [SPOUSE] stops working for pay at age [RET_AGE_S] and starts collecting Social Security at age [CLAIM_AGE_S], [SP_HISHER] Social Security benefits will be $\$ 1000$ per month.

\section{[SHOW IF BEN_LEVEL_S >3500 AND MARRIED==1 AND SS_STATUS_S $\neq 3$ ] \\ [IF BEN_LEVEL_S >3500, SET BEN_LEVEL_S=3500] \\ Q.2.10: [BEN_MAX_S] Spouse Benefits Level Follow-up D}

[SHOW IF SS_STATUS_S==1 (RECEIVING BENEFITS)]

Please assume for the remainder of the survey that your [SPOUSE]'s Social Security benefits are $\$ 3500$ per month.

[SHOW IF SS_STATUS_S==2 AND RETIRED_S==1 (NOT RECEIVING BENEFITS, BUT RETIRED)]

Please assume for the remainder of the survey that if your [SPOUSE] starts collecting Social Security at age [CLAIM_AGE_S], [SP_HISHER] Social Security benefits will be $\$ 3500$ per month.

[SHOW IF SS_STATUS_S==2 AND RETIRED_S==0 (NOT RECEIVING BENEFITS, NOT RETIRED)]

Please assume for the remainder of the survey that if your [SPOUSE] stops working for pay at age [RET_AGE_S] and starts collecting Social Security at age [CLAIM_AGE_S], [SP_HISHER] Social Security benefits will be $\$ 3500$ per month. 
[IF RET_AGE $==0$, SKIP TO NEXT SECTION (SINCE RET_AGE=0 MEANS THE PERSON NEVER WORKED)]

[IF SKIPDIS==1, SKIP TO NEXT SECTION (SINCE SKIPDIS==1 MEANS THE PERSON RECEIVES DISABILITY BENEFITS)]

[ASK IF RET_AGE $\neq$ MISSING AND CLAIM_AGE $\neq$ MISSING AND SKIPDIS $\neq$ 1]]

Q.3.1: [EXT_INCENT_MC] Extensive-margin incentives, multiple choice

[SHOW IF SS_STATUS==1 AND RETIRED==0 (RECEIVING BENEFITS, NOT RETIRED)]

You answered before that you have not yet stopped working for pay, that your Social Security benefits are \$[BEN_LEVEL] per month, and that you started collecting benefits at age [CLAIM_AGE].

Suppose you had stopped working for pay at age [CLAIM_AGE -xRET_CHG], and started collecting benefits as you did, at age [CLAIM_AGE]. As your best guess, what would happen to your current Social Security benefits?

[SHOW IF SS_STATUS==1 AND RETIRED==1 (RECEIVING BENEFITS, ALREADY RETIRED)]

You answered before that you stopped working for pay at age [RET_AGE], that your Social Security benefits are \$[BEN_LEVEL] per month, and that you started collecting benefits at age [CLAIM_AGE].

Suppose you had stopped working for pay [IF xRET_CHG==1, INSERT: one year; IF xRET_CHG==2, INSERT: two years; IF xRET_CHG==5, INSERT: five years] earlier, at age [RET_AGE -xRET_CHG], and started collecting benefits as you did, at age [CLAIM_AGE]. As your best guess, what would happen to your current Social Security benefits?

[SHOW IF SS_STATUS==2 AND RETIRED==0 (NOT RECEIVING BENEFITS, NOT RETIRED)]

You answered before that you expect your Social Security benefits to be \$[BEN_LEVEL] per month if you stop working for pay at age [RET_AGE] and start collecting benefits at age [CLAIM_AGE].

Suppose you stop working for pay [IF xRET_CHG==1, INSERT: one year; IF xRET_CHG==2, INSERT: two years; IF xRET_CHG==5, INSERT: five years] earlier, at age [RET_AGE -xRET_CHG], and start collecting benefits as planned, at age [CLAIM_AGE]. As your best guess, what would happen to your Social Security benefits?

[SHOW IF SS_STATUS==2 AND RETIRED==1 (RETIRED, BUT NOT RECEIVING BENEFITS)]

You answered before that you stopped working for pay at age [RET_AGE] and that you expect your Social Security benefits to be \$[BEN_LEVEL] per month if you start collecting benefits at age [CLAIM_AGE].

Suppose you had stopped working for pay [IF xRET_CHG==1, INSERT: one year; IF xRET_CHG==2, INSERT: two years; IF xRET_CHG==5, INSERT: five years] earlier, at age [RET_AGE -xRET_CHG], and start collecting benefits as planned, at age [CLAIM_AGE]. As your best guess, what would happen to your Social Security benefits?

[ASK FOR ALL RESPONDENTS TO Q3.1:]

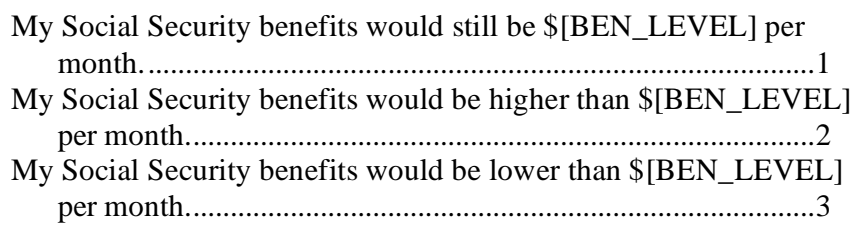

\section{[ASK IF (EXT_INCENT_MC==2 OR EXT_INCENT_MC==3) AND RET_AGE $\neq$ MISSING AND CLAIM_AGE $\neq$ MISSING]}

Q.3.2: [EXT_INCENT_AMT] Extensive-margin incentive, new amount of benefit

What would be the new amount of your Social Security benefits?

My best guess is that the new amount of my Social Security benefits would be $\$$ per month.

\section{[ASK IF EXT_INCENT_AMT<BEN_LEVEL AND EXT_INCENT_MC==2 AND RET_AGE $\neq$ MISSING AND CLAIM_AGE $\neq$ MISSING]} Q.3.2A: [EXT_INCENT2_AMT] Follow-up, Extensive-margin incentive, new amount of benefit

You just answered that the new amount of your Social Security benefits would be [EXT_INCENT_AMT] per month. Did you mean that the new benefit level would be [EXT_INCENT_AMT] higher, so that the new benefit level would be \$[BEN_LEVEL] + \$[EXT_INCENT_AMT] $=\$[$ BEN_LEVEL + EXT_INCENT_AMT $]$ ?

Yes, that is what I meant. The new benefit level would be \$[BEN_LEVEL+ EXT_INCENT_AMT] per month..... 1

No, I meant that the new benefit level would be \$[EXT_INCENT_AMT] per month 


\section{[ASK IF EXT_INCENT_AMT $<0.5 * B E N \_L E V E L$ AND BEN_LEVEL $>=100$ AND EXT_INCENT_MC==3 AND RET_AGE $\neq$ MISSING AND CLAIM_AGE $\neq$ MISSING] \\ Q.3.2B: [EXT_INCENT3_AMT] Follow-up, Extensive-margin incentive, new amount of benefit}

You just answered that the new amount of your Social Security benefits would be [EXT_INCENT_AMT] per month. Did you mean that the new benefit level would be [EXT_INCENT_AMT] lower, so that the new benefit level would be $\$\left[B E N \_L E V E L\right]-\$\left[E X T \_I N C E N T \_A M T\right]=$ \$[BEN_LEVEL - EXT_INCENT_AMT]?

Yes, that is what I meant. The new benefit level would be \$[BEN_LEVEL EXT_INCENT_AMT] per month..... ..1

No, I meant that the new benefit level would be \$[EXT_INCENT_AMT] per month

[Ask if EXT_INCENT_MC==3]

Q.3.3: [INCENT_WK_LNG] Incentives To Work Longer

[ASK IF SS_STATUS==1 AND RETIRED==0 (RECEIVING BENEFITS, NOT RETIRED)]

You answered before that you think that your benefits would be lower if you had stopped working for pay at age [CLAIM_AGE -xRET_CHG]. If you had stopped working earlier, you would also have paid into Social Security for fewer years.

\section{[ASK IF SS_STATUS==1 AND RETIRED==1 (RECEIVING BENEFITS, RETIRED)]}

[SHOW IF XRET_CHG==1]

You answered before that you thought that your benefits would be lower if you had stopped working for pay one year earlier. If you had stopped working earlier, you would have also paid into Social Security for one fewer year.

[SHOW IF XRET_CHG==2]

You answered before that you thought that your benefits would be lower if you had stopped working for pay two years earlier. If you had stopped working earlier, you would also have paid into Social Security for two fewer years.

[SHOW IF XRET_CHG==5]

You answered before that you thought that your benefits would be lower if you had stopped working for pay five years earlier. If you had stopped working earlier, you would also have paid into Social Security for five fewer years.

[ASK IF SS_STATUS==2 AND RETIRED==0 (NOT RECEIVING BENEFITS, NOT RETIRED)]

[SHOW IF XRET_CHG==1]

You answered before that you think that your benefits will be lower if you stop working for pay one year earlier than you have planned. If you stop working earlier, you will also pay into Social Security for one fewer year.

[SHOW IF XRET_CHG==2]

You answered before that you think that your benefits will be lower if you stop working for pay two years earlier than you have planned. If you stop working earlier, you will also pay into Social Security for two fewer years.

[SHOW IF XRET_CHG==5]

You answered before that you think that your benefits will be lower if you stop working for pay five years earlier than you have planned. If you stop working earlier, you will also pay into Social Security for five fewer years.

\section{[ASK IF SS_STATUS==2 AND RETIRED==1 (NOT RECEIVING BENEFITS, BUT RETIRED)]}

[SHOW IF XRET_CHG==1]

You answered before that you think that your benefits would be lower if you had stopped working for pay one year earlier. If you had stopped working earlier, you would also have paid into Social Security for one fewer year.

\section{[SHOW IF XRET_CHG==2]}

You answered before that you think that your benefits would be lower if you had stopped working for pay two years earlier. If you had stopped working earlier, you would also have paid into Social Security for two fewer years.

[SHOW IF XRET_CHG==5]

You answered before that you think that your benefits would be lower if you had stopped working for pay five years earlier. If you had stopped working earlier, you would also have paid into Social Security for five fewer years. 
[SHOW FOR ALL RESPONDENTS TO Q.3.3 WITH SS_STATUS==1 AND RETIRED==0)]

Consider all the Social Security benefits you receive over your lifetime. Which of the following is true.

If I had stopped working at age [CLAIM_AGE -xRET_CHG], I would get...

a worse deal from Social Security; i.e., money saved by paying into Social Security for fewer years would be less than the cut to my Social Security benefits....................1

roughly the same deal from Social Security; i.e., money saved by paying into Social Security for fewer years would roughly equal the cut to my Social Security benefits...... .2

a better deal from Social Security; i.e., money saved by paying into Social Security for fewer years would be greater than the cut to my Social Security benefits............3

[SHOW FOR ALL RESPONDENTS TO Q.3.3 WITH RETIRED==1]

Consider all the Social Security benefits you receive over your lifetime. Which of the following is true.

If I had stopped working [xRET_CHG] year(s) earlier, I would get...

a worse deal from Social Security; i.e., money saved by paying into Social Security for fewer years would be less than the cut to my Social Security benefits. 1

roughly the same deal from Social Security; i.e., money saved by paying into Social Security for fewer years would roughly equal the cut to my Social Security benefits.

a better deal from Social Security; i.e., money saved by paying into Social Security for fewer years would be greater than the cut to my Social Security benefits............3

[SHOW FOR ALL RESPONDENTS TO Q.3.3 WITH SS_STATUS==2 AND RETIRED==0]

Consider all the Social Security benefits you receive over your lifetime. Which of the following is true.

If I stop working [xRET_CHG] year(s) earlier, I will get...

a worse deal from Social Security; i.e., money saved by paying into Social Security for fewer years will be less than the cut to my Social Security benefits... .1

roughly the same deal from Social Security; i.e., money saved by paying into Social Security for fewer years will roughly equal the cut to my Social Security benefits......

.

a better deal from Social Security; i.e., money saved by paying into Social Security for fewer years will be greater than the cut to my Social Security benefits..... .3

Section 4: Knowledge about Early-Retirement Penalty/Delayed Retirement Credit and about Earnings Test

[IF SKIPDIS==1, SKIP TO NEXT SECTION]

\begin{tabular}{ll}
\hline [ASK IF CLAIM_AGE $\neq$ MISSING] \\
[IF XCLM_CHG $==1$ & , SET ALT_AGE=CLAIM_AGE+1] \\
[IF XCLM_CHG $==1$ & , SET ALT_WHEN=“ONE YEAR LATER”] \\
[IF XCLM_CHG $==2$ & , SET ALT_AGE=CLAIM_AGE-1] \\
[IF XCLM_CHG $==2$ & , SET ALT_WHEN=“ONE YEAR EARLIER”] \\
[IF CLAIM_AGE $\leq 62$ & , SET ALT_AGE=CLAIM_AGE+1] \\
[IF CLAIM_AGE $\leq 62$ & , SET ALT_WHEN=“ONE YEAR LATER”] \\
[IF CLAIM_AGE $>69$ & , SET ALT_AGE=CLAIM_AGE-1] \\
[IF CLAIM_AGE $>69$ & , SET ALT_WHEN=“ONE YEAR EARLIER”]
\end{tabular}

Q.4.1: [AGEDEP_NY] Benefits sensitive to age of claiming?

[SHOW IF SS_STATUS==1 AND RETIRED==0 (RECEIVING BENEFITS, NOT RETIRED)] 
You answered before that you have not yet stopped working for pay, that your Social Security benefits are \$[BEN_LEVEL] per month, and that you started collecting benefits at age [CLAIM_AGE].

Suppose you had started collecting Social Security benefits [ALT_WHEN], at age [ALT_AGE], but stop working for pay as planned, at age [RET_AGE]. As your best guess, what would happen to your Social Security benefits?

[SHOW IF SS_STATUS==1 AND RETIRED==1 AND RET_AGE $\neq 0$ (RECEIVING BENEFITS, RETIRED)]

You answered before that you stopped working for pay at age [RET_AGE], that your Social Security benefits are \$[BEN_LEVEL] per month, and that you started collecting benefits at age [CLAIM_AGE].

Suppose you had started collecting Social Security benefits [ALT_WHEN], at age [ALT_AGE], but stopped working for pay as you did, at age [RET_AGE]. As your best guess, what would happen to your Social Security benefits?

[SHOW IF SS_STATUS==1 AND RETIRED==1 AND RET_AGE = 0 (RECEIVING BENEFITS, NEVER WORKED)]

You answered before that your Social Security benefits are \$BEN_LEVEL] per month, and that you started collecting benefits at age [CLAIM_AGE].

Suppose you had started collecting Social Security benefits [ALT_WHEN], at age [ALT_AGE]. As your best guess, what would happen to your Social Security benefits?

[SHOW IF SS_STATUS==2 AND RETIRED==0 (NOT YET RECEIVING BENEFITS, NOT RETIRED)]

You answered before that you expect your Social Security benefits to be \$[BEN_LEVEL] per month if you stop working for pay at age [RET_AGE] and start collecting benefits at age [CLAIM_AGE].

Suppose you start collecting Social Security benefits [ALT_WHEN], at age [ALT_AGE], but stop working for pay as planned, at age [RET_AGE]. As your best guess, what would happen to your Social Security benefits?

[SHOW IF SS_STATUS==2 AND RETIRED==1 AND RET_AGE $\neq 0$ (NOT YET RECEIVING BENEFITS, BUT RETIRED)]

You answered before that you stopped working for pay at age [RET_AGE] and that you expect your Social Security benefits to be \$[BEN_LEVEL] per month if you start collecting benefits at age [CLAIM_AGE].

Suppose you start collecting Social Security benefits [ALT_WHEN], at age [ALT_AGE], but stopped working for pay as you did, at age [RET_AGE]. As your best guess, what would happen to your Social Security benefits?

[SHOW IF SS_STATUS==2 AND RETIRED==1 AND RET_AGE == 0 (NOT YET RECEIVING BENEFITS, NEVER WORKED)]

You answered before that you expect your Social Security benefits to be \$[BEN_LEVEL] per month if you start collecting benefits at age [CLAIM_AGE].

Suppose you start collecting Social Security benefits [ALT_WHEN], at age [ALT_AGE]. As your best guess, what would happen to your Social Security benefits?

[ASK FOR ALL RESPONDENTS TO Q4.1:]

\section{Q.4.2: [AGEDEP_RATE] Early retirement penalty / Delayed retirement credit}

\section{[ASK IF XDEP_V==1]}

Consider a person who stops working for pay at age 62. Suppose this person would receive Social Security benefits of $\$ 1000$ per month if he or she started collecting benefits at age 62 . We are interested to know what you think would happen to his/her Social Security benefits if he/she still stopped working for pay at age 62 but started collecting Social Security benefits at a different age. (Please ignore the effects of inflation.)

As my best guess, if the person ....

.... started collecting benefits at age 62 , the benefits would be $\$ 1000$ per month.

.... started collecting benefits at age 66 , the benefits would be $\$ \ldots$

.... started collecting benefits at age 70 , the benefits would be $\$$ ___ per month.

.... started collecting benefits at age 74 , the benefits would be $\$ \ldots$

[ASK IF XDEP_V==2]

Consider a person who stops working for pay at age 62. Suppose this person would receive Social Security benefits of $\$ 1000$ per month if he or she started collecting benefits at age 66 . We are interested to know what you think would happen to his/her Social Security benefits if he/she still stopped working for pay at age 62 but started collecting Social Security benefits at a different age. (Please ignore the effects of inflation.) 
As my best guess, if the person ....

.... started collecting benefits at age 62 , the benefits would be $\$$ per month.

.... started collecting benefits at age 66 , the benefits would be $\$ 1000$ per month.

.... started collecting benefits at age 70 , the benefits would be $\$$ per month.

.... started collecting benefits at age 74 , the benefits would be $\$$ per month.

\section{Q.4.3: [EARNTEST_EXIST] Knowledge of existence of the earnings test}

[SHOW IF PPAGE $<62$ AND RETIRED==0]

Suppose that you stopped working at age 62 and also claimed Social Security benefits that year.

[SHOW IF PPAGE $<62$ AND RETIRED==1]

Suppose that you claimed Social Security benefits at age 62 .

[SHOW IF PPAGE $\geq 62$ AND (RET_AGE $>62$ OR RETIRED==0)]

Suppose that you had stopped working at age 62 and also claimed Social Security benefits that year.

[SHOW IF PPAGE $\geq 62$ AND (RET_AGE $\leq 62$ AND RETIRED==1)]

Suppose that you had claimed Social Security benefits at age 62 .

[SHOW IF PPAGE $\leq$ XEARNTST (IF XEARNTST=1, 64; IF XEARNTST=2, 68)]

What would have happened to your Social Security benefits at age [IF XEARNTST=1, INSERT 64; IF XEARNTST=2, INSERT 68] if, after retiring, you return to work for one year at age [IF XEARNTST=1, INSERT 64; IF XEARNTST=2, INSERT 68] earning \$20,000 that year.

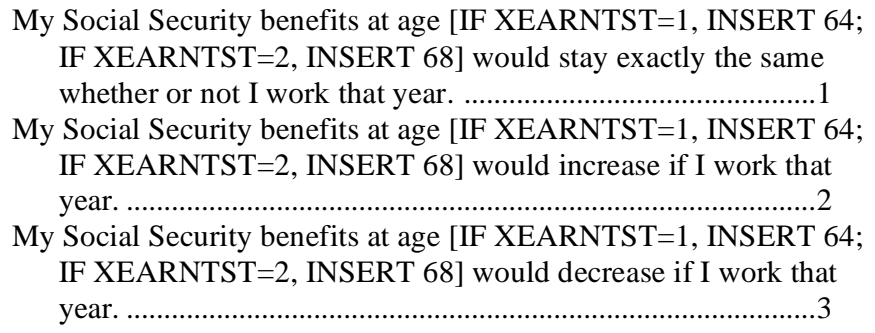

[SHOW IF PPAGE > XEARNTST (IF XEARNTST=1, 64; IF XEARNTST=2, 68)]

What would have happened to your Social Security at age [IF XEARNTST=1, INSERT 64; IF XEARNTST=2, INSERT 68] if, after retiring, you return to work for one year at age [IF XEARNTST=1, INSERT 64; IF XEARNTST=2, INSERT 68] earning \$20,000 that year.
My Social Security benefits at age [IF XEARNTST=1, INSERT 64; IF XEARNTST=2, INSERT 68] would have stayed exactly the same whether or not I had worked that year. .......................... 1
My Social Security benefits at age [IF XEARNTST=1, INSERT 64; IF XEARNTST $=2$, INSERT 68] would have increased if I had worked that year. ...2
My Social Security benefits at age [IF XEARNTST=1, INSERT 64; IF XEARNTST=2, INSERT 68] would have decreased if I had worked that year. .3

[SHOW IF EARNTEST_EXIST $==1]$ Q.4.4a: [EARNTEST_THRESA] Earnings threshold of the earnings test, A

[SHOW IF PPAGE $\leq$ XEARNTST (IF XEARNTST=1, 64; IF XEARNTST=2, 68)]

You just indicated that you thought that your Social Security benefits at age [IF XEARNTST=1, INSERT 64; IF XEARNTST=2, INSERT 68] would stay the same if you earn $\$ 20,000$ in that year. Is there any amount of earnings at age [IF XEARNTST=1, INSERT 64; IF XEARNTST=2, INSERT 68] that would cause a reduction in your benefits?

[SHOW IF PPAGE > XEARNTST (IF XEARNTST=1, 64; IF XEARNTST=2, 68)]

You just indicated that you thought that your Social Security benefits at age [IF XEARNTST=1, INSERT 64; IF XEARNTST=2, INSERT 68] would have stayed the same if you had earned $\$ 20,000$ in that year. Is there any amount of earnings at age [IF XEARNTST=1, INSERT 64; IF XEARNTST=2, INSERT 68] that would have caused a reduction in your benefits?

[SHOW FOR ALL RESPONDENTS TO Q4.4A:]

Yes, once a person earns more than roughly ___ dollars per
year at age [IF XEARNTST=1, INSERT 64; IF XEARNTST=2,
INSERT 68], benefits start being reduced. ............................. 1


[SHOW IF AGE $\leq$ XEARNTST (IF XEARNTST=1, 64; IF XEARNTST=2, 68)]

You just indicated that you thought that your Social Security benefits at age [IF XEARNTST=1, INSERT 64; IF XEARNTST=2, INSERT 68] would be reduced if you earn $\$ 20,000$ in that year. Is there any amount that you could earn at age [IF XEARNTST=1, INSERT 64; IF XEARNTST=2, INSERT 68] without having your benefits reduced?

[SHOW IF AGE > XEARNTST (IF XEARNTST=1, 64; IF XEARNTST=2, 68)]

You just indicated that you thought that your Social Security benefits at age [IF XEARNTST=1, INSERT 64; IF XEARNTST=2, INSERT 68] would have been reduced if you had earned $\$ 20,000$ in that year. Is there any amount that you could have earned at age [IF XEARNTST=1, INSERT 64; IF XEARNTST=2, INSERT 68] without having your benefits reduced?

[ASK IF EARNTEST_EXIST==3 OR (EARNTEST_EXIST==1 AND EARNTEST_THRESA<999999)]

Q.4.5: [EARNTEST_RETURN] Knowledge about whether the earnings test affects future social security benefits

Suppose that, after you started receiving Social Security benefits, you earned enough that, as a result, your Social Security benefits were reduced in that year. What would happen to your Social Security benefits in later years (assuming you don't work anymore at that point)?

My Social Security benefits in later years would not be affected.1

My Social Security benefits in later years would be increased. ...2

My Social Security benefits in later years would be reduced. ......3

\section{[ASK IF EARNTEST_RETURN==2] \\ Q.4.6: [EARNTEST_FAIR] Knowledge whether increase in future benefits is approximately fair}

Would this increase in benefits over your lifetime make up for the lost benefits in the year that you worked?

The increase in benefits over my lifetime ...

... would roughly make up for the lost benefits during the year that I worked. ...1

... would be more than what would be needed to make up for the lost benefits during the year that I worked. 2

... would be less than what would be needed to make up for the lost benefits during the year that I worked. .3

Section 5: Knowledge about the 35-Year Rule and Cost-of-Living Adjustment

Q.5.1: [RULE35_CHOICE, RULE35_AMOUNT] Knowledge of 35-year rule:

Consider a person who worked for 40 years and who claims Social Security based on his or her own earnings history. Which years of this person's earnings are taken into account when calculating the amount of his or her Social Security benefits?

Choose only one option and fill in the corresponding blank:

Based on the most recent years: ...1

The amount of Social Security benefits is based on the average of the ___ most recent years of earnings (fill in a number).

Based on the highest years: ...........................................................2

The amount of Social Security benefits is based on the average of the ___ highest years of earnings (fill in a number).

Based on earnings at particular ages:............................................ 3 
The amount of Social Security benefits is based on the average earnings for the years when this person was between the age of 16 and ___ (fill in an age).

Based only on number of years with earnings but not on level of earnings:

The amount of Social Security benefits is based on the total number of years that this person had earnings of at least about $\$ 2500$ (in today's dollars) for years when this person was between the age of 16 and (fill in an age).

\section{Q.5.2: [COLA] Cost-of-living adjustment}

How closely do you think Social Security benefits adjust with the overall cost of living, after a worker retires?

After a worker retires, Social Security benefits adjust ...

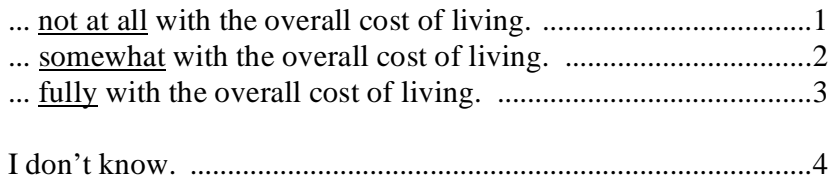

Section 6. Respondent Characteristics -- Information to Enable Us to Estimate the Actual Incentives that Individuals Face

Q.6.1: [WHOSE_RECORD] Type of Social Security benefits the person expects to claim

[SHOW IF SS_STATUS==1 (ALREADY RECEIVING BENEFITS)]

You answered before that your monthly Social Security benefits are \$[BEN_LEVEL].

[SHOW IF SS_STATUS==2 (NOT YET RECEIVING BENEFITS)]

You answered before that you expect your monthly Social Security benefits to be \$[BEN_LEVEL].

[SHOW FOR ALL RESPONDENTS TO Q.6.1]

On whose earnings record do you think your benefits are based? They are based ...

... only on my own earnings record ............................................... 1

... only on my current [SPOUSE]'s earnings record......................2

... only on my previous [SPOUSE]'s earnings record .................... 3

... only on my late [SPOUSE]'s earnings record .......................... 4

... on both my own and my current [SPOUSE]'s earnings records

... on both my own and my previous [SPOUSE]'s earnings records

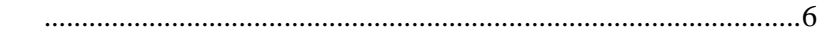

... on both my own and my late [SPOUSE]'s earnings records ....7

[ASK IF MARRIED==1 AND SS_STATUS_S $\neq 3$ AND BEN_LEVEL_S $\neq$ MISSING]

Q.6.2: [WHOSE_RECORD_S] Type of Social Security benefits Respondent's [SPOUSE] Expects to Claim

[SHOW IF SS_STATUS_S==1 (ALREADY RECEIVING BENEFITS)]

You answered before that your [SPOUSE]'s monthly Social Security benefits are \$[BEN_LEVEL_S].

[SHOW IF SS_STATUS_S==2 (NOT YET RECEIVING BENEFITS)]

You answered before that you expect your [SPOUSE]'s monthly Social Security benefits to be \$[BEN_LEVEL_S].

[SHOW FOR ALL RESPONDENTS TO Q.6.2]

On whose earnings record do you think that your [SPOUSE]'s benefits are based? They are based...

... only on [SP_HISHER] own earnings record..........................1

$\ldots$ only on my earnings record..............................................

... on both [SP_HISHER] own and my earnings records............ 3 
Q.6.3: [PENSION_TYPE]

Now we'd like to ask you about pensions.

In some retirement plans, Type A, benefits are usually based on a formula involving age, years of service, and salary. Type A plans are often called "defined benefit" plans. In other plans, Type B, money is accumulated in an account for you. 401-K, 403-B, ESOP, SRA, thrift/savings, stock/profit sharing, and money purchase plans are all type B retirement plans. Type B plans are often called "defined contribution."

[SHOW IF RETIRED==0]

Do you have a pension at your current job or from a former job; and if so, what type of pension is it, Type A or Type B?

[SHOW IF RETIRED==1]

Do you or will you receive pension benefits from a former job; and if so, what type of pension is it, Type A or Type B?

[SHOW FOR ALL RESPONDENTS TO Q.6.3]

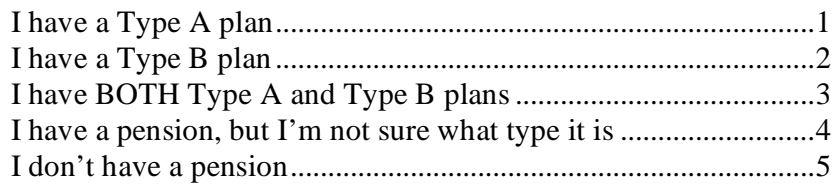

Section 7: Information to enable us to estimate how important Social Security wealth is for this person (or other features of Social Security rules) and Predictors of Retirement and/or Social Security Knowledge

\section{Q.7.1: [SS_WORK] Planning to work after claiming benefits}

[SHOW IF SS_STATUS==1 (ALREADY RECEIVING BENEFITS)]

How likely do you think it is that you will decide to work for pay at least part-time sometime in the future?

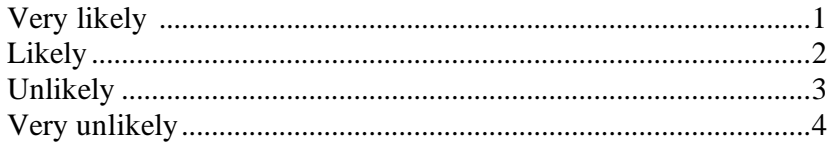

[SHOW IF SS_STATUS==2 (NOT YET RECEIVING BENEFITS)]

How likely do you think it is that you will decide to work for pay at least part-time after you have started collecting Social Security benefits?

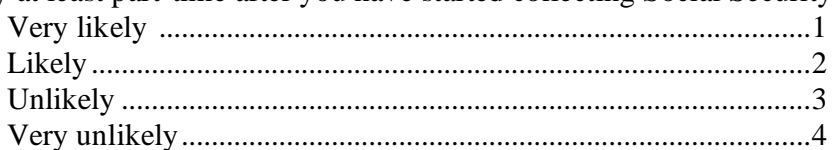

Section 8: Converting flow benefits to expected PDV of benefits (and vice versa)

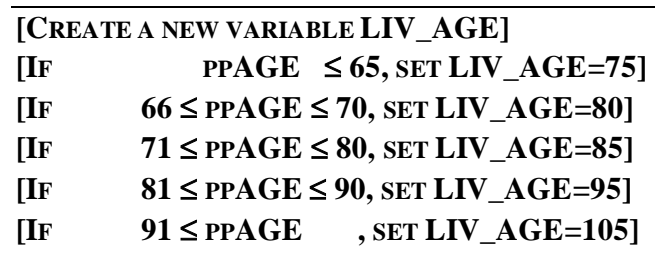

Q.8.1a: [PROB_LIVE] Expected Longevity

For the next questions, please answer on a scale of 0 to 100 , where " 0 " means that you think there is absolutely no chance it will happen, and "100" means that you think it is absolutely sure to happen.

As your best guess, what is the percent chance that you will live to be [LIV_AGE] or more?

[GIVE A SCALE OF 0-100 WITH 0 MARKED “ABSOLUTELY NO CHANCE” AND 100 MARKED “ABSOLUTELY CERTAIN”]

\begin{tabular}{|c|c|c|}
\hline \multicolumn{3}{|c|}{ [CREATE A NEW VARIABLE LIV_AGE_S] } \\
\hline$[\mathbf{I F}$ & AGE_S $\leq 65$ & , SET LIV_AGE_S=75] \\
\hline$[\mathbf{I F}$ & $66 \leq$ AGE_S $\leq 70$ & , SET LIV_AGE_S=80] \\
\hline$[\mathbf{I F}$ & $71 \leq$ AGE_S $\leq 80$ & , SET LIV_AGE_S=85] \\
\hline$[\mathbf{I F}$ & $81 \leq$ AGE_S $\leq 90$ & , SET LIV_AGE_S=95] \\
\hline$[\mathbf{I F}$ & $91 \leq$ AGE_S & , SET LIV_AGE_S=105 \\
\hline
\end{tabular}


Q.8.1b: [PROB_LIVE_S] Expected Longevity Spouse

As your best guess, what is the percent chance that your [SPOUSE] will live to be [LIV_AGE_S] or more?

[GIVE A SCALE OF 0-100 WITH O MARKED “ABSOLUTELY NO CHANCE” AND 100 MARKED “ABSOLUTELY CERTAIN”]

Q.8.2: [PROB_LIV_IND] Expected Longevity of Typical American Individual of the Gender of the Respondent

[SHOW IF PPGENDER==1 (MALE RESPONDENT)]

Think of the typical 65-year old man. What is the percent chance that he will live to the age 90 or beyond?

[SHOW IF PPGENDER==2 (FEMALE RESPONDENT)]

Think of the typical 65-year old woman. What is the percent chance that she will live to the age of 90 or beyond?

[GIVE A SCALE OF 0-100 WITH O MARKED “ABSOLUTELY NO CHANCE” AND 100 MARKED “ABSOLUTELY CERTAIN”]

Q.8.3: [PROB_LIV_CPL] Expected Longevity of Typical American Couple

Think of a typical couple in which both spouses are 65 years old. What is the percent chance that at least one spouse will live to age 90 or beyond?

[GIVE A SCALE OF 0-100 WITH 0 MARKED “ABSOLUTELY NO CHANCE” AND 100 MARKED “ABSOLUTELY CERTAIN"]

Q.8.4: [RECALL_B] Recall Receiving the Brochure

After we gave a survey on Social Security in 2008, several participants asked for more information about Social Security rules. About a year ago (in February of 2009), we sent the following informational brochure to a number of Knowledge Network panelists.

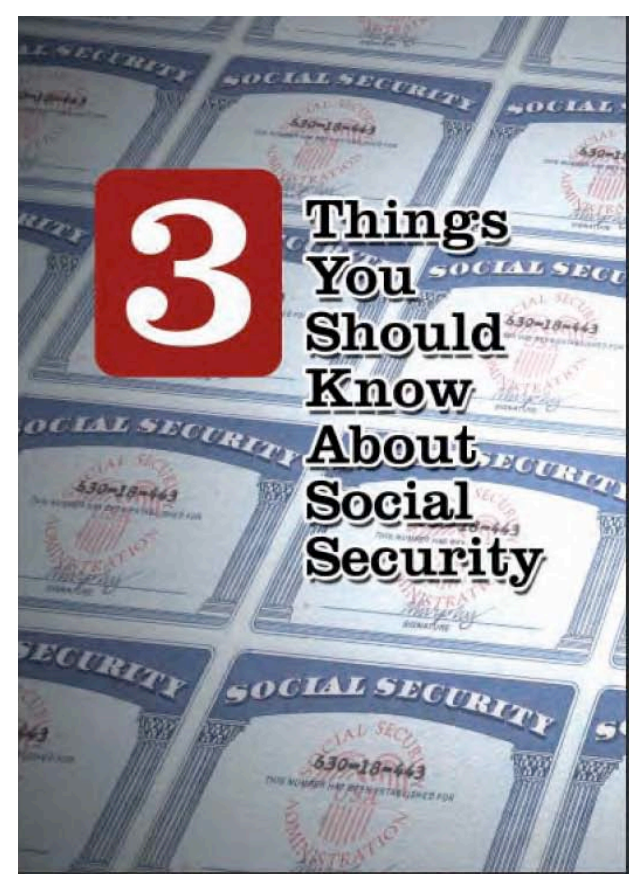

Do you remember receiving this informational brochure about Social Security rules in the mail?

Yes

Q.8.5: [RECALL_M] Recall Receiving the Online Module 
About a year ago (in February/March of 2009), we invited a number of Knowledge Networks panelists to participate in an online module that provided additional information about Social Security rules, and which was tailored to each person's individual situation.

To help you remember this survey from the many other surveys you have taken, the online module contained stories about the experiences of two retirees, 91-year old Leon and 66-year-old Elena:

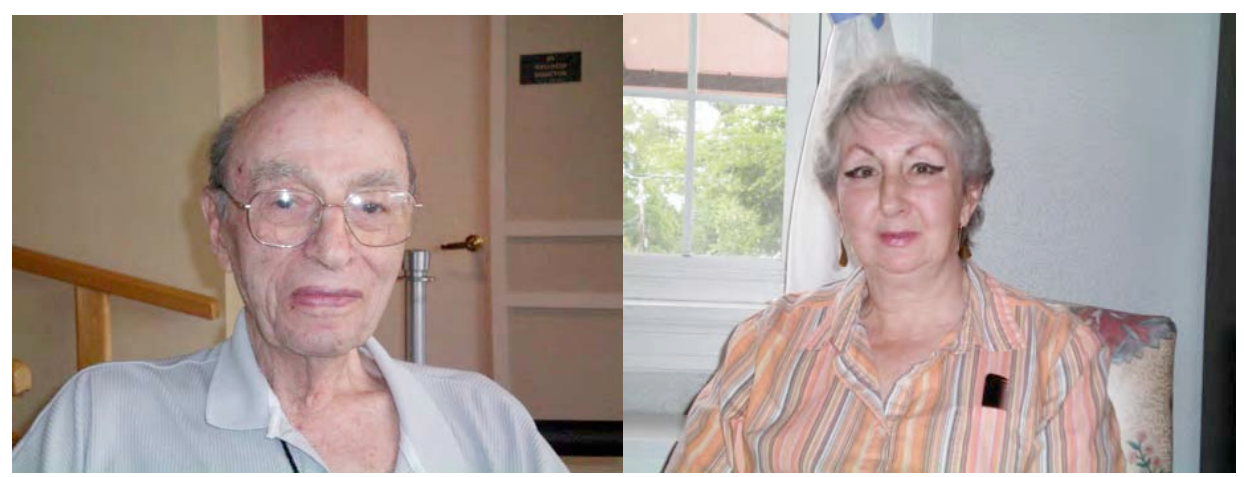

At the very end of the online module, we provided the links to various websites from organizations that give out helpful information about Social Security.

Do you remember taking part in this online module about Social Security rules?

Yes. 1

No....... 2

Section 9 - Standard Close

[INSERT THE KN STANDARD CLOSE HERE (THIS QUESTION IS AN OPEN-ENDED QUESTION THAT KNOWLEDGE NETWORKS ASKS AT THE END OF EACH SURVEY AND IN WHICH RESPONDENTS CAN MAKE ANY COMMENT ABOUT THE SURVEY THEY HAVE JUST TAKEN)] 